$\frac{544}{3-20}-85 y, 0.00$

\title{
$1-1998^{3}$
}

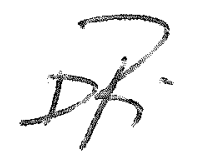

$0874=5$ GEND

$\therefore$
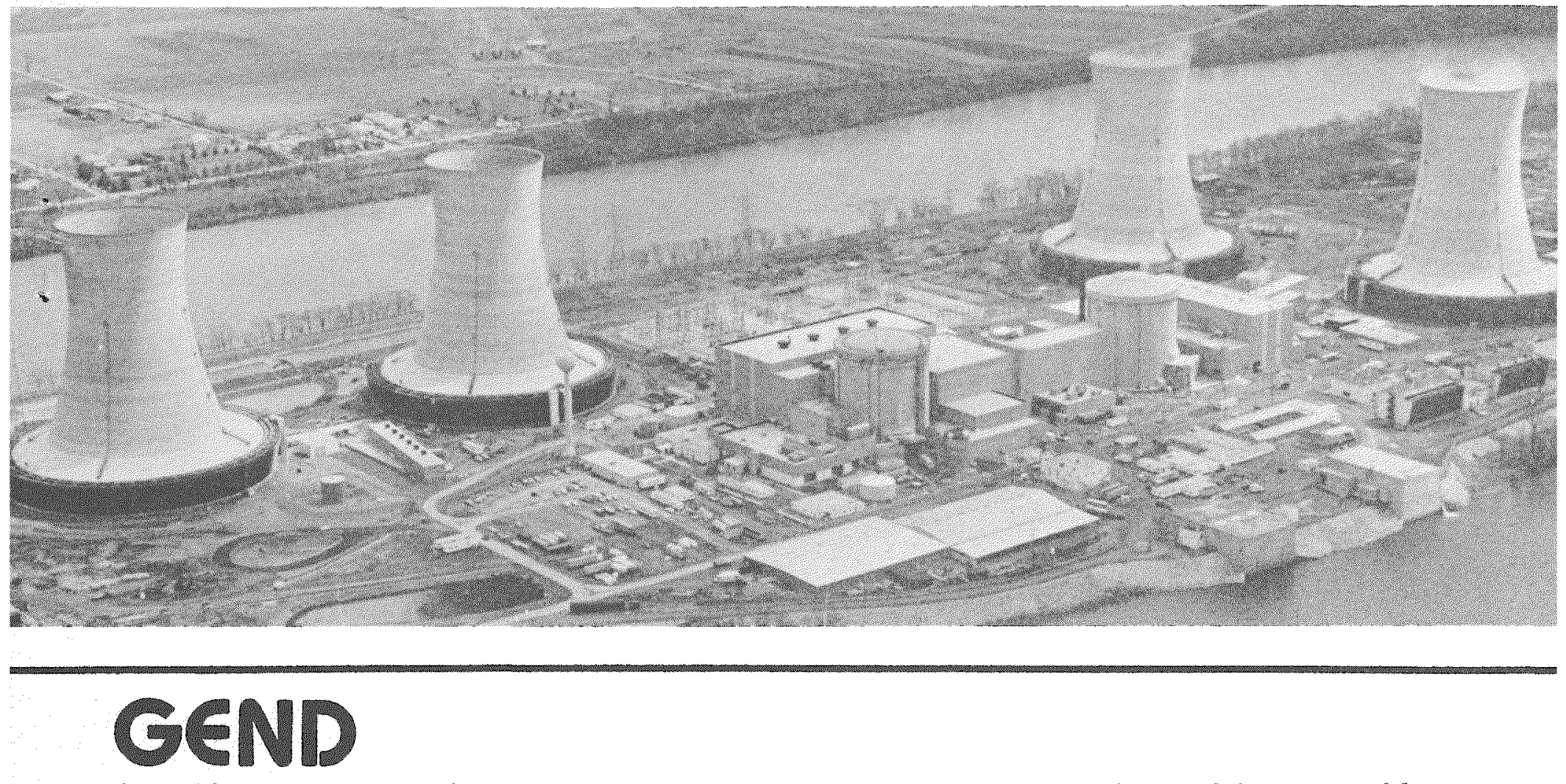

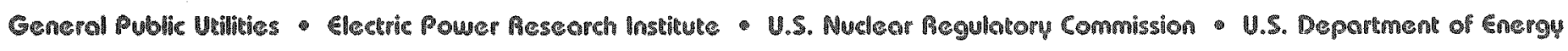

\section{Disposal Demonstration of a High Integrity Container (HIC) Containing an EPICOR-II Prefilter from Three Mile Island}

\section{O NOT MICROFILM COVER}

John W. McConnell, Jr. Michael J. Tyacke

February 1985
Richard C. Schmitt

Harley W. Reno 
Prnted in the Unted States of America

Avatable from

National Techncal Information Service

US. Department of Commerce

5285 Port Royal Road

Sprngheld. VA 22161

NTIS Pnco Codes Pnuted Copy A06

Microfiche A01

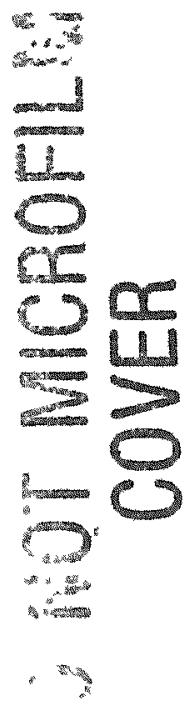

\section{DISCLAIMER}

This book was prepared as an account of work sponsored by an agency of the Unied States Government Nether the United States Govermment nor any agency thereof. nor any of ther employees, makes any warranty. express or impled, or assumes any legal habity or responsibity for the accuracy. completeness, or usefulness of any milormation, apparatus, product or process disctosed, or represents that us use would not infunge privately owned rights Refarences heren to any specitic commercal product, process, or service by irade name, trademark. manutacturer or otherwse, does not necessarly constitute or imply its endorsement, recommendation, or favoring by the Unted States Government or any agancy thereof The vews and opmons of authors expressed heren do not necessanty state of reflect those of the Unted States Government or any agency thereof 


\section{DISCLAIMER}

This report was prepared as an account of work sponsored by an agency of the United States Government. Neither the United States Government nor any agency Thereof, nor any of their employees, makes any warranty, express or implied, or assumes any legal liability or responsibility for the accuracy, completeness, or usefulness of any information, apparatus, product, or process disclosed, or represents that its use would not infringe privately owned rights. Reference herein to any specific commercial product, process, or service by trade name, trademark, manufacturer, or otherwise does not necessarily constitute or imply its endorsement, recommendation, or favoring by the United States Government or any agency thereof. The views and opinions of authors expressed herein do not necessarily state or reflect those of the United States Government or any agency thereof. 


\section{DISCLAIMER}

Portions of this document may be illegible in electronic image products. Images are produced from the best available original document. 


\title{
DISCLAIMER
}

This report was prepared as an account of work sponsored by an agency of the United States Government. Neither the United States Government nor any agency thereof, nor any of their employees, makes any warranty, express or implied, or assumes any legal liability or responsibility for the accuracy, completeness, or usefulness of any information, apparatus, product, or process disclosed, or represents that its use would not infringe privately owned rights. Reference herein to any specific commercial product, process, or service by trade name, trademark, manufacturer, or otherwise does not necessarily constitute or imply its endorsement, recommendation, or favoring by the United States Government or any agency thereof. The views and opinions of authors expressed herein do not necessarily state or reflect those of the United States Govermment or any agency thereof.

\section{DISPOSAL DEMONSTRATION OF A HIGH INTEGRITY CONTAINER (HIC) CONTAINING AN EPICOR-II PREFILTER FROM THREE MILE ISLAND}

\author{
John W. McConnell Jr. \\ Michael J. Tyacke \\ Richard C. Schmit \\ Harley W. Reno
}

Published February 1985

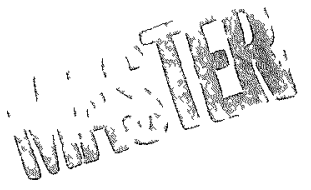

EGEG Idaho, lnc. Idaho Falls, Idaho 83415

\section{NOTICE}

MTIOMS OF TMIS MEPORT ARE MLERIPEE

: hros bern reproduced from the best

" "sillable copv to permit the broadest : r.sible ay âlabillity.

Prepared for the

U.S. Department of Energy

Three Mile Island Operations Office

Under DOE Contract No. DE-ACO7-76IDO1570 
A high integrity container (HIC) was developed, tested, and certified for use in disposing of unusual low-level radioactive waste from Three Mile Is Iand Unit 2 (TMI-2). The work was coordinated by EG\&G Idaho, Inc. and funded by the U.S. Department of Energy. A disposal demonstration using an HIC containing an EPICOR-II prefilter from TMI-2 was completed at the commercial disposal facility in the State of Washington. A Certification of Compliance was issued by the Department of Social and Health Services of the State of Washington to use the HIC in disposing of up to 50 EPICOR-II prefilters. That Certification of compliance was issued after rigorous review of the HIC design and test program by the State and by the U.S. Nuclear Regulatory Commission.

This report describes the processes of loading, transporting, and disposing of the demonstration HIC and briefly describes the design, testing, and approval effort leading up to the demonstration. The significance of this effort is that the disposal demonstration was a first-of-a-k ind use of a reinforced concrete HIC at the US Ecology, Inc. commercial disposal facility in the State of Washington. 
SUMMARY

The cleanup of Three Mile Is land Unit 2 (TMI-2) produced 50 EPICOR-II prefilters, containing dewatered, radioactive ion-exchange resins and zeolites. As part of the EPICOR-II Research and Disposition Program, EPICOR-II prefilters were transported to the Idaho National Engineering Laboratory (INEL) for research, inter im storage, and ultimate disposal. The program developed the first-of-a-kind reinforced concrete high integrity container (HIC) approved for use by the State of washington. The program then used the first production prototype model in disposing of an EPICOR-II prefilter as a disposal demonstration. This document presents information gained from the HIC disposal demonstration and related work leading to that demonstration.

The disposal demonstration was performed at the commercial low-level radioactive waste disposal facility in the State of Washington. Obtaining approval for use of the HIC for disposing of EPICOR-II prefilters required applying to the State of Washington for approval and satisfying technical concerns raised by the State and the U.S. Nuclear Regulatory Commission. Successful completion of the HIC disposal demonstration is the result of about four years of intense effort that involved (a) obtaining approvals for transporting and disposing of the HIC loaded with an EPICOR-II prefilter, (b) designing and fabricating an HIC, (c) testing the HICs, (d) developing a process for preparing an EPICOR-II prefilter and HIC for disposal, and (e) acquiring equipment for the project.

The process for preparing the EPICOR-II prefilter and HIC for disposal required developing procedures, training personnel, and performing the actual process. Preparing the prefilter and HIC required designing and fabricating specialized equipment for remote use in the Hot shop of Test Area North at INEL.

The HIC disposal demonstration is an example of federal and state government agencies, a private utility, a federal contractor, and industry working together to solve a difficult waste disposal problem. It demonstrates that the HIC is an adequate alternative to solidification of 
resin waste for disposal and that the remaining EPICOR-II prefilters can be disposed of in a similarmanner. Finally, the demonstration illustrates the effectiveness of the U.S. Department of Energy in generating information of generic benef it to the nuclear industry and how this involvement is assisting in the cleanup of TMI-2. 


\section{CONTENTS}

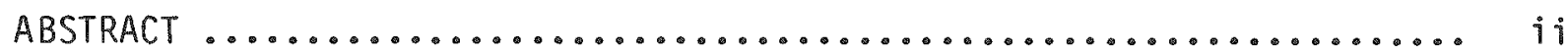

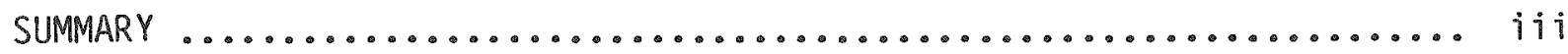

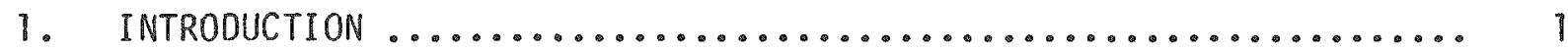

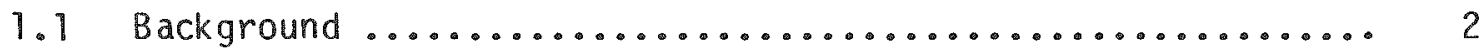

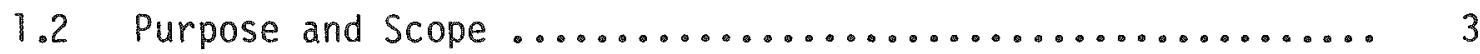

2. HARDWARE AND FACILITIES ............................. 4

2.1 EPICOR-II Prefilter .......................... 4

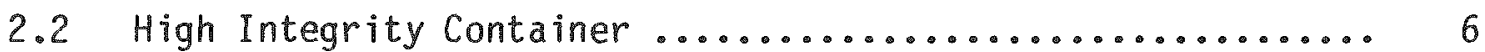

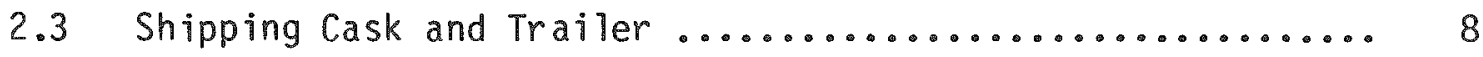

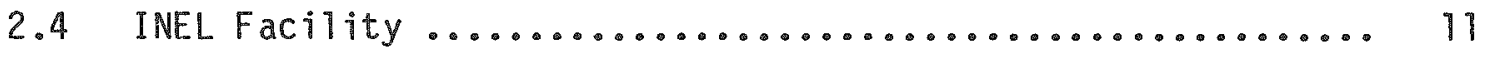

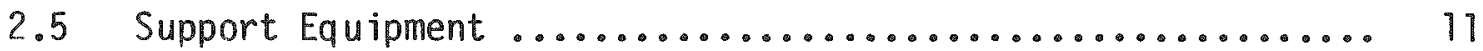

2.6 Commercial Disposal Facility ..................... 13

3. REGULATORY APPROVAL PROCESS ...................... 14

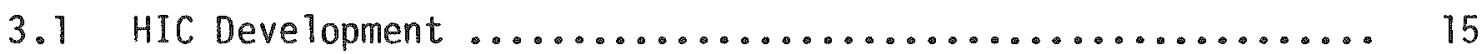

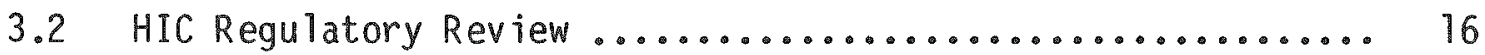

3.3 Shipping Cask Approval ....................... 18

3.4 Technical Issues in the Regulatory Approval Process ....... 19

4. HIC DISPOSAL DEMONSTRATION ........................ 20

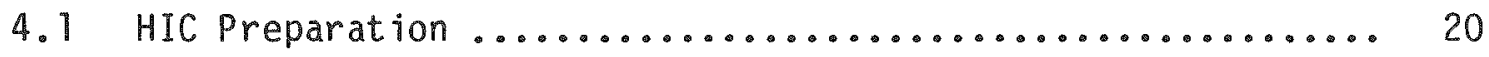

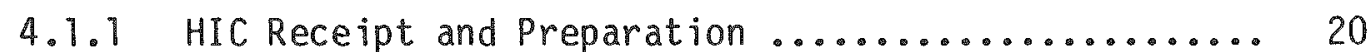

4.1.2 EPICOR-II Prefilter Preparation ............... 20

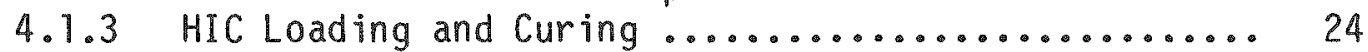

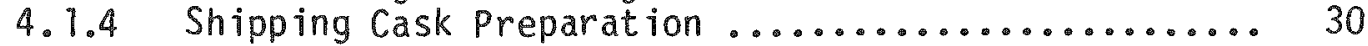

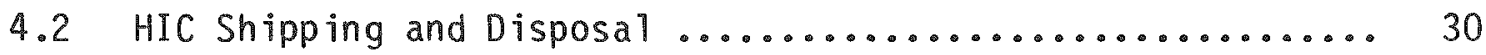

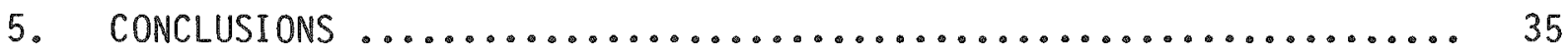

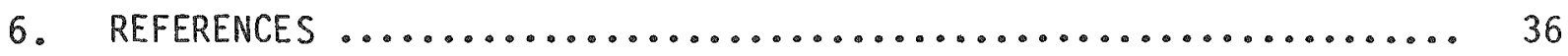


APPENDIXES

APPENDIX A-.HIGH INTEGRITY CONTAINER .......................

APPENDIX B-.IMPACT TESTS OF THE HIGH INTEGRITY CONTAINER .......... B -1

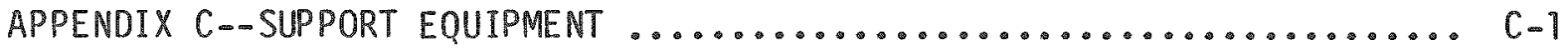

APPENDIX D--CERTIFICATION OF COMPLIANCE FOR THE HIGH INTEGRITY

CONTAINER ...................................

APPENDIX E--CERTIFICATE OF COMPLIANCE FOR THE CNS 14-190 SHIPPING

CASK $\ldots \ldots \ldots \ldots \ldots \ldots \ldots$

FIGURES

1. Schematic of an EPICOR-II prefilter ................... 5

2. Design configuration of the HIC without an enclosed EPICOR-II prefilter .....................................

3. Schematic of the tractor and trailer loaded with a shipping cask, HIC, and EPICOR-II prefilter for transport to the

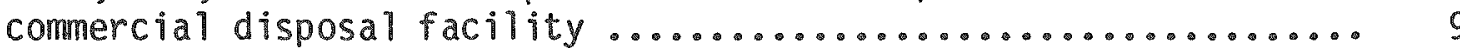

4. Schematic of the CNS 14-190 Type B shipping cask ............ 10

5. Floor plan and cross-sectional view of the TAN-607 Hot Shop ...... 12

6. Photograph of railroad equipment used to move the TSC-2 temporary storage cask containing PF-18 into the Hot Shop ....... 21

7. Schematic of the dewatering and purging equipment used to prepare PF-18 for loading into the HIC

8. Photograph of the scaffolding being adjusted around the HIC ..... 25

9. Photograph of the primary sealant (caulk) being applied to

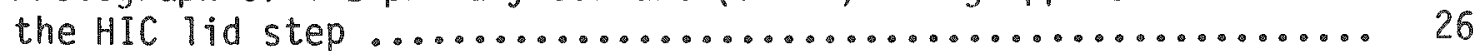

10. Photograph of an EPICOR-II prefilter being lowered into an HIC

11. Photograph of the HIC funnel bracket assembly being placed on the HIC lid. (The final design used rectangular-shaped

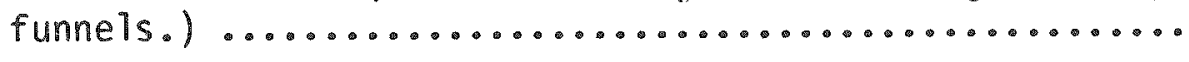

12. Photograph showing the grout being poured into the funnel bracket assembly using the grout pouring cup. (The final design used rectangular-shaped funne1s.) 
13. Map showing the route for transporting HICs from INEL to the commercial disposal site at Hanford County, Washington

14. Photograph of the HIC being unloaded from the CNS 14-190

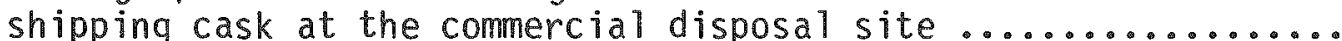

15. Photograph of the HIC, with cask cribbing attached, being

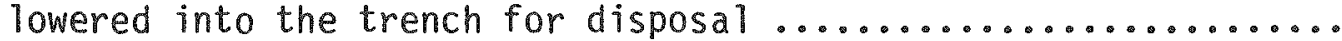

16. Photograph of the HIC being buried in the trench at the commercial disposal site.

TABLE

1. Radiation level comparison for the demonstration HIC 
$+$ 
DISPOSAL DEMONSTRATION OF A HIGH INTEGRITY CONTAINER (HIC)

CONTAINING AN EPICOR-II PREF ILTER FROM THREE MILE ISLAND

\section{INTRODUCTION}

A first-of-a-kind, high integrity container (HIC) has been developed, tested, and approved by the State of Washington for use in disposing of EPICOR-II prefilters that were used in the cleanup of Unit 2 of Three Mile Island (TMI-2). Fifty of those prefilters, which processed about $2100 \mathrm{~m}^{3}$ (560,000 gal) of accident-generated contaminated water from the Auxiliary and Fuel Handling Buildings, were transported to the Idaho National Engineering Laboratory (INEL) for interim storage, research, and disposition. The successful disposal demonstration of one EPICOR-II prefilter contained in an HIC paved the way for GPU Nuclear Corp. (GPU) and the U.S. Department of Energy (DOE) to begin disposing of 45 additional prefilters in HICS at the waste disposal facility operated by US Ecology, Inc., in the State of Washington. [Disposal of four prefilters still being used in research will be determined in the future.]

Each EPICOR-II prefilter contained up to $2200 \mathrm{Ci}$ of radioactive isotopes. In order to meet the 10 CFR 61 criteria for disposal as Class C low-level radioactive waste, either (a) the ion exchange media of the prefilter must be solidified or (b) the prefilter must be enclosed in an HIC before disposal.' A reinforced concrete HIC was chosen over solidification, after studies projected that the HIC would be cost-effective for the disposal of the unusual EPICOR-II prefilter wastes. [This projection was reaffirmed after the disposal demonstration. ${ }^{2}$ ] Developing the first-of-a-kind reinforced concrete HIC, locating/fabricating a suitable shipping cask, ${ }^{3}$ receiving regulatory approval for use of the HIC in a disposal demonstration, and effecting the disposal demonstration of that HIC with a prefilter were major undertakings which, when accomplished, provided major benefits for the nuclear industry and regulatory authorities. 


\subsection{Background}

The TMI-2 accident on 28 March 1979 provided an opportunity for both the nuclear industry and federal government to benefit from evaluating how the accident happened, effects of the accident, and how to clean up such an accident. DOE was given the responsibility for conducting research and development activities of generic value to the nuclear industry. ${ }^{4,5}$ one DOE program developed to accomplish that responsibility is the Waste Immobilization Program (WIP). Objectives of WIP include evaluating existing technologies/techniques or developing new methods to implement safe, cost-effective handiing, transportation, interim storage, and disposal of highly radioactive ion exchange media (as exemplified by the EPICOR-II ion exchange wastes) and transferring information of generic benefit to the nuclear industry. On 15 July 1981, a Memorandum of Understanding between DOE and the U.S. Nuclear Regulatory Commission (NRC) was signed whereby DOE agreed to accept 50 EPICOR-II prefilters for research, interim storage, and disposition.

The EPICOR-II Research and Disposition Program (1ater renamed the EPICOR and Waste Research and Disposition Program) is being conducted by EG\&G Idaho, Inc., to satisfy part of the WIP objectives. ${ }^{6}$ The overall goal of the EPICOR-II Research and Disposition Program is to perform research of generic value to the nuclear industry and safely dispose of the 50 EPICOR-II prefilters as Class C low-level waste. The HIC development and disposal demonstration is one activity undertaken to meet that goal. The HIC disposal demonstration has paved the way for GPU and DOE to dispose of the remaining prefilters and thus has assisted materially in the cleanup of TMI-2.

Successful completion of the HIC disposal demonstration required the participation of many organizations. EG\&G Idaho had the administrative and technical responsibility of developing and testing the HIC, acquiring regulatory approvals, and demonstrating commercial disposal of the HIC loaded with an EPICOR-II prefilter. GPU agreed to dispose of 45 additional prefilters in a similar manner if the demonstration proved successful. Under subcontract to EG\&G Idaho, Sandia National Laboratories developed 
specifications for an HIC; Nuclear Packaging, Inc. (NuPac) designed the HIC, presented a design review, built two prototype HICs, and tested one unit; and US Ecology provided the disposal service for the demonstration and will provide disposal services for the remaining EPICOR-II prefilters loaded in HICS. ATso under subcontract, US Ecology prepared and submitted an HIC Use Application to the State of Washington Department of Social and Health Services. The State, with support from NRC, commented on the HIC design and reviewed the disposal program. Those comments were resolved, and a Certification of Compliance from the State of Washington was obtained by US Ecology for disposal of the 50 EPICOR-II prefilters using the HIC designed by NuPac.a

\subsection{Purpose and Scope}

Objectives of the EPICOR-II Research and Disposition Program include development of an HIC system and disposal of the 50 EPICOR-II prefilters in HICs. In order to complete these objectives, a suitable HIC had to be specified, designed, fabricated, tested, and used in a disposal demonstration operation. This document presents a history of processes used in the disposal demonstration of an EPICOR-II prefilter sealed in an HIC. The document includes brief descriptions of the equipment and facilities used; acquisition of regulatory approvals; and processes for preparing, transporting, and disposing of the HIC.

a. To avoid confusing the reader, it is noted that the HIC Use Application to the State of Washington subsequently cited in this report resuited in a Certification of compliance being issued by the state for use of the HIC in burial operations. 


\section{HARDWARE AND FACILITIES}

This section provides descriptions of the EPICOR-II prefilter, HIC, shipping cask and trailer, INEL facility used for storing EPICOR-II prefilters, support equipment used for the disposal process, and disposal facility where the HIC was disposed.

\subsection{EPICOR-II Prefilter}

Each EPICOR-II prefilter liner is a cylinder $1.2 \mathrm{~m}$ (48 in.) in diameter by $1.4-m\left(54-i n_{0}\right)$ high, fabricated from $6.4-m m\left(1 / 4-i n_{0}\right)$ welded steel (Figure 1). Each 1iner contains $\sim 850 \mathrm{~m}^{3}\left(30 \mathrm{ft}^{3}\right)$ of ion exchange media which are either organic resins or organic resins and zeolite adsorbers. An inlet header system was used to spread unprocessed water over the top of the ion exchange media, while an outlet header system collected water processed through the ion exchange media. Each liner is coated inside and out with Phenoline $368^{\mathrm{a}}$ paint to protect it against corrosion. Metallurgical examination of two prefilter liners, performed as part of the EPICOR-II Research and Disposition Program, has shown that the estimated life of the liners before failure by corrosion is greater than 50 years. ${ }^{7}$ An EPICOR-II liner weighs $635 \mathrm{~kg}(1400 \mathrm{lb})$ empty and $21542 \mathrm{~kg}(3400 \mathrm{lb})$ when loaded with resin. Resin loadings range from $585 \mathrm{~kg}(1290 \mathrm{lb})$ to $880 \mathrm{~kg}(1940 \mathrm{lb})$.

In processing water from the Auxiliary and Fuel Handling Buildings of TMI, each prefilter collected radionuclides consisting mostly of CS-137, -134, and their daughter products; small amounts of Ru-106, Rh-106, Sr-90, $\mathrm{Co}-60$, and $\mathrm{Ba}-137$; and trace amounts of $\mathrm{U}-238$ and some transuranic elements. Hydrogen gas is generated in the prefilters from radiolytic degradation of demineralizer materials and radiolysis of water. ${ }^{8}$ To prevent buildup of that gas, a plug was removed remotely from the vent port of each prefilter upon arrival at INEL. Removal of the vent plug allows

a. Phenoline 368 is a product of the Carbolic Co. 


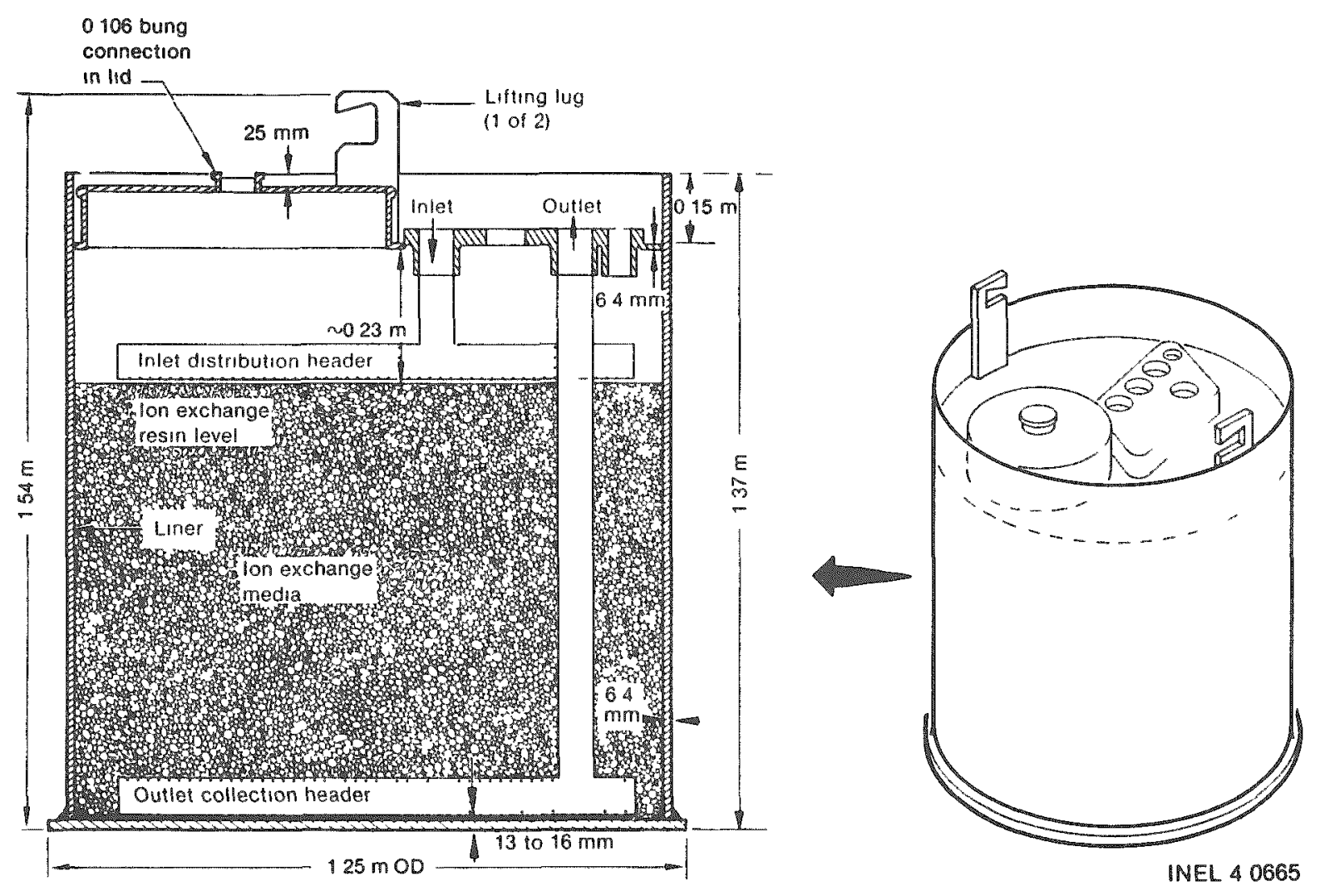

Figure 1. Schematic of an EPICOR-II prefilter. 
the gas to exit continuously from the prefilter during storage. The gas is collected and routed to the heating and ventilation system of the storage facility.

\subsection{High Integrity Container}

The HIC is a reinforced concrete cylindrical container designed for disposal of an EPICOR-II prefilter at a commercial disposal facility for low-level radioactive waste. 9 The container is designed to ensure safe, reliable, below ground disposal of radioactive waste for a minimum of 300 years ( 10 half-ijves of the predominant isotopes) while radioactive isotopes contained in the resins decay to a nonhazardous level.

Figure 2 illustrates the design configuration of the HIC. Leakage is prevented by a corrosion-resistant steel liner which is coated inside and out with phenolic paint. Durability of the container is enhanced by the pH-adjusting amphoteric material placed on the inside bottom of the container. The container lid is sealed and then bonded to the HIC body using a bead of adhesive gel concressive AEX-1513 and flowable grout material Concressive AEX-1512, respectively. ${ }^{a}$ The HIC is equipped with a vent system to allow the escape of gas produced by radiolysis in the EPICOR-II prefi]ter. [The EPICOR-II prefilter is purged with argon gas before being loaded into the HIC.] The vent is cast into, and protected by, the reinforced concrete lid assembly. Without venting, the HIC has sufficient burst strength to contain the gas that may be generated, based on a 300-year life. The concrete container attenuates radiation from the enclosed EPICOR-II prefilter by a factor of about nine: that is not enough shielding to permit hands-on operation but enough to simplify handiing procedures and safety precautions. Appendix A provides a detailed description of the HIC, and Appendix $B$ gives an evaluation of the HIC when transported and contained within the CNS 14-190 shipping cask.

a. Concressive $A E X-1512$ and $A E X-1513$ are products of Adhesive Engineering Company. 


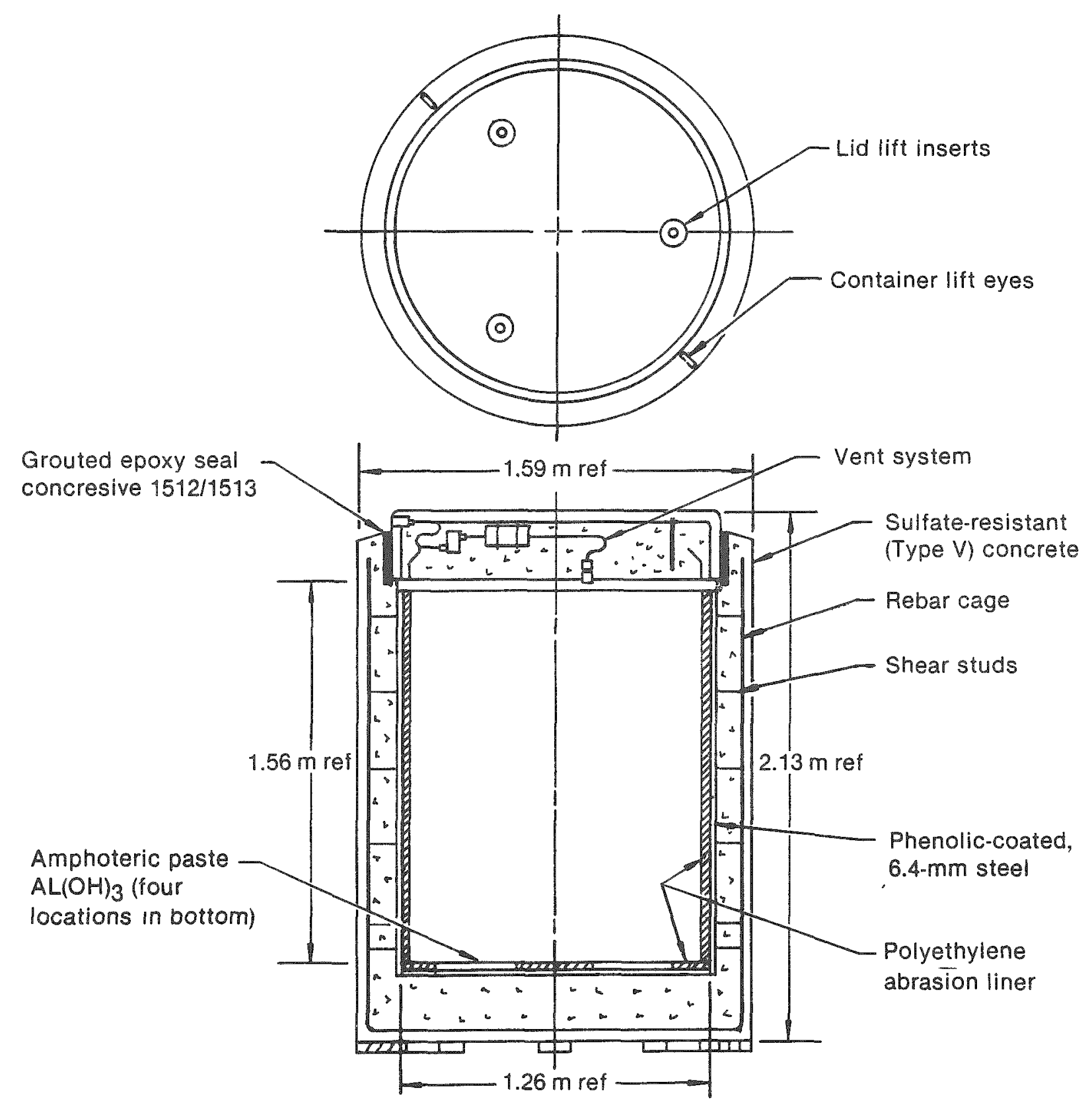

INEL 40666

Figure 2. Design configuration of the HIC without an enclosed EPICOR-II prefilter. 


\subsection{Shipping Cask and Trailer}

A certified Type B shipping cask, CNS 14-190, was used to contain the HIC with its prefilter during transport by truck from INEL to the disposal facility in the State of Washington (Reference 3). Figure 3 shows the tractor, trailer, and shipping cask loaded with the HIC and EPICOR-II prefilter. Figure 3 also shows the cribbing which was placed between the HIC and cask to prevent shifting of the HIC during transport. The cask was purchased from Chem Nuclear Systems, Inc. by DOE specifically for this task and will be used to transport the remaining 45 prefilters to the commercial disposal facility.

CNS $14-190$ is a steel-encased, concrete-shielded shipping cask (Figure 4). The cask is $2.39 \mathrm{~m}(94.25 \mathrm{in}$.) in diameter by $2.64-\mathrm{m}$ (103.75-in.) long. Reinforced concrete occupies the $17.8 \mathrm{-cm}(7-\mathrm{in.})$ annular space between two shelis and base plates. The 1id is a 12.1-cm (4.75-in.) thick, laminated steel cover held in place by 32 high-strength, $3.18-\mathrm{cm}\left(1-1 / 4-i n_{0}\right)$-diameter bolts. A silicone 0 -ring is used to seal the joint between the lid and the cask body. The outer shell and base plate are 6.4-cm (1-1/4-in.) thick, while the inner shell and base plate are $5.1-\mathrm{cm}(2-\mathrm{in.})$ thick. The cask is reinforced at the top and bottom with steel rings and equipped with lifting lugs. The lid is provided with two access ports. Empty weight of the cask is $224,500 \mathrm{~kg}(\sim 54,000 \mathrm{lb})$; the maximum payload of the cask is $\sim 10,400 \mathrm{~kg}(\sim 23,000 \mathrm{~Tb})$.

The trailer also was purchased by DOE specifically for use with the shipping cask. The trailer is a three axle, fifth wheel low-boy with a $36,300-\mathrm{kg}(80,000-1 \mathrm{~b})$ capacity. The cask is held to the trailer by sixteen 3.18-cm (1-1/4-in.) bolts (Figure 4). The empty weight of the cask, trailer, and tractor is $\sim 39,500 \mathrm{~kg}(\sim 87,000 \mathrm{lb})$, and the maximum loaded weight (with HIC) is $246,700 \mathrm{~kg}(2109,000 \mathrm{lb})$. To use the system on public thoroughfares necessitates acquisition of overweight permits. 


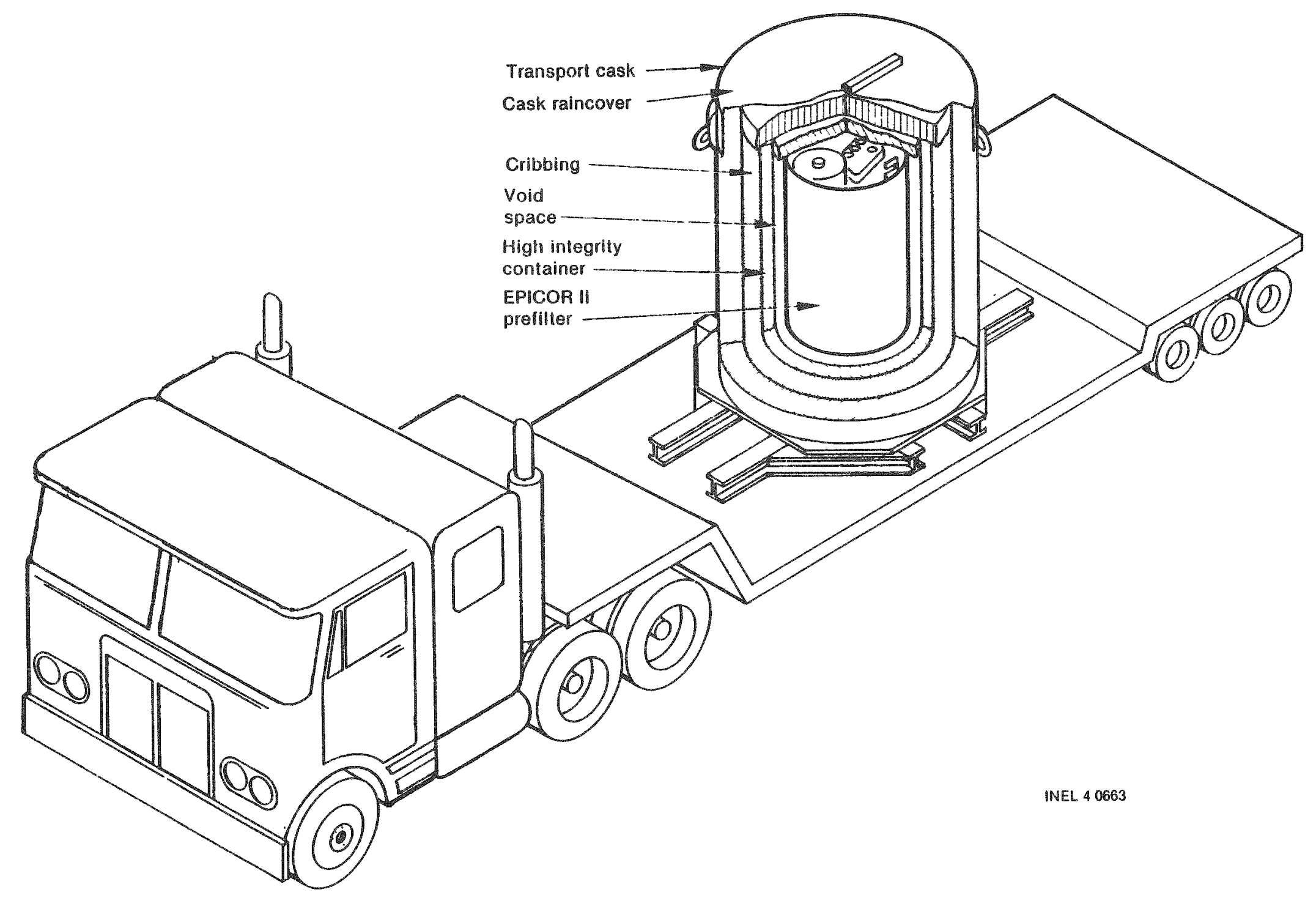

Figure 3. Schematic of the tractor and trailer loaded with a shipping cask, HIC, and EPICOR-II prefilter for transport to the commercial disposal facility. 


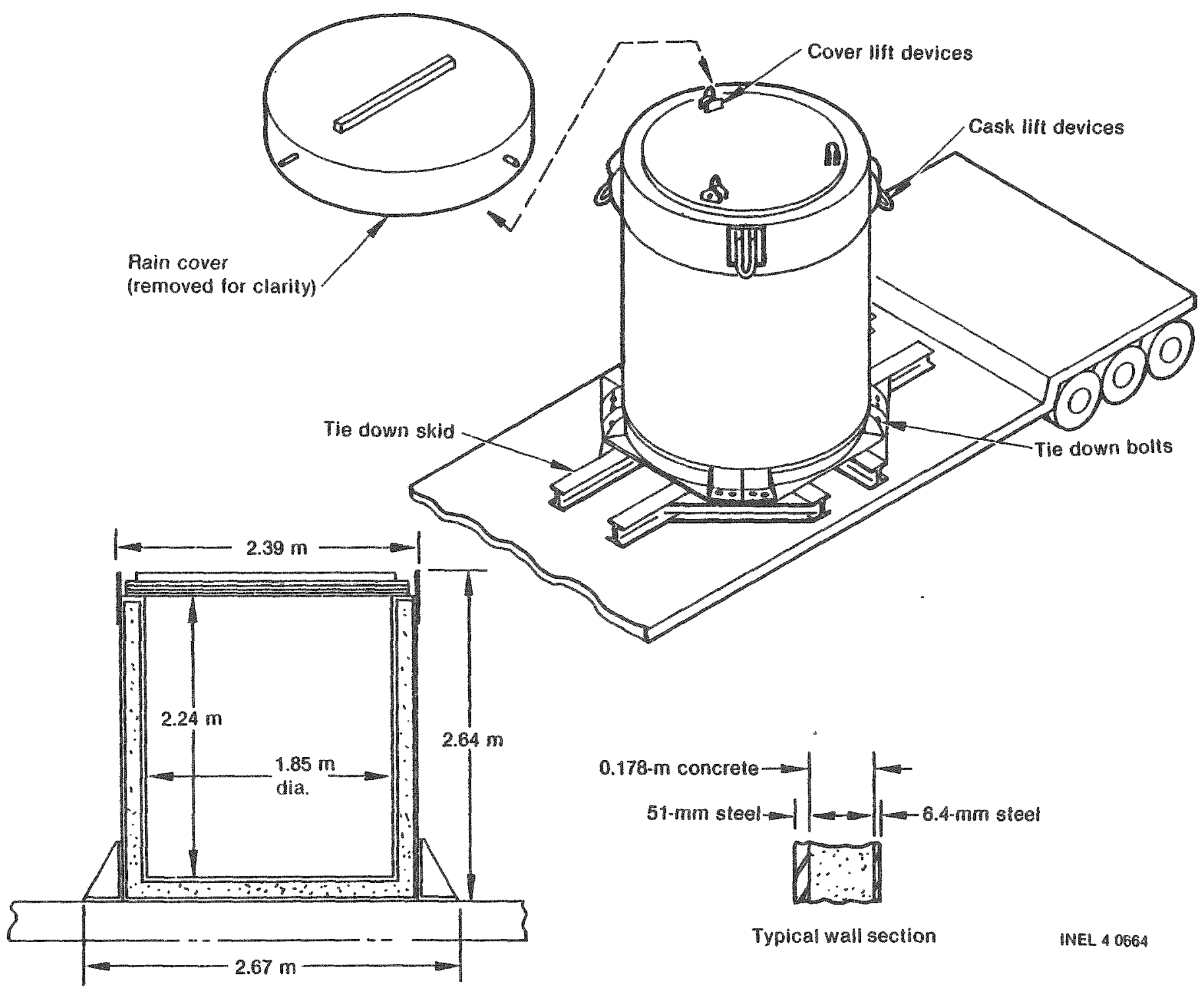

Figure 4. Schematic of the CNS 14-190 Type B shipping cask. 


\subsection{INEL Facility}

The Hot Shop of Test Area North Building 607 (TAN-607) at INEL was used for the EPICOR-II Program because the facility was able, after modifications, to receive, handle, and store the EPICOR-II prefilters. The TAN-607 Hot Shop is a large, shielded high bay with rail and truck access through two $327,000-\mathrm{kg}$ (360-ton) concrete doors, each 1.2-m (4-ft) thick by 4.3-m (14-ft) wide by $10.1-\mathrm{m}(33-\mathrm{ft})$ high, with staggered joints and mounted on rollers. The Hot Shop is equipped with two overhead cranes $[91,000-\mathrm{kg}$ (100 ton) and $9,000-\mathrm{kg}(10$ ton $)]$ on a rolling crane bridge, a large overhead manipulator (located on a second rolling bridge), auxiliary wall-mounted manipulators, and other equipment for remote handling of radioactive material (Figure 5). The walls of the Hot Shop are constructed of concrete 2.1-m (7-ft) thick with shielded viewing windows built into the north and south walls. Operating galleries, located behind each shielded window, allow control of remotely operated equipment anywere in the Hot Shop.

\subsection{Support Equipment}

Preparation of the EPICOR-II prefilter and HIC in the Hot Shop of TAN-607 required specially designed equipment that could be used remotely. That equipment included: (a) liner lifting device (T-bar) for lifting the prefilter; (b) venting tool for removing the lower distribution port plug from the prefilter; (c) dewatering and purging equipment for removing water and gas from the prefilter; (d) HIC spreader bar for lifting the HIC; (e) lid lifting assembly for lifting the HIC lid; (f) liner interface collar for protecting the HIC and guiding the prefilter into the HIC; and (g) grouting equipment (funnel bracket assembly and a pouring cup) for attaching the HIC lid to the HIC body. Appendix C provides a more detailed description of the support equipment. 

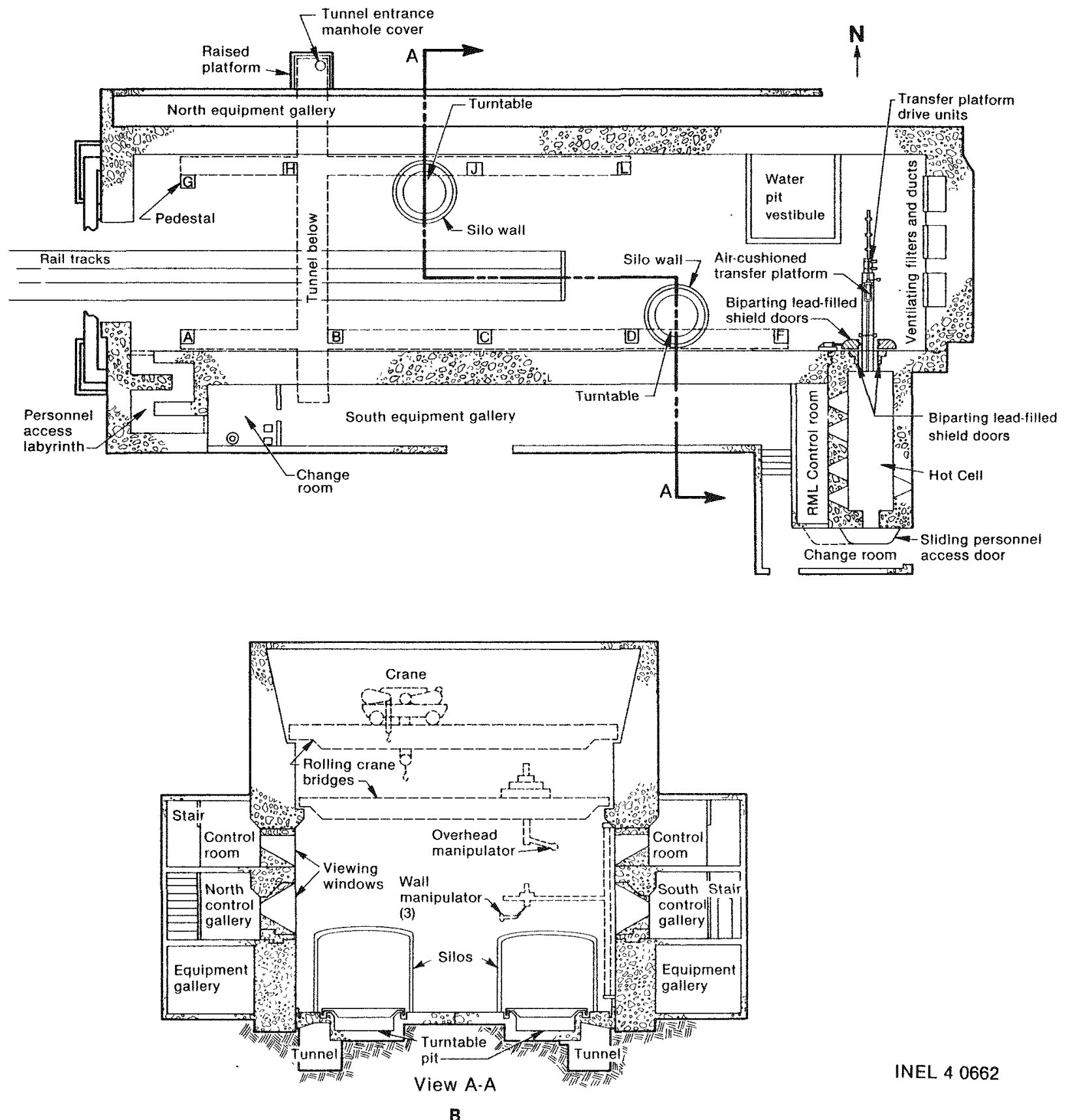

INEL 40662

Figure 5. Floor plan and cross-sectional view of the TAN-607 Hot Shop. 


\subsection{Commercial Disposal Facility}

The demonstration HIC was disposed at the Low-Level Radioactive Waste Disposal Facility in Benton County, Washington. That facility is on the Hanford Nuclear Reservation, 25 miles northwest of Richland. The State of Washington, under the guidance of the NRC, regulates the disposal facility, which is operated by US Ecology. The types of wastes authorized for receipt and methods of handling, transportation, and disposal all are subject to regulatory approval. Among the low-level radioactive wastes disposed at the site are solid or solidified materials, contaminated equipment, cleaning wastes, tools, protective clothing, gloves, and laboratory wastes. The contaminated materials are received from hospitals, laboratories, universities, industry, and nuclear power facilities.

The average burial trench at the disposal site is about $46-\mathrm{m}$ (150-ft) wide by $14-m(45-f t)$ deep by $244-m(800-f t)$ long. Filled trenches are marked with permanent monuments which describe the contents, boundaries, dates of use, and other pertinent information. Several locations on the site and in the surrounding area are monitored environmentally. 


\section{REGULATORY APPROVAL PROCESS}

One of the most important outcomes of the HIC work that led to the disposal demonstration was the achievement of regulatory approval for using this particular HIC. Approvals were required from regulatory authorities at a time when the regulatory position on HICs was not well established, criteria for HICs were still being developed, and the HIC concept was relatively untested. The regulation 10 CFR Part 61 , "Licensing Requirements for Land Disposal of Radioactive Waste, "establishes a waste classification system based on radionuclide concentrations in the wastes. $\mathrm{Cl}$ ass $\mathrm{C}$ wastes are required to be stabilized. The NRC Technical Position on Waste Form gave guidance for stability (e.g., solidification or use of high integrity containers), along with criteria for high integrity containers. However, that technical position was formative at the start of the DOE effort described in this report.

The approval process for use of the HIC took approximately four years and involved the cooperation of federal and state governments, a public utility, and private industry working together for a common goal. The process was a pathfinder; therefore, it is believed that much of the regulatory deliberation will be shortened for similar, future approval actions.

In the following discussions, it is important to recognize that NRC (a) reviewed, critiqued, and consuited in matters related to design and test requirements for the HIC; (b) specified tests and analyses for the prefilters to be placed within the HICS; and (c) functioned as a technical consultant to the State of Washington in approving use of the HIC. The State of Washington independently reviewed the HIC design, procedures for preparing the HIC for burial, and procedures for handling the HICS at the disposal facility. The State issued final approval for use of the HIC in the form of a Certification of Compliance. EG\&G Idaho originally initiated the approval process as a licensing effort. However, at the suggestion of NRC, that was changed to an "HIC Use Application." Ultimately, the effort resulted in approval being issued as a Certification of Compliance by the State of Washington. 
The approval process for the HIC involved two identifiable (and roughly simultaneous) parallel efforts: (a) the HIC development effort (Section 3.1) and (b) the regulatory review effort (Section 3.2). These parallel efforts began with the regulatory agencies reviewing the HIC design so that concerns could be addressed, testing performed, and modifications incorporated as necessary, thus permitting final approval.

Obtaining a suitable shipping cask and trailer for moving a loaded HIC from INEL to the US Ecology site required approval by NRC for use of an existing cask design. The process of obtaining approval for the cask (Section 3.3) was much easier than acquiring approval for use of the HIC, because requirements were well defined and the process for obtaining that approval was well established. It should be noted that approval for use of a shipping cask is by "Certificate of Compliance," while approval for use of the HIC is by "Certification of Compliance."

\subsection{HIC Development}

Discussions began in mid-1980 between DOE, GPU, and EG\&G Idaho concerning use of HICs to dispose of EPICOR-II prefilters. The principal considerations at that time were the possible cost competitiveness of an HIC system versus in situ solidification of resins and the need for an HIC demonstration within the industry.

In early 1981, Sandia was contracted to develop design requirements for an HIC. Those requirements were subjected to extensive peer review after completion in Apri1 1981. The resulting requirements are enumerated in Appendix A. Those Sandia-developed design requirements constituted one of the earlier definitions of an HIC and preceded the publication of Proposed Rules, Licensing Requirements for Land Disposal of Radioactive Waste, 10 CFR Part 61, dated 24 July 1981.

NuPac then was selected to design the HIC. That design was completed and also subjected to rigorous peer review and program reviews at TMI and DOE Headquarters. Early in 1982, a contract was awarded to NuPac to provide two prototype HICs, based on the design. 
Upon completion of fabrication in July 1982, the first prototype HIC was subjected to several tests at NuPac, including vent system flow rate tests and a $0.9-\mathrm{m}(3-\mathrm{ft})$ drop test onto an unyielding surface in accordance with requirements of 10 CFR 71.35 for Type A concainers. Acceptance testing was completed satisfactorily that month by NuPaC on the first HIC prototype. The second prototype HIC was delivered to EG\&G Idaho in September 1982, where independent testing was conducted. Those tests included internal pressurization, thermal cycling, vibration, vent rate into compacted soi 7 , and a $7.6-\mathrm{m}(25-\mathrm{ft})$ drop test onto soil simulating the burial facility soil. The $7.6 \mathrm{-m}(25-\mathrm{ft})$ drop test was specified by the State of Washington as part of their requirements for acceptance. The HIC successfully passed all of the tests.

\subsection{HIC Regulatory Review}

An original issue of the NuPac HIC Design Analysis Report, dated 4 December $1981,{ }^{a}$ was reviewed with the State of Washington in January 1982 regarding a possible Use Application for disposal of EPICOR-II prefilters using HICs. ${ }^{10}$ Both active nuclear waste disposal site operators (US ECology for the State of Washington and Chem Nuclear Systems for South Carolina) were contacted in early 1982 concerning their interest in submitting an HIC Use Application to an appropriate state regulatory agency. The State of South Carolina would not allow the acceptance of any TMI-generated waste; however, US Ecology expressed interest. In September 1982, US Ecology was contracted to develop and submit an HIC Use Application to the State of Washington Department of Social and Health Services. The application included procedures for disposal operations that would be implemented at the US Ecology site. Both the design features of the HIC and the site handling procedures were subjects of subsequent reviews. A draft application was submitted informally by US Ecology to the

a. Also in the same timeframe, DOE gave NRC the original issue of the NuPaC HIC Design Analysis Report 10 to review. NRC comments resulting from that review were transmitted to DOE on 21 June 1982. Responses to those comments were prepared by EG\&G Idaho and submitted to DOE on 25 August 1982. Revision 1 of the NuPac HIC Design Analysis Report 11 was issued in September 1982. 
State in Apri1 1983. A meeting on that submittal was held in early May, resulting in resubmittal of the HIC Use Application to the State on 17 May 1983. Transmitted with that submittal were Revision 1 of the NuPac HIC Design Analysis Report, 11 an HIC Design Evaluation Report by US Ecology, additional information on design that was requested at the May meeting, and results from the $7.6 \mathrm{~m}(25 \mathrm{-ft})$ drop test. A meeting was held involving representatives of the State, US Ecology, and EG\&G Idaho to discuss that submittal. The application was revised to comply with state recommendations, and a follow-up application was submitted in July 1983. The documentation from that application was sent by the state to NRC for assistance in technical evaluation.

Another meeting was held between EG\&G Idaho, US Ecology, and the State in early September 1983, at which time the State requested further information on the EPICOR-II prefilter and HIC processing.

In early October 1983, NRC forwarded to the State and DOE a set of 46 comments concerning HIC Use Application documentation submitted by US Ecology. Both the State and DOE forwarded those comments to US Ecology and EG\&G Idaho. Responses to the comments were developed cooperatively by US Ecology, NuPac, EG\&G Idaho, and Chem Nuclear Systems and sent to the State in early November. A meeting was held with US Ecology, the State, and EG\&G Idaho on 9 November 1983 to review the responses. Additional information requested by the State was added to the responses, with final submittal of the HIC Use Application to the State in late November 1983. That submittal was forwarded to NRC by the state on 5 December 1983.

Final NRC concurrence with the HIC Use Application came in a letter to the State from NRC dated 1 February 1984. That letter recommended approval of the HIC Use Application. On 23 March 1984, the State of Washington issued a Certification of Compliance for 50 HICs to be used in disposing of EPICOR-II prefilters at the US Ecology site at Hanford, Washington (Appendix D). Upon receipt of the Certification of Compliance, US Ecology notified EG\&G Idaho that the loaded HIC demonstration unit could be accepted for disposal. 


\subsection{Shipping Cask Approval}

A suitable shipping cask was required to transport the loaded HIC from INEL to the disposal site, and a Safety Assessment Document (Reference 3) was required to evaluate that transport activity. Only one cask system existed in the United States that could accommodate the HIC and provide adequate shielding. That cask system was owned by Chem Nuclear Systems and had an existing Certificate of Compliance. However, the cask was withdrawn from service by Chem Nuclear Systems because it needed refurbishment and required a new transport trailer. Therefore, Chem Nuclear Systems urged that a new issue cask and trailer be constructed. The new issue cask would benefit from some modifications over its predecessor (e.g.g it would be constructed of a steel that meets latest material brittle fracture requirements). However, the Certificate of Compliance used for the predecessor cask would require revision to allow transport of the EPICOR-II/HIC units.

After ensuring that a revision to the Certificate of Compliance could be obtained for transporting EPICOR-II prefilters in HICs, EG\&G Idaho requested a cost estimate from Chem Nuclear Systems. Numerous discussions were held between NRC, Chem Nuclear Systems, and EG\&G Idaho to revise the Certificate of Compliance for the cask. After analyses by NuPac showed that the cask would provide sufficient shielding, a contract was awarded in May 1983 for Chem Nuclear Systems to supply a new issue of the CNS 14-190 cask and trailer. The new issue cask and trailer were fabricated and delivered in September 1983. Agreement finally was reached with NRC to revise the Certificate of Compliance to include (a) dewatered resins as one of the materials that can be transported and (b) a statement on gas generation within the container. Application was made in mid-January 1984, and the approved Revision 10 to the Certificate of Compliance (Appendix E) for the CNS 14-190 cask was issued 24 January 1984. 


\subsection{Technical Issues in the Regulatory Approval Process}

In reviewing the HIC design, processing, and disposal procedures, several issues were raised by the State of Washington and NRC. The most significant issues focused on (a) adequacy of the HIC design for the required 300-year disposal period, (b) characteristics of the wasteform being placed within the HIC, and (c) concerns over safe transportation. Issues raised concerning the HIC design included adequacy of the inner and outer moisture barriers during the required 300-year disposal period, maintenance of integrity during all disposal handling operations (including hypothetical accidents), and ability of the HIC lid-body seal material (epoxy) to maintain its integrity in a high radiation field over the disposal period. Procedures used for dewatering EPICOR-II prefilters to meet the waste disposal limits of $<7 \%$ free standing liquid and specification of the $\mathrm{pH}$ of that residual water $(\mathrm{pH} \geq 4)$ also were issues. Also, confirmation was required that the transuranic material in the waste not exceed $10 \mathrm{nCi} / \mathrm{g}$ and plutonium not exceed $100 \mathrm{nCi} / \mathrm{g}$ in accordance with the State of Washington requirements. Finally, the issues of the CNS 14-190 cask being approved for transporting dewatered resins and the adequacy of the cask shielding and containment under normal and hypothetical accident conditions had to be evaluated. All of the issues were satisfactorily resolved through the combined efforts of EG\&G Idaho, US Ecology, NuPac, Chem Nuclear Systems, and GPU. Those organizations, working together, provided additional testing, analyses, procedure development, and data, where appropriate, for resolving the issues. 


\section{HIC DISPOSAL DEMONSTRATION}

The HIC disposal demonstration was divided into the following two activities: (a) HIC preparation and (b) HIC shipping and disposal. Preparation of the HIC involved receiving the empty HIC from the manufacturer, preparing and moving it into the Hot Shop of TAN-607, retrieving an EPICOR-II prefilter from a temporary storage cask, preparing and loading the prefilter into the HIC, bonding (grouting) the lid onto the HIC, curing the bond, and loading the HIC into the shipping cask. HIC shipping and disposal involved preparing the shipping cask for transport, transporting the cask to the disposal facility, and disposing of the HIC. The following sections provide detailed descriptions of the HIC disposal processes.

\subsection{HIC Preparation}

\subsubsection{HIC Receipt and Preparation}

The HIC used for the disposal demonstration was fabricated by Bingham Mechanical and Metal Products Inc. of Idaho Falls, Idaho. Upon receipt of that HIC, outside surfaces of the body up to the lip and the top of the lid were covered with plastic sheets. The plastic prevented exterior surfaces of the HIC from becoming contaminated while in the Hot Shop. Two slings were attached to the HIC, one to each of the HIC lifting eyes. The HIC then was moved into the Hot Shop for loading.

\subsubsection{EPICOR-II Prefilter Preparation}

EPICOR-II prefilter PF-18 was chosen for the disposal demonstration because it contained one of the highest curie contents (viz., 2025-Ci total activity). [The results of a radiation survey of $\mathrm{PF}-18$ are compared to HIC and cask measurements in Section 4.2 of this report.] It was stored outside the Hot Shop of TAN-607 in a temporary storage cask (TSC) mounted on a railroad flatcar (Figure 6). The flatcar was moved into the Hot Shop, where the prefilter was removed from the TSC and placed behind shielding. 


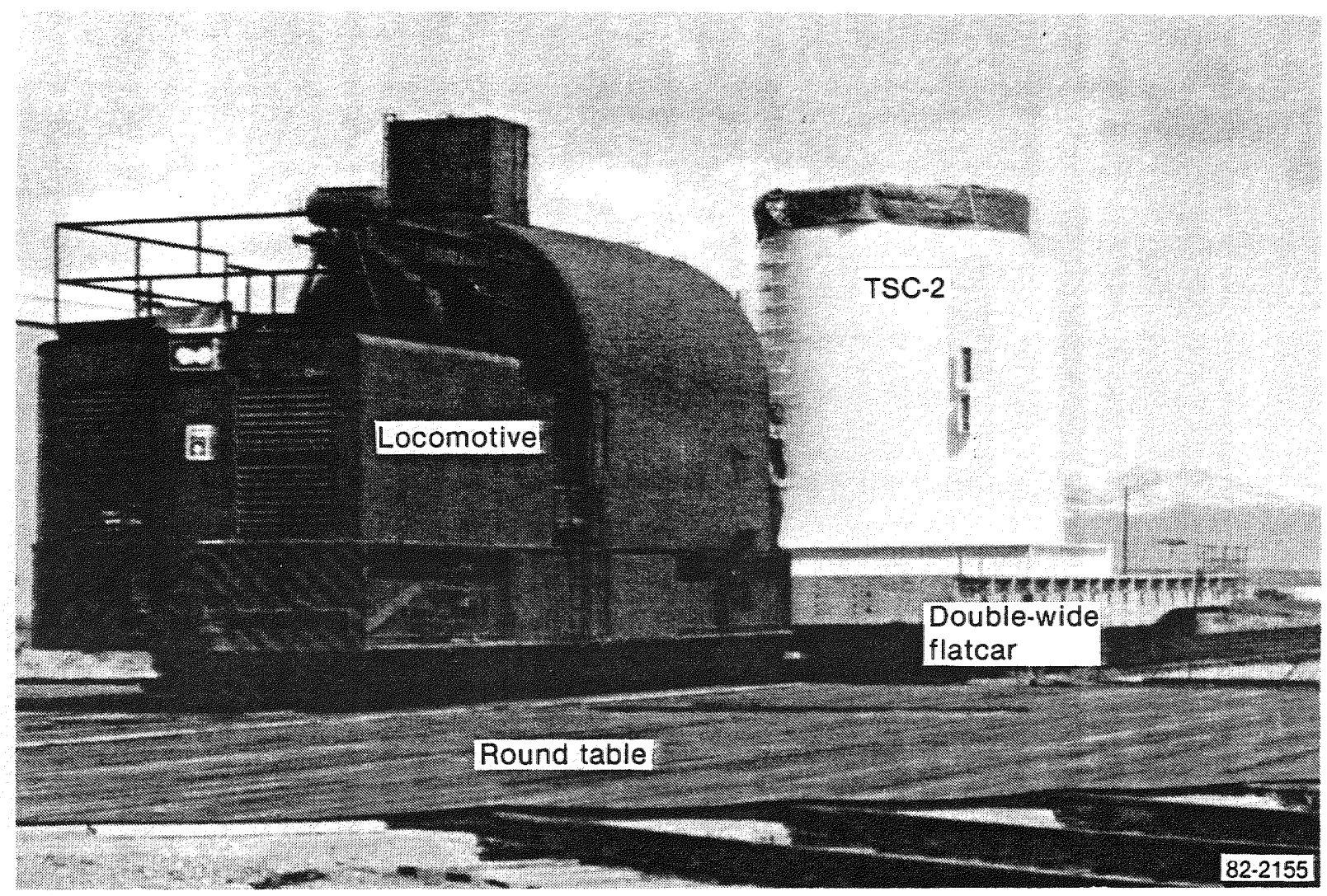

Figure 6. Photograph of railroad equipment used to move the TSC-2 temporary storage cask containing PF-18 into the Hot Shop. 
After the flatcar and personnel were removed from the Hot Shop, PF-18 was moved remotely to the dewatering area, and the plug from the prefilter effluent port was removed remotely using the venting tool. An adapter was inserted into the effluent port, and the hose from the dewatering system (Figure 7) was connected to the adapter. The vacuum pump of the dewatering system was started, and the prefilter was dewatered. Residual water from the prefilter was drawn from the lower distribution header of the prefilter, through a hose, and dumped into the water extraction drum of the dewatering system. The vacuum pump was left on for $1 \mathrm{~h}$ and then shut off for $1 \mathrm{~h}$, so that water trapped in the resin could filter down to the header. To complete the dewatering process, the vacuuming process was repeated two more times, for a total of $5 \mathrm{~h}$. At the end of each pumping sequence, the water extraction drum was emptied into the hot waste drain of the Hot Shop. It is estimated that between 19 and $57 \mathrm{~L}$ (5 and 15 gal) were removed from the prefilter. Less than $1 \%$, or about $19 \mathrm{~L}$ (5 gal) of water remained in the prefilter. A water sample $2500 \mathrm{~mL}(15 \mathrm{oz})$ was obtained to measure the $\mathrm{pH}$ level. The average $\mathrm{pH}$ value of the $\mathrm{PF}-18$ water sample was $5.8 \pm 0.1 \mathrm{pH}$ units.

After dewatering PF-18, purging was started (see Figure 7). First, an adapter was inserted into the vent port of the prefilter. [The vent port plug had been removed upon receipt at INEL so the prefilter could vent continuously during storage.] Next, a tube was attached to the adapter. The tube was routed from the adapter, through the Hot Shop wall, to an argon bottle in the Gallery; thus, technicians could operate the purge system remotely. Argon flowed through the prefilter for $6 \mathrm{~h}$ at about $0.03 \mathrm{~m}^{3} / \mathrm{min}(1 \mathrm{cfm})$ for a total of $210 \mathrm{~m}^{3}\left(360 \mathrm{ft}^{3}\right)$, or 12 volumes, of gas. The argon gas entering the vent port of the prefilter forced any combustible gas out the effluent port.

With the dewatering and purging of the prefilter completed, the purge tube and vacuum hose were disconnected and the two adapters were removed. A porous plug was inserted into the vent port, and a solid plug was inserted into the effluent port. 


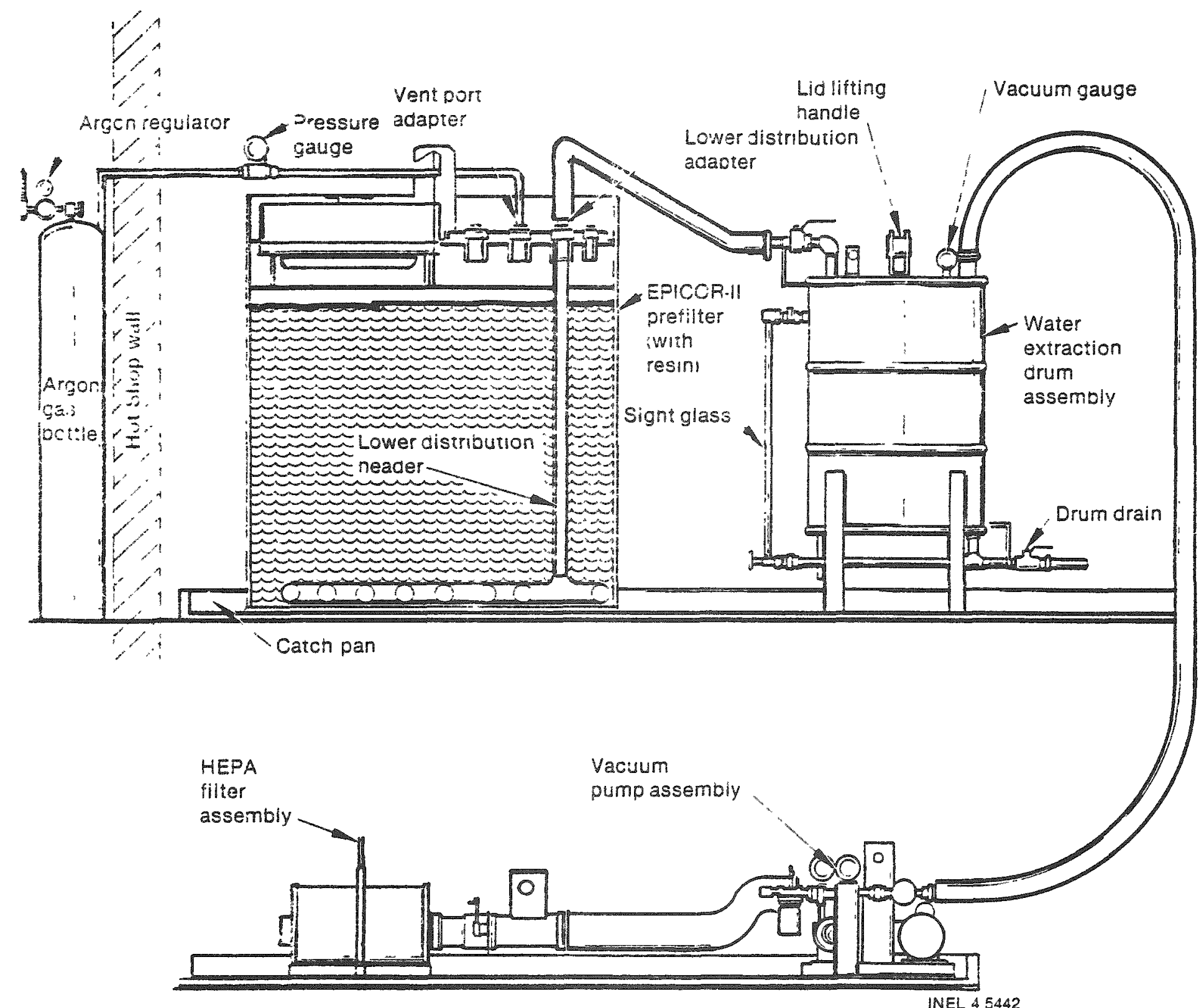

Figure 7. Schematic of the dewatering and purging equipment used to prepare PF-18 for loading into the HIC. 


\subsubsection{HIC Loading and Curing}

PF-18 was placed behind shielding so technicians could enter the Hot Shop and prepare the HIC for loading. A wood sceffolding, with space in the middle for the HIC, was set up and covered with plastic. The HIC was placed inside the scaffolding (Figure 8 ), and its lid was removed. The technicians inspected the inside of the HIC (j.e., the polyethylene sleeve, base disk, and aluminum hydroxide paste in each of the disk cutouts). A 1.3-cm (0.5-in.) bead of primary sealant Concressive AEX-1513 was applied around the inside diameter of the HIC lid step (Figure 9). The insertion collar, which guides the prefilter into the HIC, was placed on the HIC, and personnel were removed from the Hot Shop. PF-18 was retrieved, inserted into the HIC (Figure 10), and the insertion collar removed. The Iid was placed onto the HIC Iid step, where it contacted the sealant and formed the primary seal. Next, the grouting assembly was placed on the HIC Tid (Figure 11).

Outside the Hot Shop, the epoxy Concressive AEX-1512 grout was mixed. One batch of grout was composed of $3.8 \mathrm{~L}(1 \mathrm{gal})$ of Concressive AEX- 1512 (1/3 Part $B$ and $2 / 3$ Part $A)$ and one bag of $A / E$ special grout blend. One batch made $224 \mathrm{~kg}(2.54 \mathrm{lb})$ of grout with a volume of $001 \mathrm{~L}(23 \mathrm{gal})$.

The grout was taken into the Hot Shop, where it was transferred into a pouring cup held by the overhead manipulator (0-man). The 0-man was used to transfer the grout to the HIC, where it was poured through the three funnels on the grout assembly into the lid-body void of the HIC (Figure 12). When an area of the HIC void was filled, the grouting assembly was moved with the 0 -man. After the void was completely filled, the grouting assembly was removed, and the lid lifting recesses were filled (Figure 8) directly from the cup. Three batches of grout were used to fill the HIC lid-body void and lid recesses. The HIC was stored behind shielding for two days while the grout cured. A radiation survey was then conducted on the HIC; results of this survey are given in section 4.2 . 


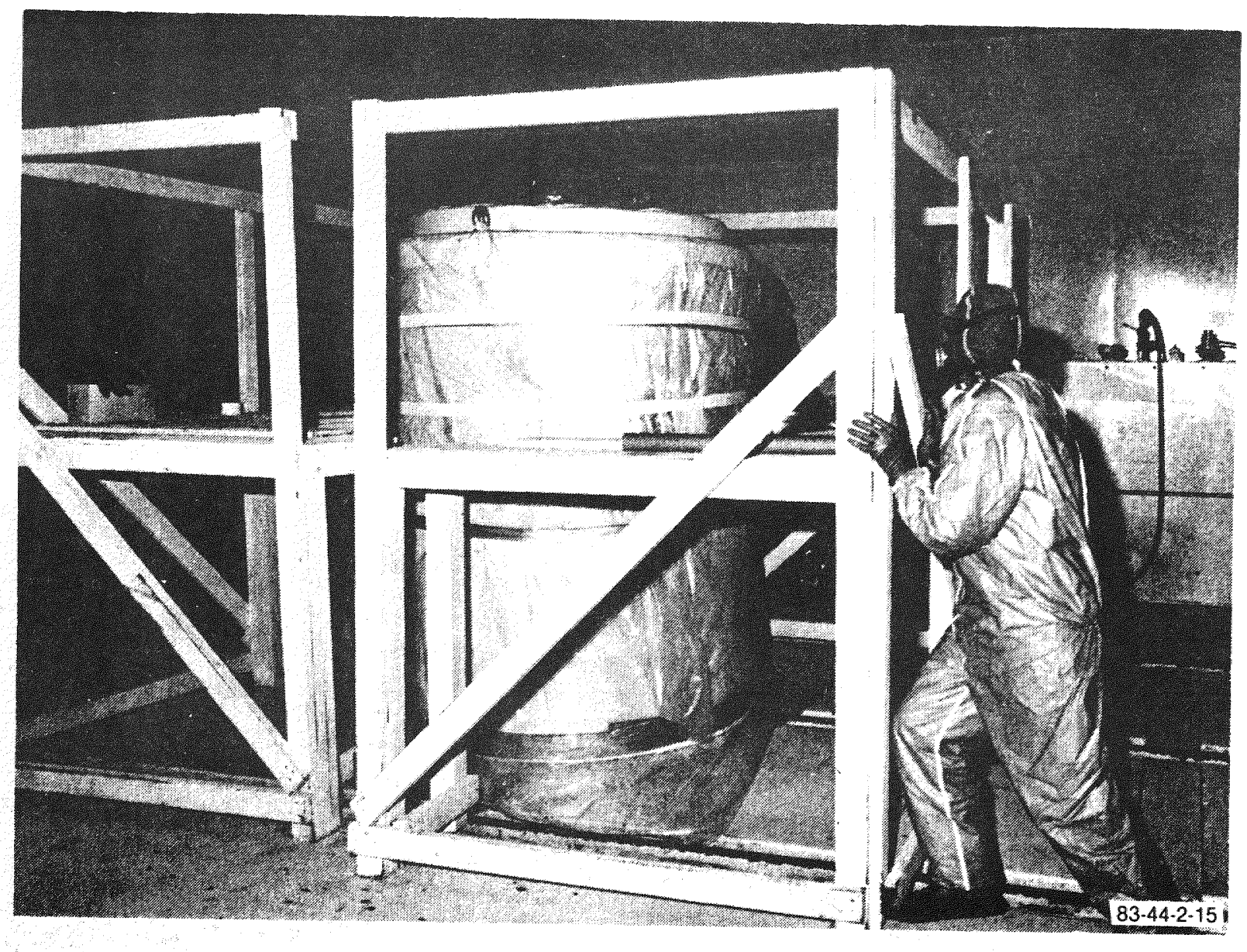

Figure 8. Photograph of the scaffolding being adjusted around the HIC. 


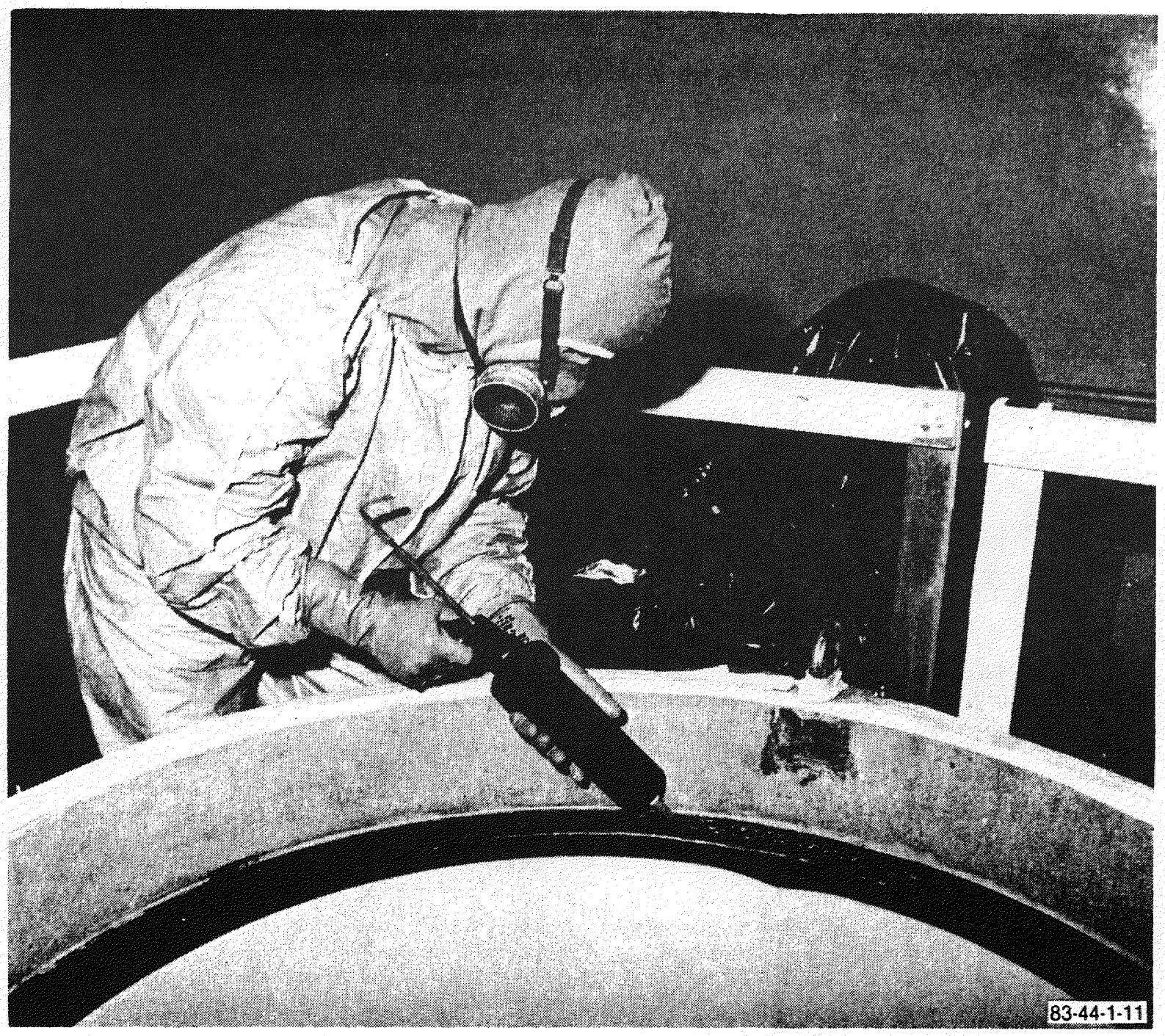

Figure 9. Photograph of the primary sealant (caulk) being applied to the HIC lid step. 


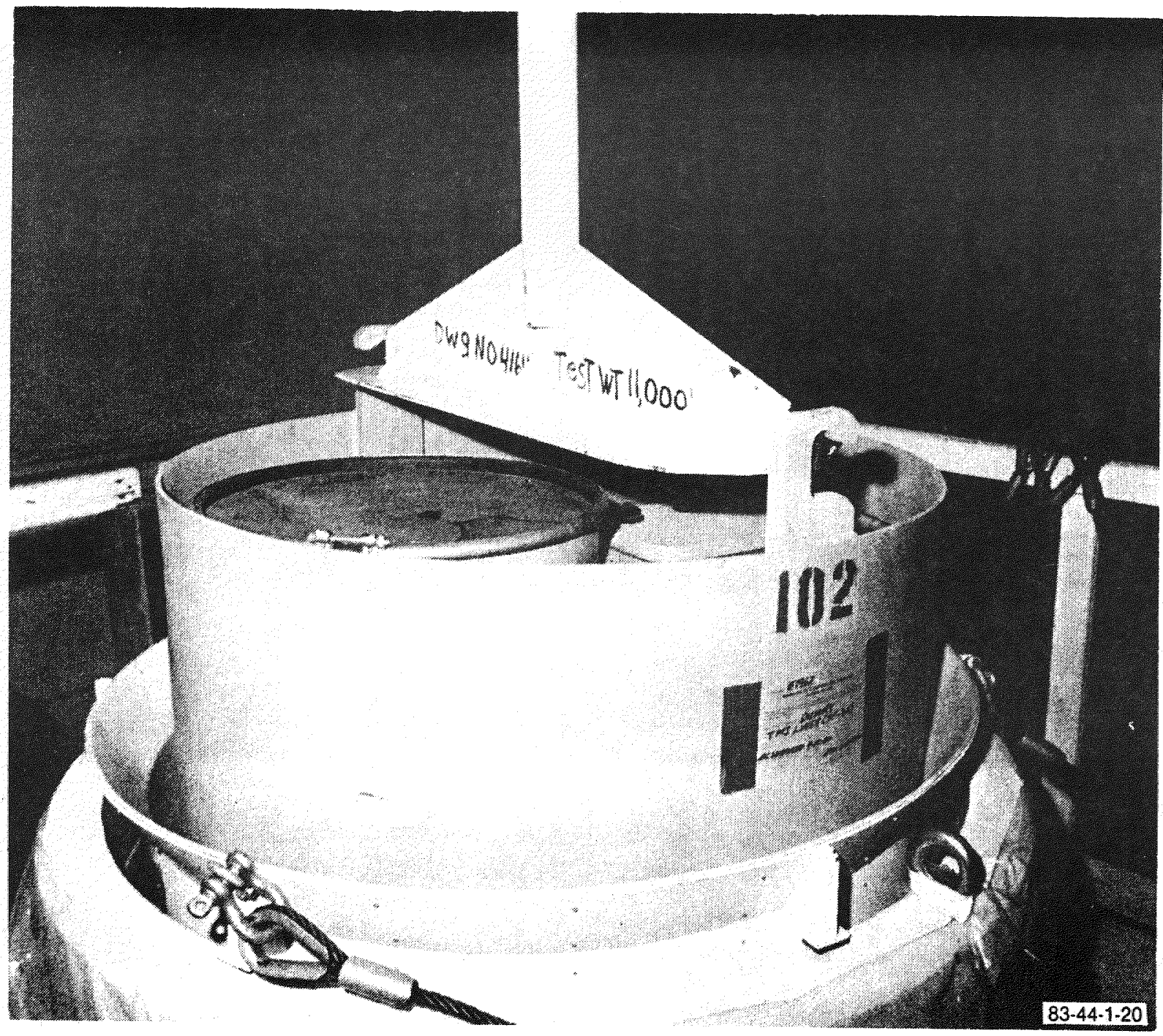

Figure 10. Photograph of an EPICOR-II prefilter being lowered into an HIC. 


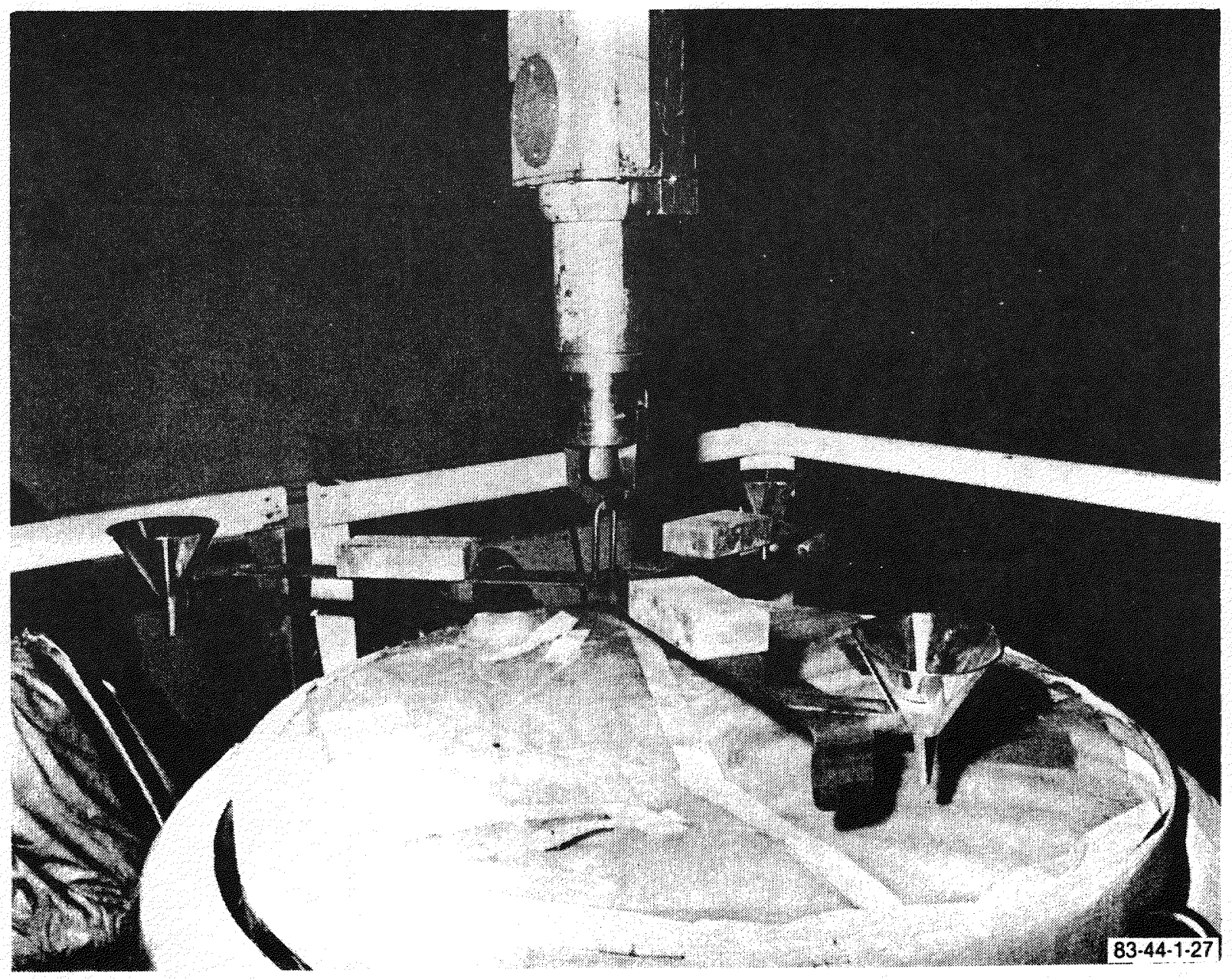

Figure 11. Photograph of the HIC funnel bracket assembly being placed on the HIC 1id. (The final design used rectangular-shaped funnels.) 


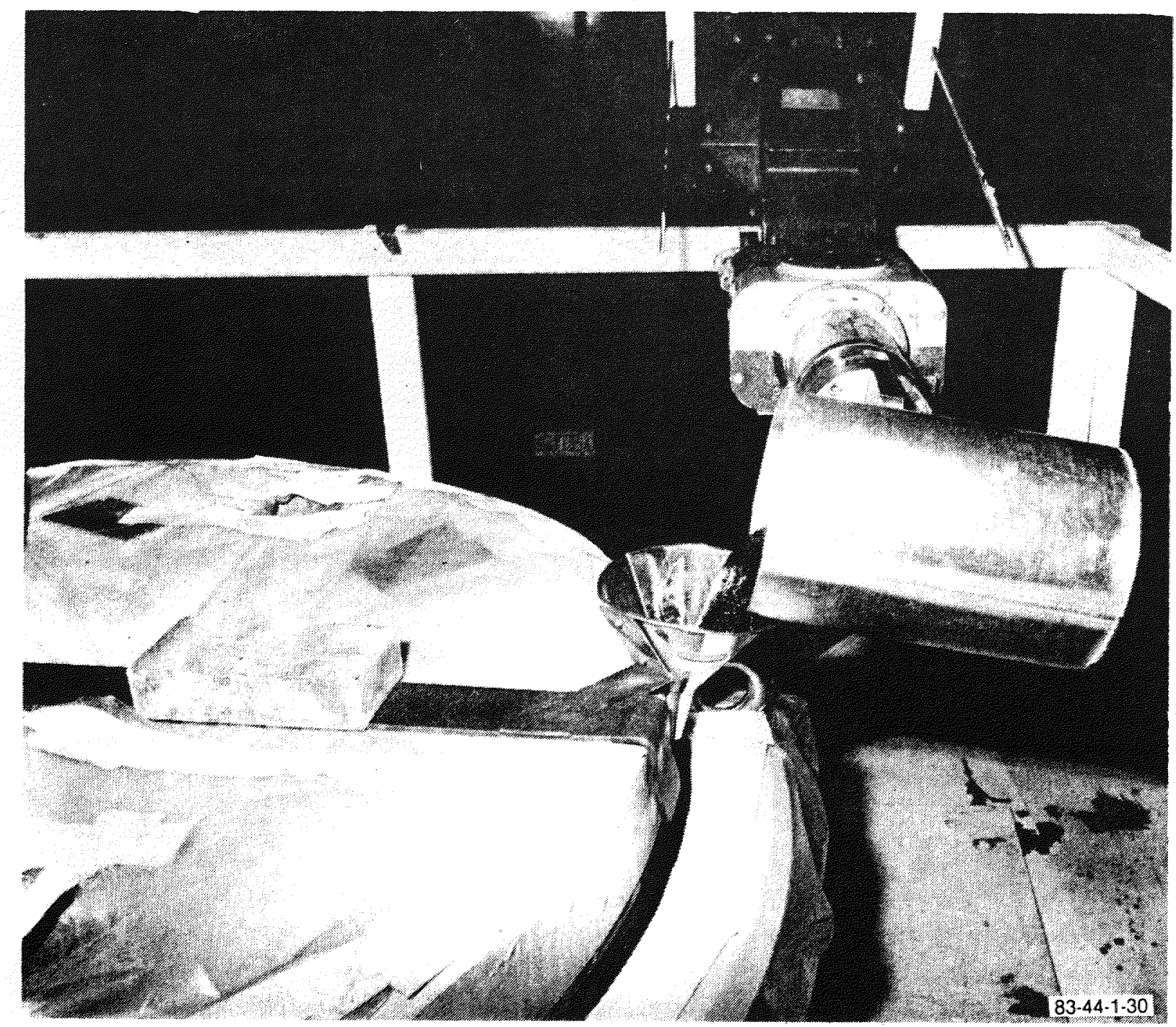

Figure 12. Photograph showing the grout being poured into the funnel bracket assembly using the grout pouring cup. (The final design used rectangular-shaped funnels.) 


\subsubsection{Shipping Cask Preparation}

The CNS 14-190 shipping cask was moved to the Hot Shop of TAN-607, where it was prepared for use. The trailer was backed into the Hot Shop and disconnected, the tractor was moved outside, and the Hot Shop doors were closed. The cask lid was removed, wood cribbing was installed in the cask, and all Hot Shop personnel were removed from the Hot Shop. The HIC was retrieved remotely from storage, the plastic was removed, and the MIC was placed inside the cask. The lid was replaced on the cask, bolts were inserted and torqued, and seal wires were inserted into marked bolts. The rain cover was placed on the cask, and the tiedown clips were tightened. The cask and trailer were surveyed for contamination, and the Hot Shop doors were opened. The tractor was coupled to the trailer: and the tractor, cask, and trailer were moved to a storage area outside the Hot Shop, where a radiation survey was conducted. Results of that survey are shown in Table 1, along with measurements of the HIC and prefilter. The cask and trailer were stored in that location for six months. The vent plug was removed from the cask lid so gases produced in the prefilter could be vented during storage.

TABLE 7. RADIATION LEVEL COMPARISON FOR THE DEMONSTRATION HIC

\begin{tabular}{lcc}
\hline & \multicolumn{2}{c}{ Radiation Level } \\
\cline { 2 - 3 } & $\frac{\text { Contact }}{\text { EPICOR Prefilter (PF-18) }}$ & $\frac{1 \text { meter }(\sim 3 \mathrm{ft})}{20 \mathrm{R}}$ \\
HIC & $30 \mathrm{R}$ & $\mathrm{a}$ \\
Shipping Cask (CNS 14-190) & $80 \mathrm{mR}$ & $20 \mathrm{mR}$
\end{tabular}

a. Readings not available.

\subsection{HIC Shipping and Disposal}

After the State of Washington issued the Certification of Compliance for the HIC, the tractor, trailer, and cask were weighed; and the load 
distribution was adjusted to ensure that the shipment met overload requirements of the states being traversed (viz., Idaho, Oregon, and Washington). The cask was purged with argon gas for three days at $0.14 \mathrm{~m}^{3} / \mathrm{h}(5 \mathrm{cfh})$ to displace gases that may have built up in the cask from the prefilter during storage. On 22 March 1984, after final inspections, the trailer and cask were released for the trip to Hanford, Washington (Figure 13).

The HIC arrived at the US Ecology site on the morning of 3 April 1984. The tractor and trailer were moved to the trench area, where the cask was surveyed and the lid removed, using a mobile crane. Using a hook, the HIC slings were lifted out of the cask and attached to a spreader bar held by the crane. With all personnel clear of the immediate area, the HIC was removed from the cask (Figure 14). The cask cribbing and HIC became wedged together, resulting in both the HIC and cribbing being removed from the cask. The HIC was swung over and lowered $14-\mathrm{m}(45 \mathrm{ft})$ onto a flat spot on the bottom of the main trench (Figure 15) that had been prepared previously. The spreader bar was disconnected from the HIC remotely and removed from the area. A crawler tractor with a front-end loader covered the HIC with soil (Figure 16).

The lid was replaced on the shipping cask, and the cask was secured. With the HIC disposal demonstration completed, the tractor, trailer, and cask were returned to INEL, where the trailer and cask were stored until the next EPICOR-II/HIC unit was ready for transport. 


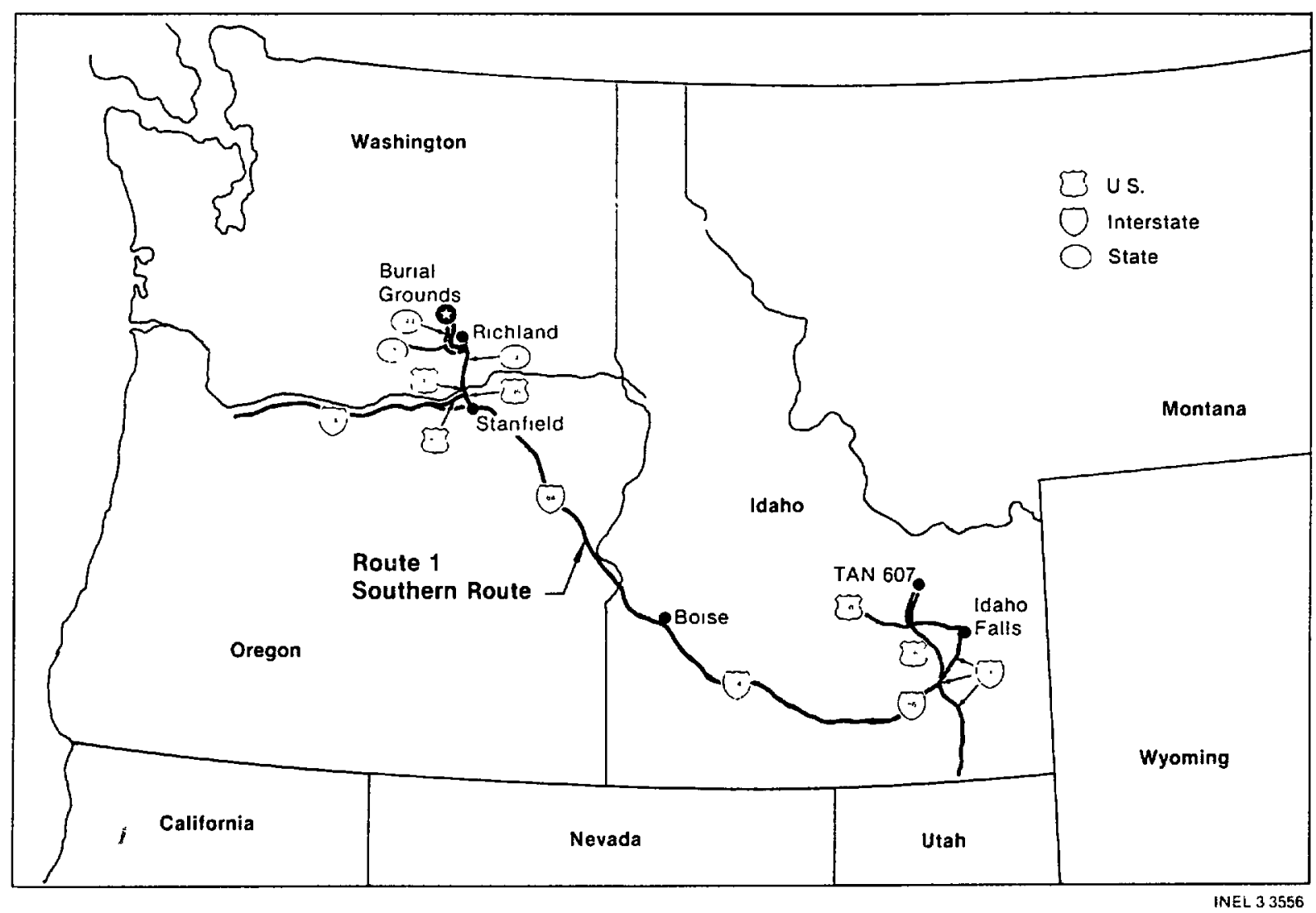

Figure 13. Map showing the route for transporting HICs from INEL to the commercial disposal site in Hanford County, Washington. 


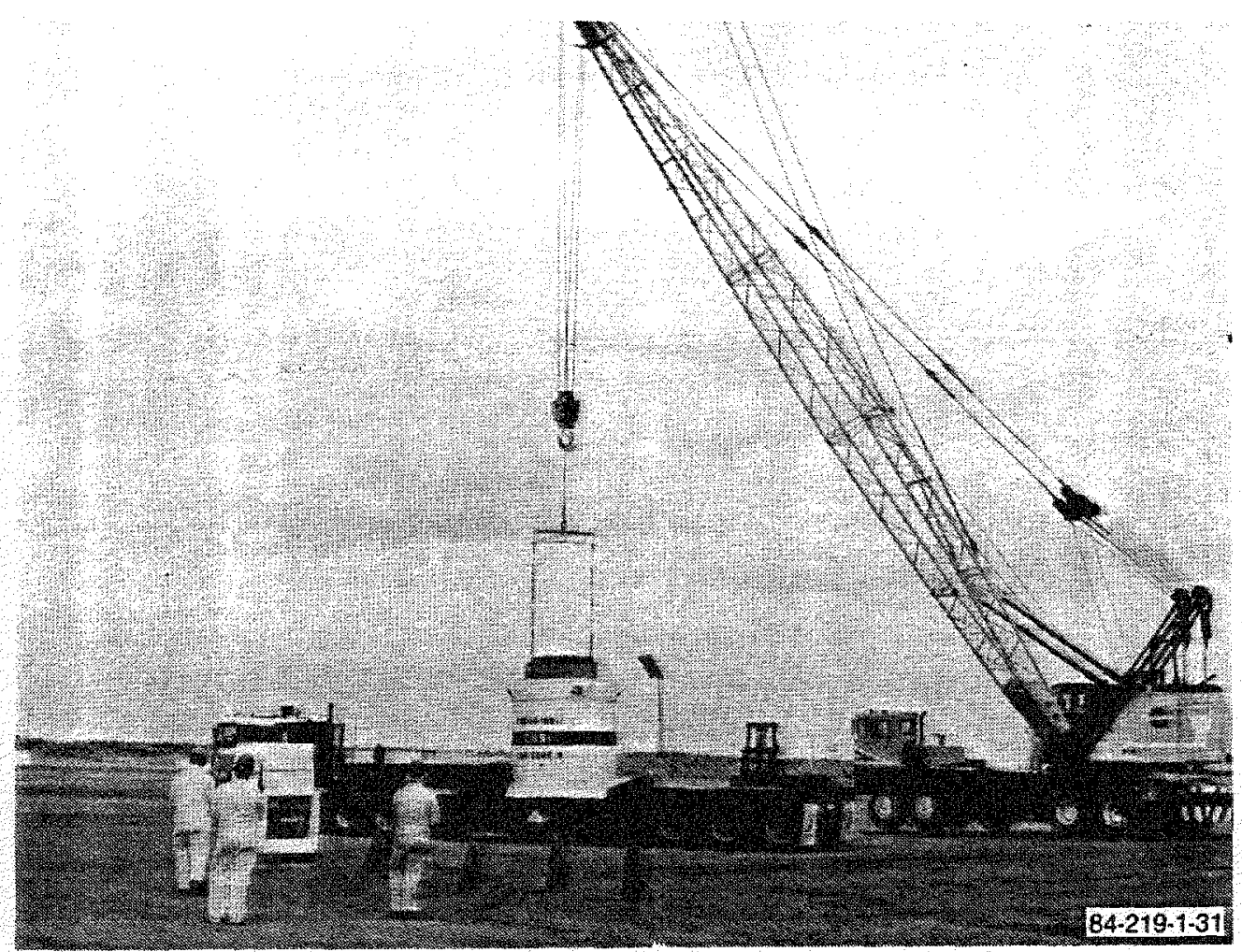

Figure 14. Photograph of the HIC being unloaded from the CNS 14-190 shipping cask at the commercial disposal site.

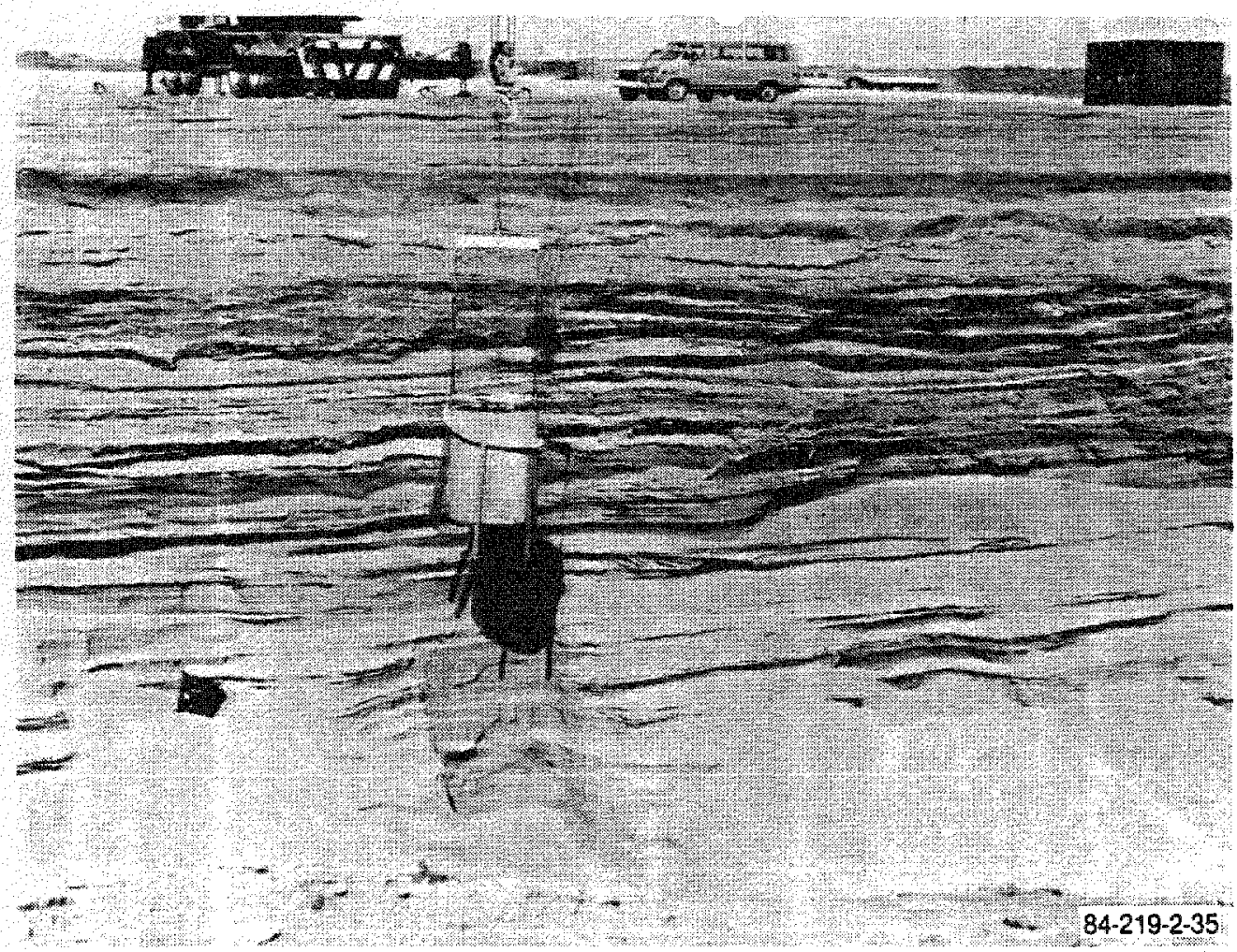

Figure 15. Photograph of the HIC, with cask cribbing attached, being lowered into the trench for disposal. 


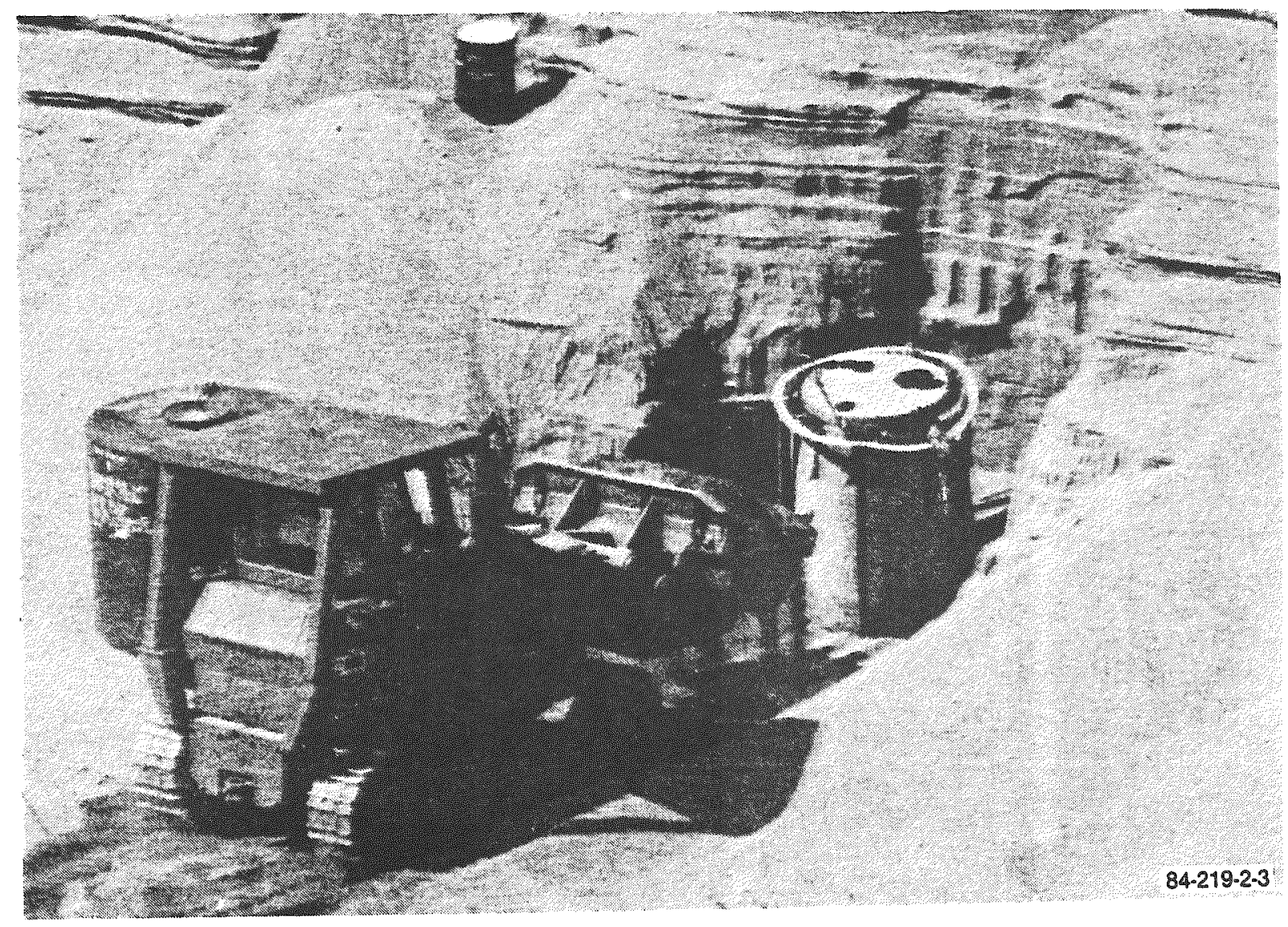

Figure 16. Photograph of the HIC being buried in the trench at the commercial disposal site. 


\section{CONCLUSIONS}

Disposal of an EPICOR-II prefilter at a commercial low-level radioactive waste disposal site is a significant accomplishment in that it required the participation and cooperation of DOE, NRC, the state of Washington, a private utility (GPU), a government contractor (EG\&G Idaho), and private industry (NuPac, US Ecology, and Chem Nuclear Systems). The participants, working together, solved a difficult waste disposal problem by applying available technologies in a new and novel application of an HIC. The result of that cooperation was a first-of-a-kind HIC, which was also the first HIC to be accepted by the State of Washington. Approval for, and disposal of, an EPICOR-II prefilter sealed inside an HIC has demonstrated that the HIC is an adequate alternative to solidifying resins for disposa1. HICs of this design, or of other designs, offer the potential for future options in disposing of other similar wastes by industry at large. Because the NRC Technical Position on Waste Form criteria for HICS was relatively untried before this HIC, and the State of Washington criteria for HICs was undeveloped, the disposal demonstration was largely a pathfinder, clearing the way for more expeditious decisions in the future.

The overall process of confronting a waste problem such as presented by the EPICOR-II prefilters, designing a disposal solution, acquiring appropriate regulatory approvals for transportation and disposal, preparing the waste for disposal, and disposing of the waste can be valuable for planning and executing future waste disposal projects. The HIC disposal demonstration also illustrates how effective DOE is in sponsoring projects that both assist in the cleanup of TMI-2 and provide information of generic value to the nuclear industry.

The disposal demonstration also has paved the way for disposing of the remaining highly loaded EPICOR-II prefilters in HICS at the commercial disposal facility. It has shown that the process and equipment used to prepare the prefilter and HIC for disposal are adequate and will require only minor changes for the remaining prefilters. 


\section{REFERENCES}

1. "Licensing Requirements for Land Disposal of Radioactive Waste, "U.S. Nuclear Regulatory Commission, 10 CFR 61.

2. R. C. Schmitt et al., "High Integrity Containers: A Demonstration Disposal Alternative to Solidification of Radioactive Wastes, "Waste Management 84, Volume 2, Low-Level Waste, Volume Reduction Methodologies and Economics, Tucson, Arizona, March 17-15, 1984, p. 537.

3. A. L. Ayers et al., Safety Assessment Document with Environmental Synopsis for Shipping HICS Loaded with EPICOR-II Liners from INEL to Richland Disposal Facility, EGG-TMI-6474, September 1983.

4. Memorandum for the President of the United States from James B. Edwards, Secretary of Energy, "Resolution of Remaining Civilian Nuclear Program Policy and Budget Issues for FY 1982, 2 March 1981.a

5. Memorandum for the Secretary of Energy from the President of the United States, "Decisions on Department of Energy Budget Appeal," 20 March 1981.a

6. H.W. Reno, J.W. McConne 11, Jr., R. C. Schmitt, EPICOR II Research and Disposition Program: FY-1983 Annual Report, EGG-2287, ApriT 1984.

7. J.W. McConnel1, Jr. and H. Spaletta, Metallurgical Examination of and Resin Transfer from Three Mile Island Prefilter Liners, GEND-036, August 1984.

8. J. D. Yesso, V. Pasupathi, L. Lowry, Characterization of EPICOR-II Prefilter Liner 16, GEND-015, Battelle Memorial Institute Columbus Laboratories, August 1982.

9. R. L. Chapman and H. W. Reno, Design Analysis Report: High Integrity Container for Disposal of EPICOR-II Prefilter Liners, EGG-TMI-6304, June 1983.

10. Design Analysis Report for High Integrity Waste Disposal Container, Nuctear Packaging, Inc., 4 December 1981. a

11. Design Analysis Report for High Integrity Waste Disposal Container, Nuclear Packaging, Inc., Rev. 1, September 1982.व

a. Copies of internal documents are available through the TMI-2 Technical Integration office. 
APPENDIX A

HIGH INTEGRITY CONTAINER

$A-1$ 
APPENDIX A

\section{HIGH INTEGRITY CONTAINER}

The following material is from Design Analys is Report: High-Integrity Container for Disposal of EPICOR-II Prefilter Liners (EGG-TMI-6304) by R. L. Chapman and H. W. Reno, published June 1983. The information has been adapted for use in this appendix, and the data have been updated to reflect the actual high integrity container (HIC) design.

HIC Design

The HIC design was developed to meet several criteria. First, the HIC must be able to contain the EPICOR-II prefilter waste while the radioactive isotopes contained in the resins decay to a nonhazardous level. That is, the container must be able to resist breaching from internal and external loading and corrosion, biological degradation, and intruders for a minimum of $300 \mathrm{yr}$, while in a disposed configuration. Second, the HIC must be able to contain or control gas buildup occurring from radiolysis and/or chemical activity in the resins. Third, the HIC must minimize the safety hazards associated with preparing, transporting, and disposing of the waste, both during routine operations and in the unlikely event of an accident. Finally, the HIC must be designed to minimize costs of fabrication, processing, transportation, and disposal.

A reinforced concrete overpack vessel was selected as the most cost-effective HIC. The phenolic-coated steel liner of the HIC was selected as part of the internal corrosion barrier, after comparing its advantages and disadvantages with liners constructed of various stainless steels or polyethylene. An amphoteric material, another part of the internal corrosion barrier, was placed in the bottom of the polyethylene sleeve lying between the EPICOR-II prefilter and HIC to neutralize any low-pH liquid that might leak from the prefilter into that space. Coatings of phenolic on the surfaces of the steel liner of the container body were selected in constructing the corrosion barrier of the container system because of their ability to maintain integrity in extreme radiation and 
chemical environments. The special filters of the vent system in the container lid were selected because of their mechanical simplicity and prolonged operability in high radiation fields. Because of their strength, better sealing capabilities, and ease of installation during in-field operations, redundant epoxy seals were chosen in lieu of mechanical devices for binding the lid of the HIC to the container body.

\section{Structural Features}

Mechanical properties of materials used for the HIC are listed in Table A-1. The center of gravity of the HIC is the geometric center of the body. Weights of the container and its ancillary equipment are summarized in Table $A-2$.

\section{Concrete Structure}

The cylindrical walls of the concrete structure are $15-\mathrm{cm}(6-\mathrm{in}$. thick, and the ends are 28-cm (11-in.) thick. The reinforced concrete is capable of withstanding an internal pressure of $1.7 \times 10^{6} \mathrm{~Pa}(250 \mathrm{psig})$ and an external pressure of $1 \times 10^{6} \mathrm{~Pa}(150 \mathrm{psig})$. Formulation of the concrete provides $41.4 \times 10^{6} \mathrm{~Pa}(6000-\mathrm{psi})$ compression strength. A complex rebar cage is encapsulated in the concrete for strength. The rebar cage is constructed as follows: side- -22 circumferential wraps $[6.4 \mathrm{~mm}$ (1/4-in.) wire] and 20 longitudinal bars (No. 5 rebar); bottom- -12 crisscrossing bars (No. 4 and 5 rebar); and lid- -24 crisscrossing bars (No. 4 rebar).

The HIC is lifted by two $2.5 \mathrm{~cm}(1-\mathrm{in}$.) forged stainless steel eyebolts connected to rods embedded in the concrete. The eyebolts have a safety factor of 5.5 to 1 , based on ultimate strength. The embedded rods are designed with a safety factor of 7.7 to 1 , based on pullout capacity. The assembly is tested to $150 \%$ of design 10 ad. 
TABLE A-T. MECHANICAL PROPERTIES OF MATERIALS USED FOR THE HIC

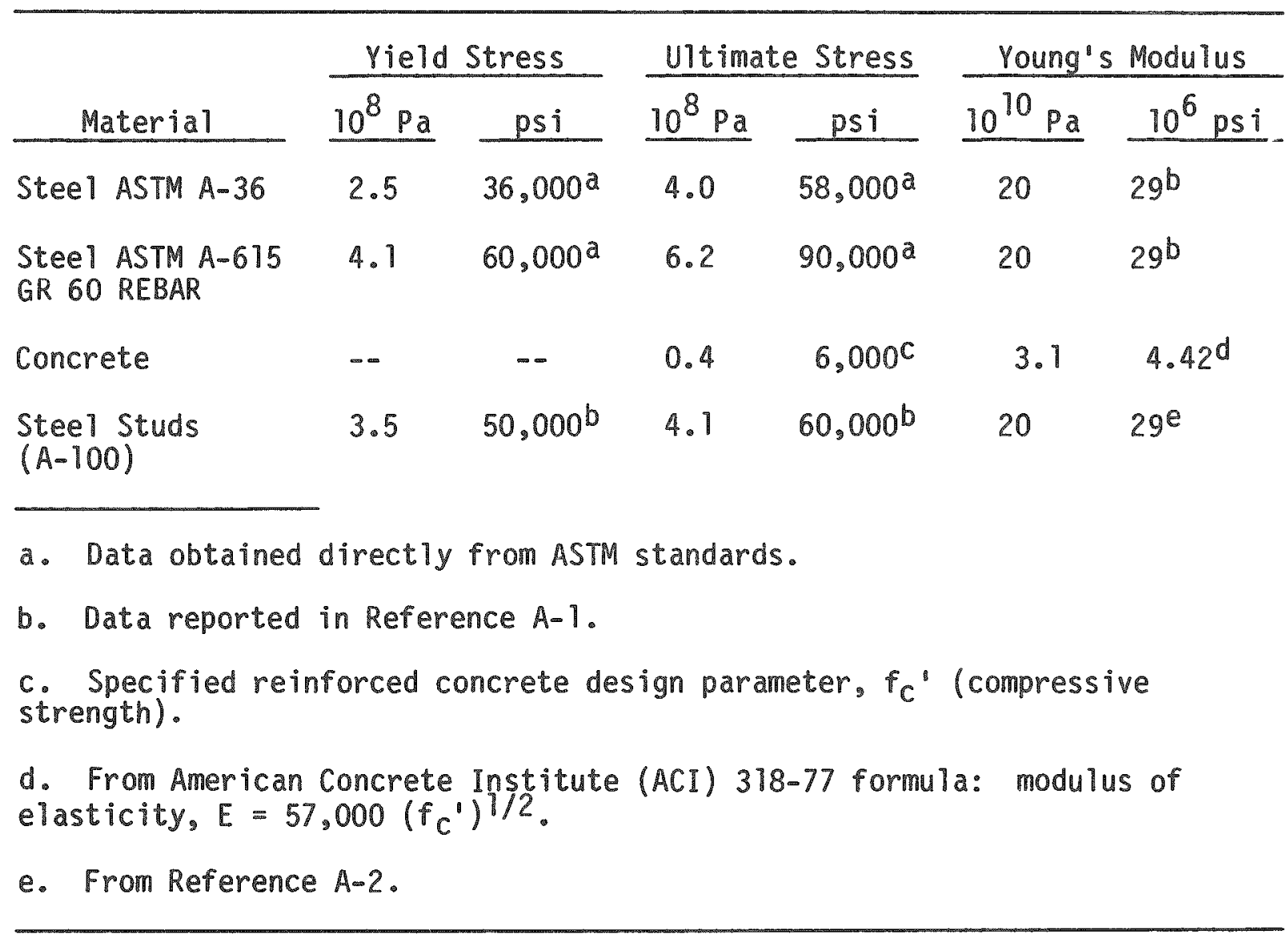

TABLE A-2. WEIGHTS OF THE HIC COMPONENTS

\begin{tabular}{|c|c|c|c|}
\hline \multirow[b]{2}{*}{ Component } & & \multicolumn{2}{|c|}{ Weight } \\
\hline & & $(\mathrm{kg})$ & ( Ib) \\
\hline $\begin{array}{l}\text { Container body } \\
\text { Lid } \\
\text { Payload (EPICOR-II prefilter) (maximum) } \\
\text { Seals (caulk and grout) } \\
\text { Polyethylene sleeve and amphoteric material }\end{array}$ & $\dot{s}$ & $\begin{array}{r}5,038 \\
1,149 \\
1,474 \\
50 \\
63 \\
\end{array}$ & $\begin{array}{r}11,096 \\
2,531 \\
3,250 \\
110 \\
139 \\
\end{array}$ \\
\hline Total & & 7,768 & 17,126 \\
\hline
\end{tabular}


Seals

Redundant seals bond the HIC lid securely and permanently to the HIC body. The interior, or primary, seal is formed from Concressive AEX-1513 which is a custom-formulated epoxy gel compatible with the phenolic coatings on the steel liner of the HIC. The primary seal is applied to the mating metal surface of the HIC body before the EPICOR-II prefilter is inserted.

The external, or secondary, seal is formed from Concressive AEX-1512 (also a custom-formulated epoxy), which fills the gap between the HIC lid and body. That epoxy grout is a flowable material, containing rounded aggregate (sand-like material) to effect self-leveling.

The seals are expected to receive a maximum total accumulated radiation dose of $2 \times 10^{8}$ rads. Chemically similar compounds have been tested to 7 to $10 \times 10^{8}$ rads without significant shrinkage or reduction in flexure strength. Failure of the seals is not expected until doses of greater than $9 \times 10^{8}$ rads are accumulated. Therefore, the seals should maintain their integrity over the life of the HIC $(\sim 300 \mathrm{yr})$.

\section{Venting Features}

The vent system can accommodate 0.15 mol of hydrogen per day, a flow rate nearly three times greater than the design basis of 0.052 mol/day. The vent system consists of the following components:

1. A stainless steel in-line filter element with a $40-\mu$ pore size. The filter ensures that solid (resin) particles will not escape from the container to the external environment.

2. A PVC water trap, which is self-purged by gases generated within the container. 
3. A 70- $\mu$ polyethylene external filter with large surface area. That filter, located in a recessed PVC pocket at the lid edge, keeps mud and debris from entering the vent.

\section{HIC Fabrication}

Fabrication of Steel Liner

The steel liner consists of a right-circular cylinder with a flat plate bottom and a rolled-angle top flange (Figure A-1). Reinforcing studs were attached to the liner with an automatic stud gun. Coatings were applied to the steel liner using strictly controlled conditions. The coatings used are Phenoline 300 orange primer and Phenoline 302 finish. ${ }^{2}$

Nondestructive examinations were performed to verify that the coatings were applied correctly. To ensure adequate film thickness and coating adhesion, the coating was applied by brush to tight areas, welds, and corners on the concrete anchor studs.

The following coating inspections were performed:

1. Verification that the coating manufacturer had provided the appropriate documentation required by ANSI N101.4, "Quality Assurance for Protective Coatings Applied to Nuclear Facilities."

2. Verification that the applier of the coating had written procedures conforming to the requirements of ANSI N101.4, and the written procedures had been followed.

3. Verification that the blast-cleaned steel surfaces conformed to the requirements of SSPC-SP5, "White Metal Blast Cleaning." Surface preparations were inspected to verify the rounding of sharp corners and removal of weld spatter, as recommended by the coating manufacturer.

a. Phenoline 300 orange primer and Phenoline 302 finish are products of Carboline Co. 


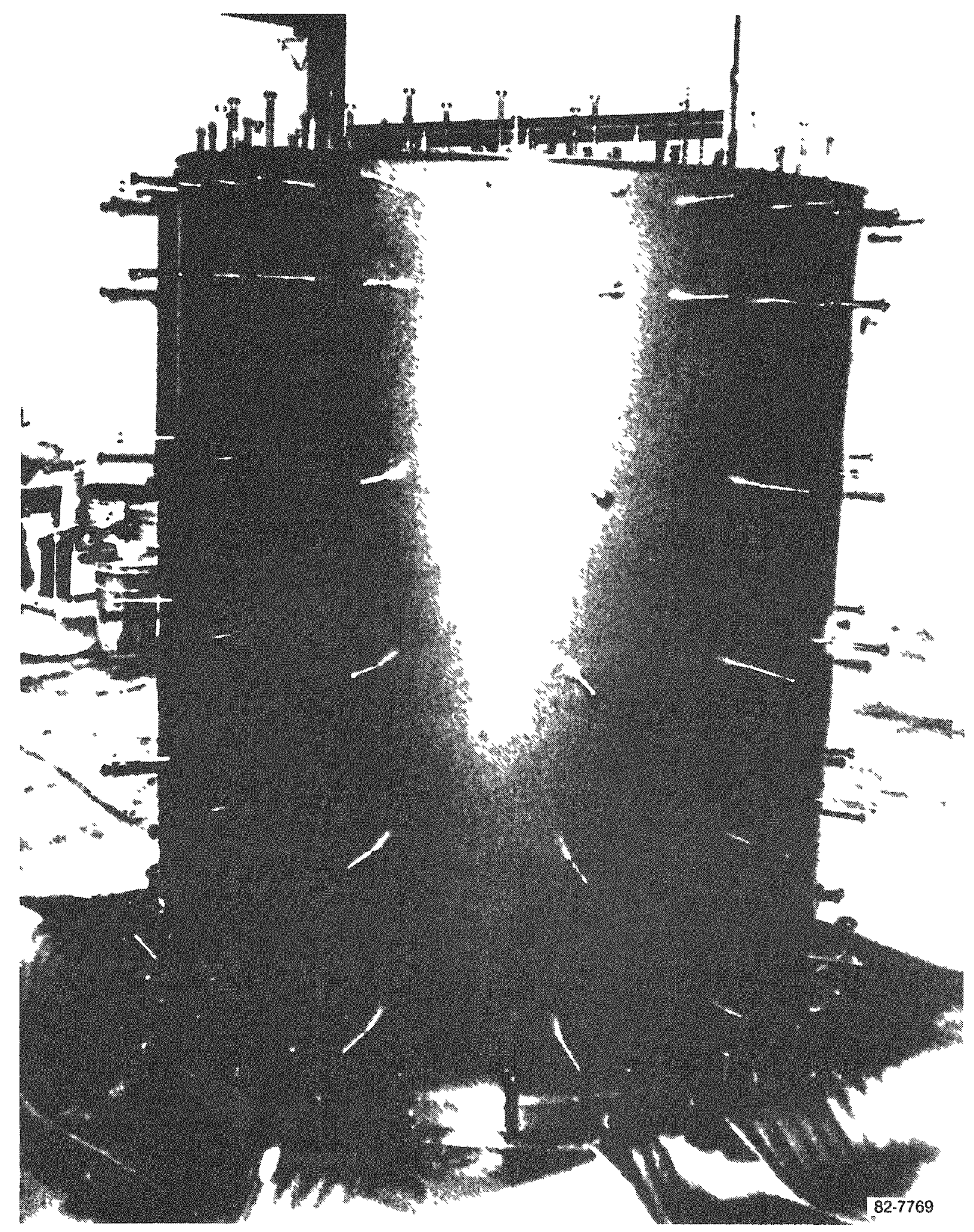

Figure $A-1$. Photograph of the steel liner of the HIC with reinforcing studs after being coated with epoxies. 
4. Inspection of the applied coating with pinhole detectors, holiday detectors, and dry-film-thickness gauges to verify that the coating conformed to specified requirements.

Fabrication and Installation of Vent Assembly

The principal component of the vent assembly is a machined housing containing the filter stack. The housing is connected at one end to a PVC water trap and outlet fitting via stainless steel tubing. At the other end, the filter assembly connects to a $5-\mu$ stainless steel filter nipple attached to the lid corrosion barrier. The installed components of the assembly are shown in Figure $A-2$.

Fabrication of Rebar Cage

Spira1, circumferential reinforcing bars (rebars) were wound by an automatic wrapping machine and welded to straight, longitudinal spacer bars. Longitudinal structural bars were bent to a U-shape (Figure $\mathrm{A}-3$ ). The steel liner was inverted and supported on a circular steel form which shaped the lid lip.

\section{Concrete Casting}

The low water/cement ratio of 00.32 produced concrete with minimum permeability. The concrete mix contained air-entraining agents and superplasticizers to improve workability.

After completion of rebar fabrication, a split steel casting form was placed around the rebar cage. Concrete was poured into the annular space between the steel casting form and the rebar cage. Voids in the concrete were eliminated during casting by using pneumatic form vibrators similar to the one pictured in Figure $A-4(A)$. The photograph in Figure $A-4(B)$ shows concrete being poured into the HIC casting. 


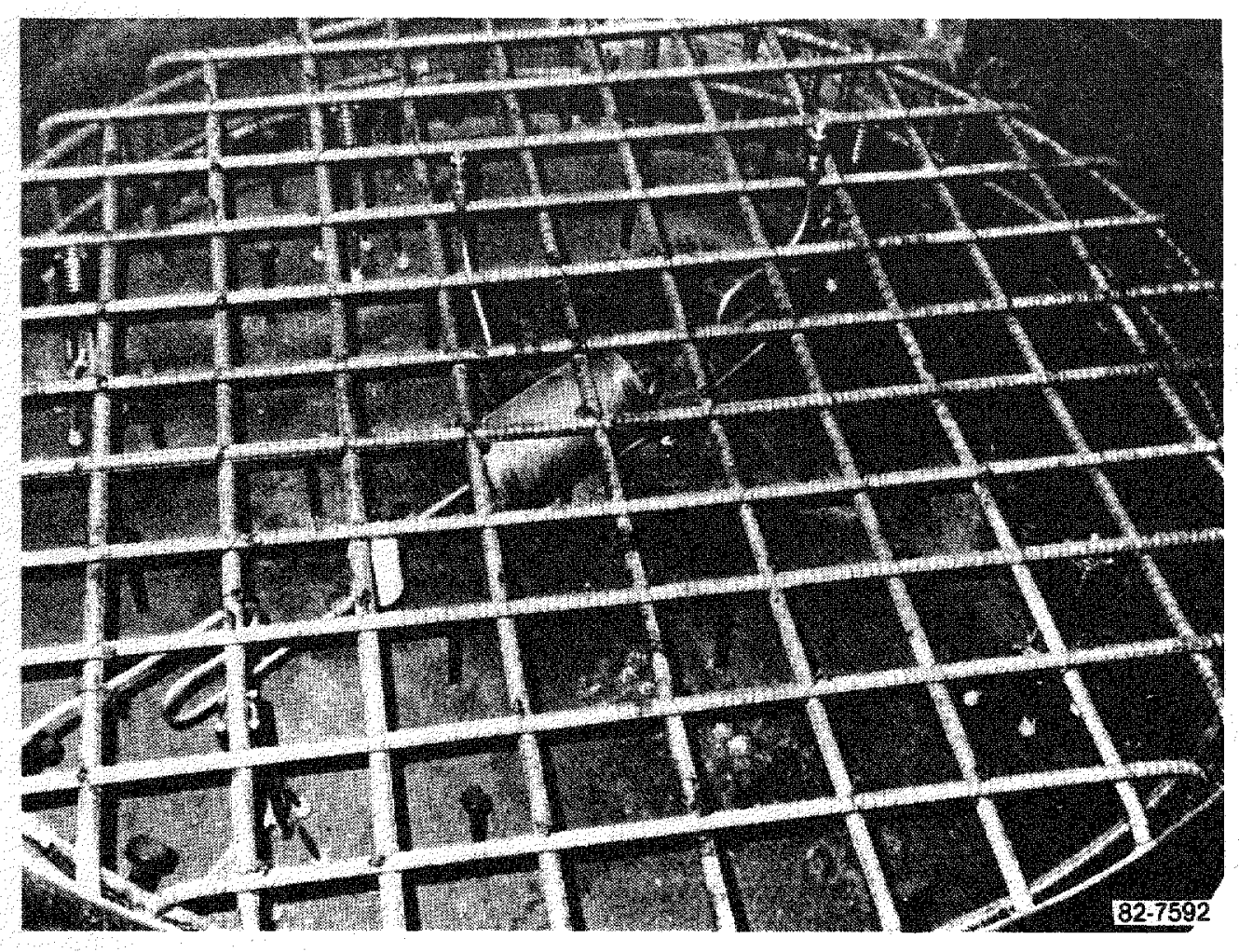

Figure A-2. Photograph of the vent system in the lid of an HIC.

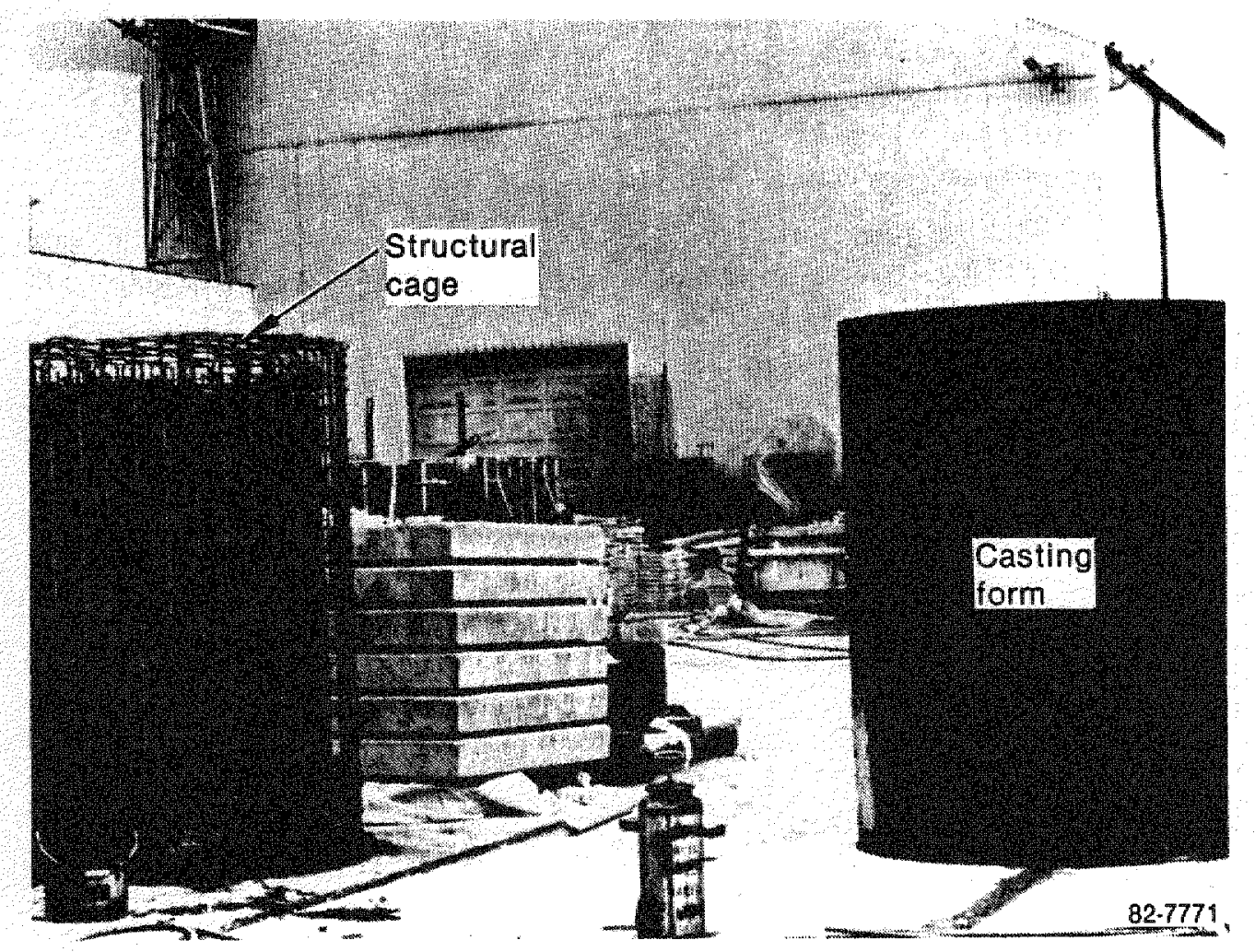

Figure A-3. Photograph of the reinforcing steel and steel liner of the HIC before casting. 


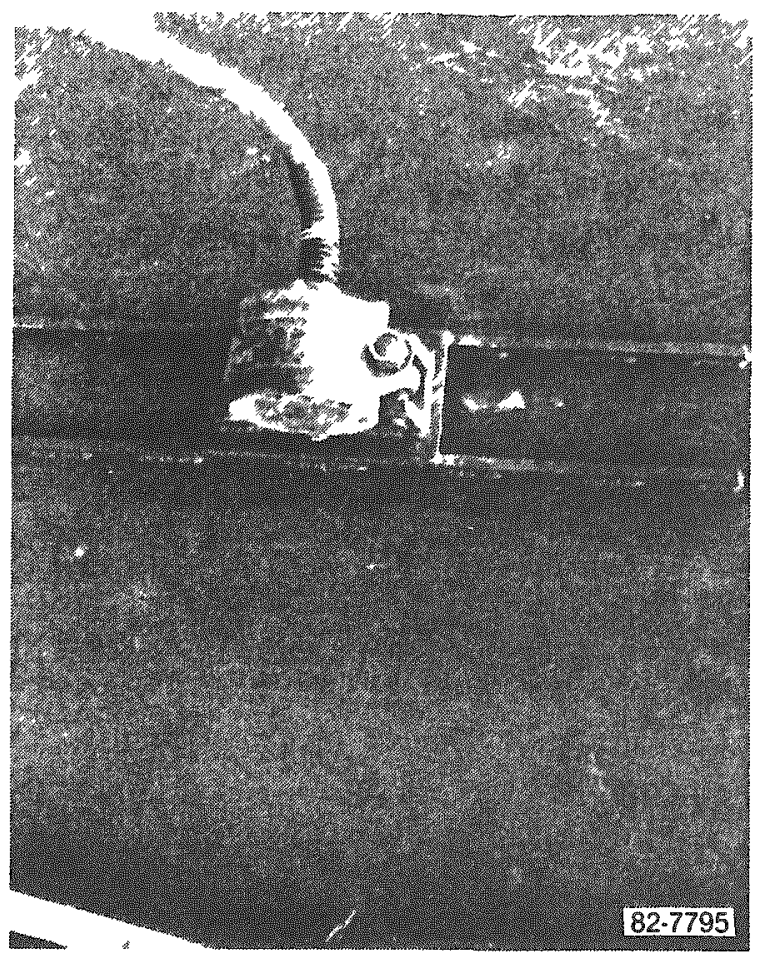

(A)

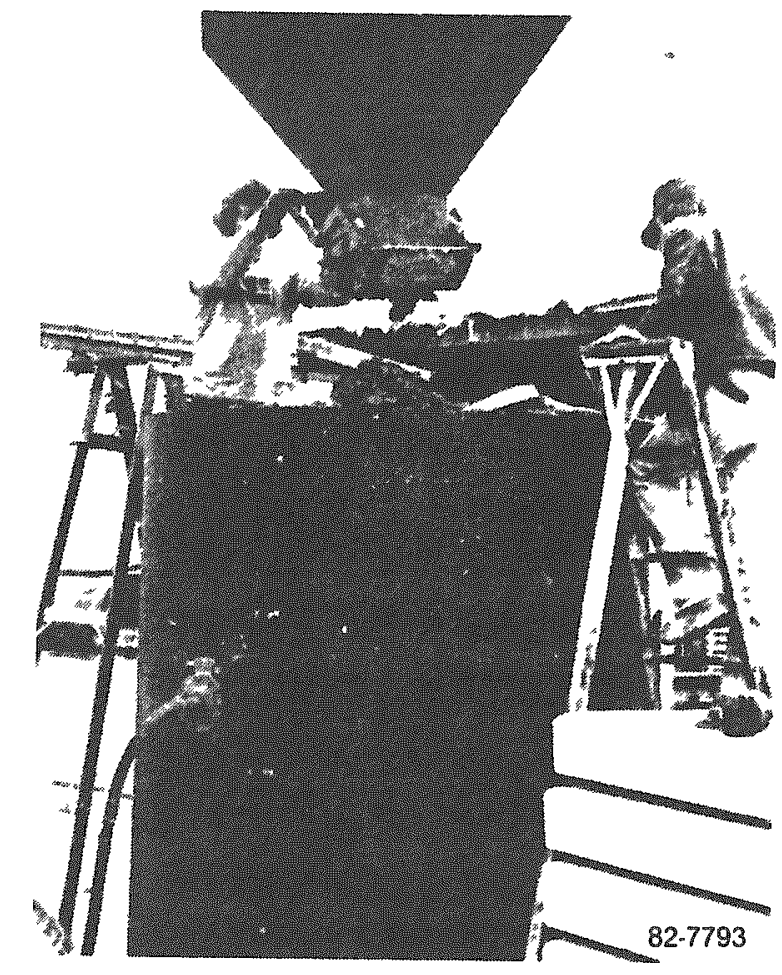

(B)

Figure A-4. Photographs of the (A) installation of a form vibrator and (B) pouring of concrete into the HIC casting. 
Similar techniques were used for constructing the HIC lid, except voids were prevented by using small hand-held vibrators [Figure A-5(A)]. Recessed lifting lugs were positioned in the lid as pictured in Figure $A-5(B)$. The lifting lugs are designed for remote use with a three-legged lifting fixture.

Upon completion of the castings, stainless steel lifting eyes were threaded into inserts located at the base of "cutout" pockets (Figure A-6). The pockets subsequently were filled with a radiation-resistant epoxy mortar. All lifting inserts were tested to $150 \%$ of individual working loads.

\section{References}

A-1. TRW--Ne1son, Embedment Properties of Headed Studs, Design Data Bulletin 70 .

A-2. AISC, Specification for the Design, Fabrication, and Erection of Structural Steel for Buildings, 7 th edition, Chicago: AISC. 


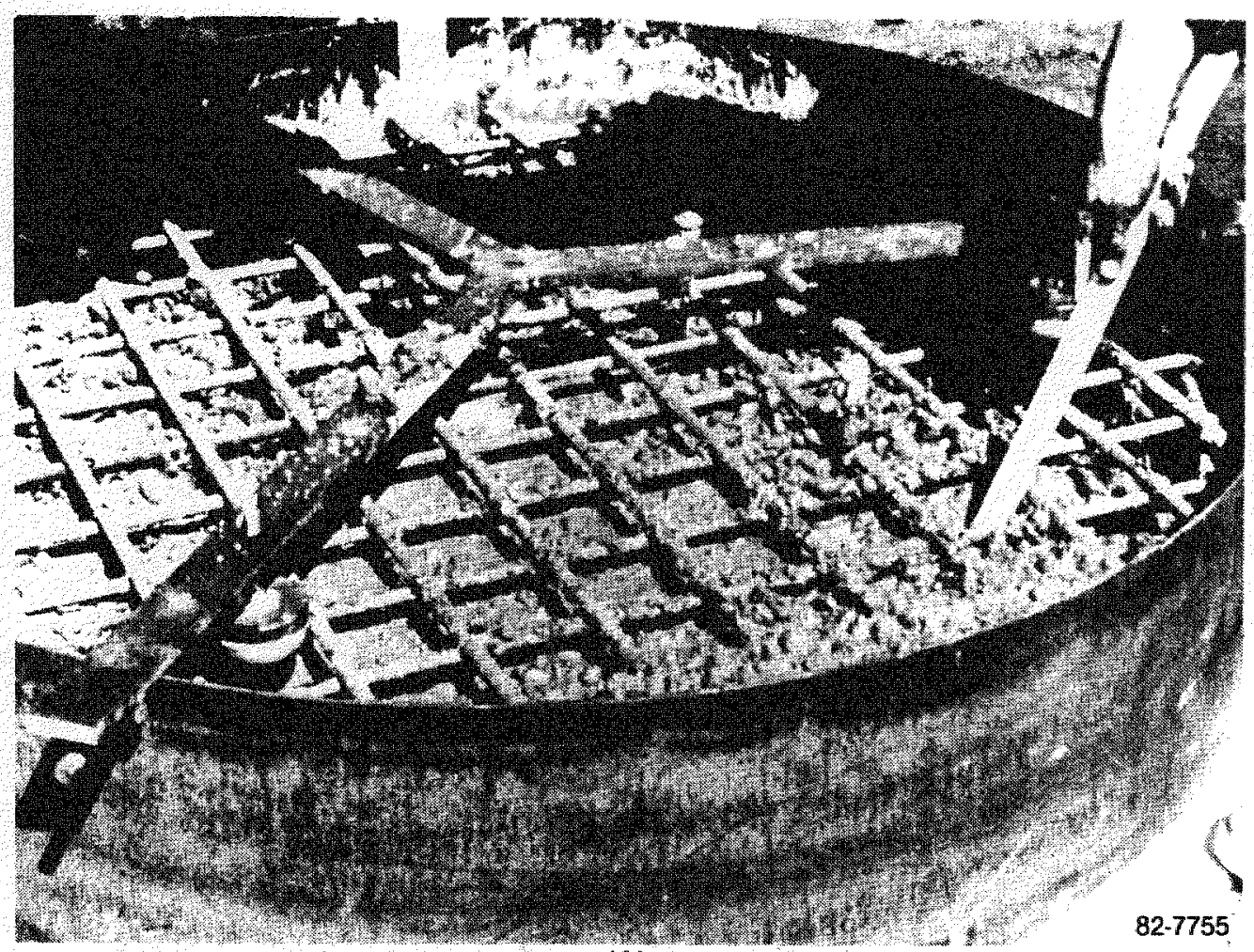

(A)

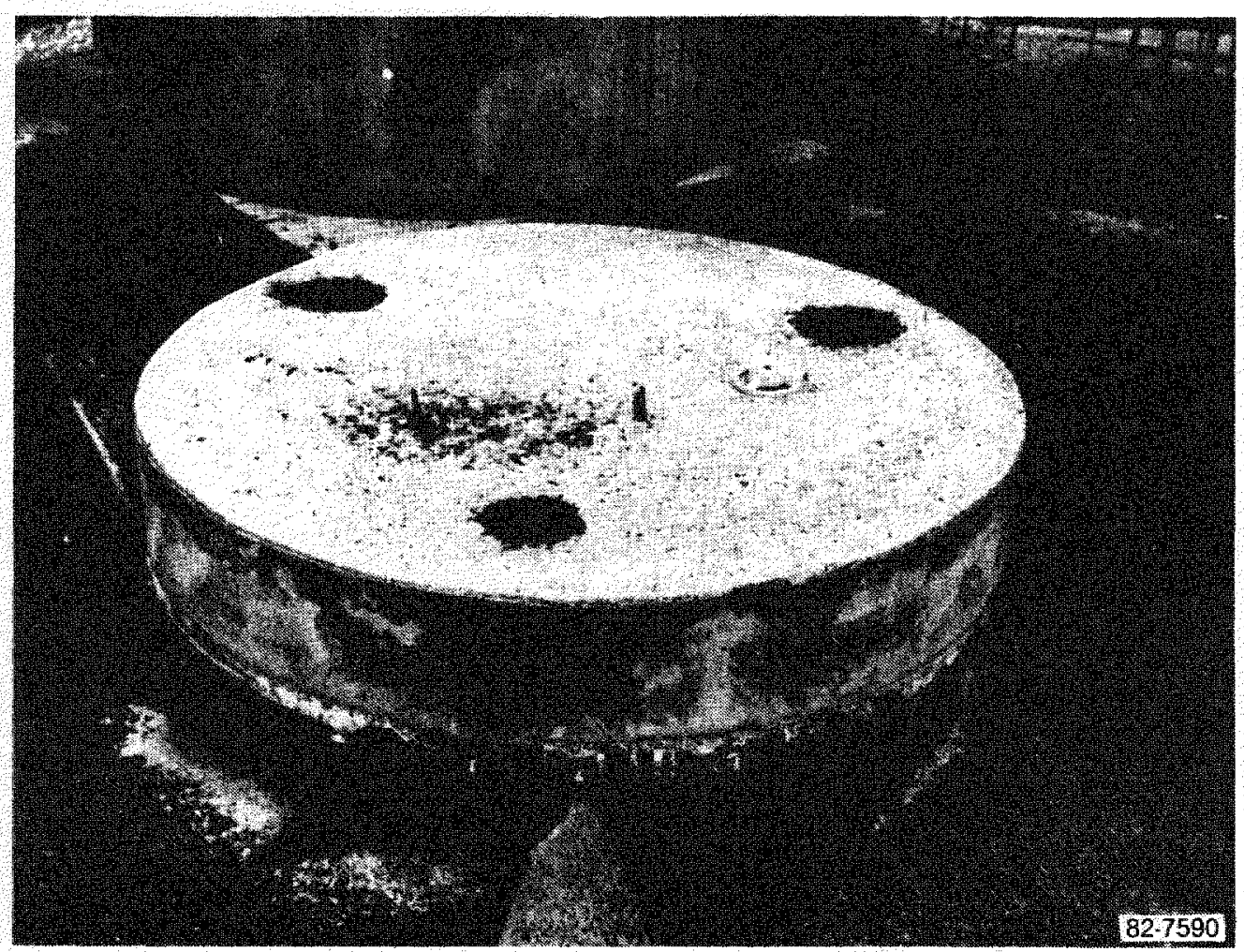

(B)

Figure A-5. Photographs of (A) lid fabrication with use of a submerged vibrator and $(B)$ the finished casting showing the recessed lifting lugs. 

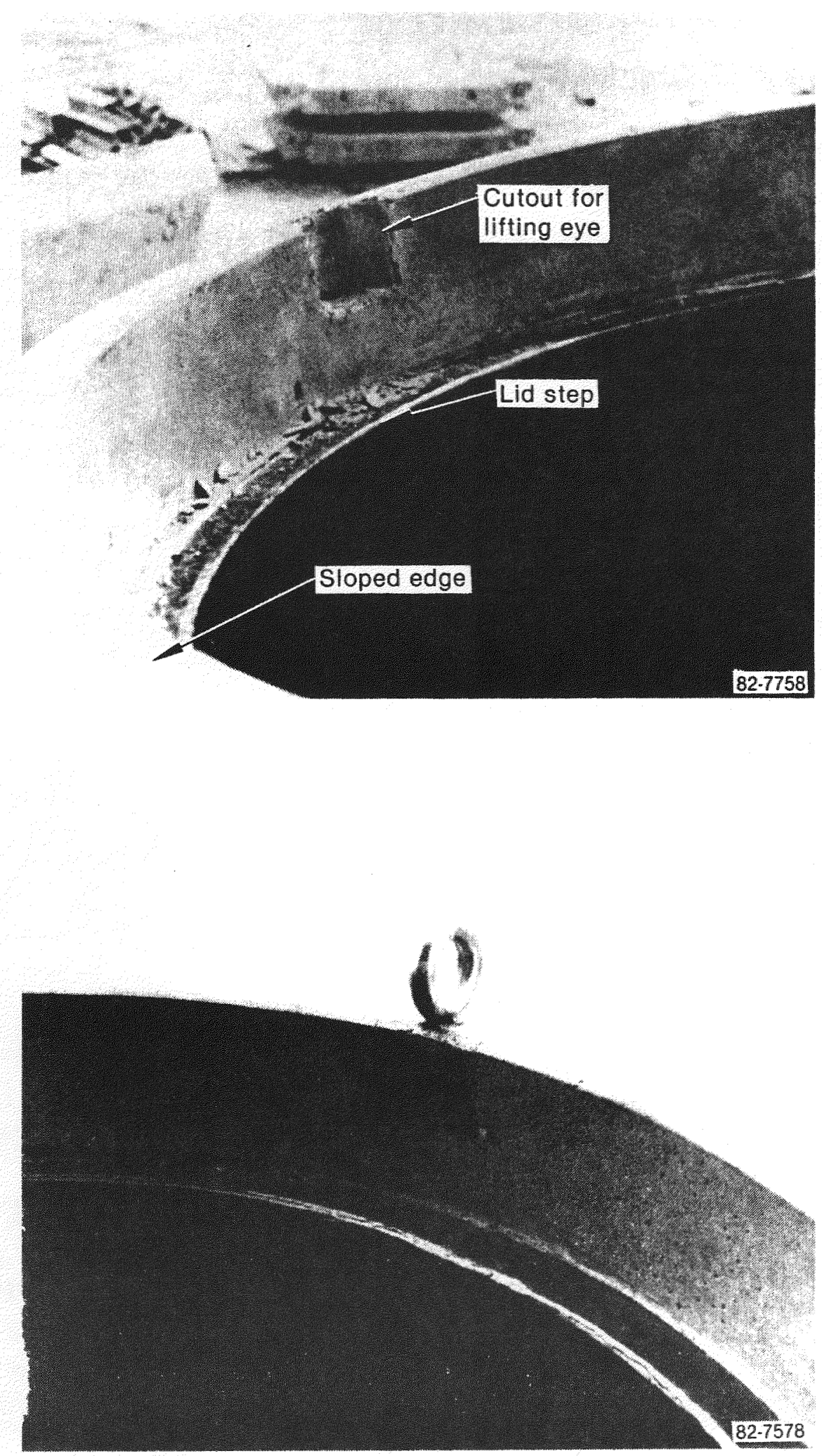

Figure A-6. Photographs showing the top edge detail of an HIC before and after installation of lift eyes. 


\section{APPENDIX B}

IMPACT TESTS OF THE HIGH INTEGRITY CONTAINER

R. T. Haelsig

Nuclear Packaging, Inc. 
, 


\title{
APPENDIX B
}

\section{IMPACT TESTS OF THE HIGH INTEGRITY CONTAINER}

\author{
R. T. Haelsig \\ Nuclear Packaging, Inc.
}

The following material is a Safety Analys is Report Supplement for the CNS 14-190 cask. It describes the high integrity waste disposal container and was prepared by R. T. Haelsig of Nuclear Packaging, Inc. of Tacoma, Washington, under EG\&G Idaho Contract C83-130189. 
2.10.3 Evaluation of a High Integrity Paste Disposal Container (HIwC) within the CNS $14-190 \mathrm{Cas}$

\subsubsection{Introduction}

The BIDDC is a reinforced concrete container designed for the burial of radioactive wste. s characterized by the TMI-2 EPICOR II spent resin liners. The container has been designed to provide safe, reliable, below ground storage of radioactive wate for period of 300 years (10 half lives of the predominat isotopes).

When transported within the CNS 14-190 package, calculations indicate thet integrity of HIWDC shielding wast be maintained only for mormal conditions of transport', 10 CFR 71.35. These same shielding calculations show that bypothetical loss of HIWDC shielding capability does not violate the permissible external pactage dose limits of 10 CFR 71.36(1) for hypothetical accident conditions.

This appendir demonstrates that HIFDC conservatively provides both necessary shielding and containment of the radiogetive wate materials wher transported within the CNS $14-190$ package. This demonstration compares the proven physical capabilities of the HIWDC to the relevant eaviroments experienced by the CNS $14-190$ package under both normal and hypothetical accident conditions of transport.

The HIWC has beendesigned as an extraordinarily robust high integritg container:

- HIWDC ill withstand sustained external pressure differentials of $150 \mathrm{psi}$.

- MIWDC demonstrates an internal burst pressure differential capability of 250 psi. at 28 -day concrete strength, and in excess of 400 psi burst strength, at 10-year concrete strength. 
- HIWD has been tested and qualified to Type 'A' drop heights of 3 feet $(17,126 \mathrm{lbs}$. - gross loaded veight) upon an unyielding surface, with no loss of containment or degredation of shielding capabilities. Engineering development drop tests at 9 feet, upon an unyelding surface, and 25 feet, upon typical soils, a Iso show no loss of containment and no degradation of shielding or strength capabilities.

These verified physical characteristics demonstrate that the HIVC can readily survive the environmental and handing conditions associated with 'normal conditions of transport' per 10 CFR 71.35 withont any form of mitigation. The presence of the surrounding CNS 14-190 package provides a conservative additional measure of assurance that containment and shielding integrity remain intact.

\subsection{0 .3 .2 Configuration}

Figure 2.10.3-1 provides illustration of the HIDDC configuration. The disposable high integrity container consists of a right circalar cylinder of reinforced concrete, 62.5 inches indiameter, 84.5 inches high, with 6 inch thick cylindrical wals and 11 inch thich ends, lined with corrosion protective coatings inside and ont.

The reinforced concrete structure, $f_{c}^{\prime}=6,000$ psi, provides capabilities to resist all specified internal and external loads. Recessed eyes and precast inserts provide for convenient handing and allow stacking of the containers. These recessed eyes and inserts ate at ached to reuseable quick-disconnect 1 ifting hooks and eyes.

The container has been desigaed to provide high degree of corrosion resistance through the very conservative use of redudant corrosion barriers and corrosion mitigation features. Each of these redudant elements could reasonably be assumed to fford adequate containment of prescribed corrosives for the lift of the container; talen collectively, reliability analyses forecast a life in excess of 1200 years. 


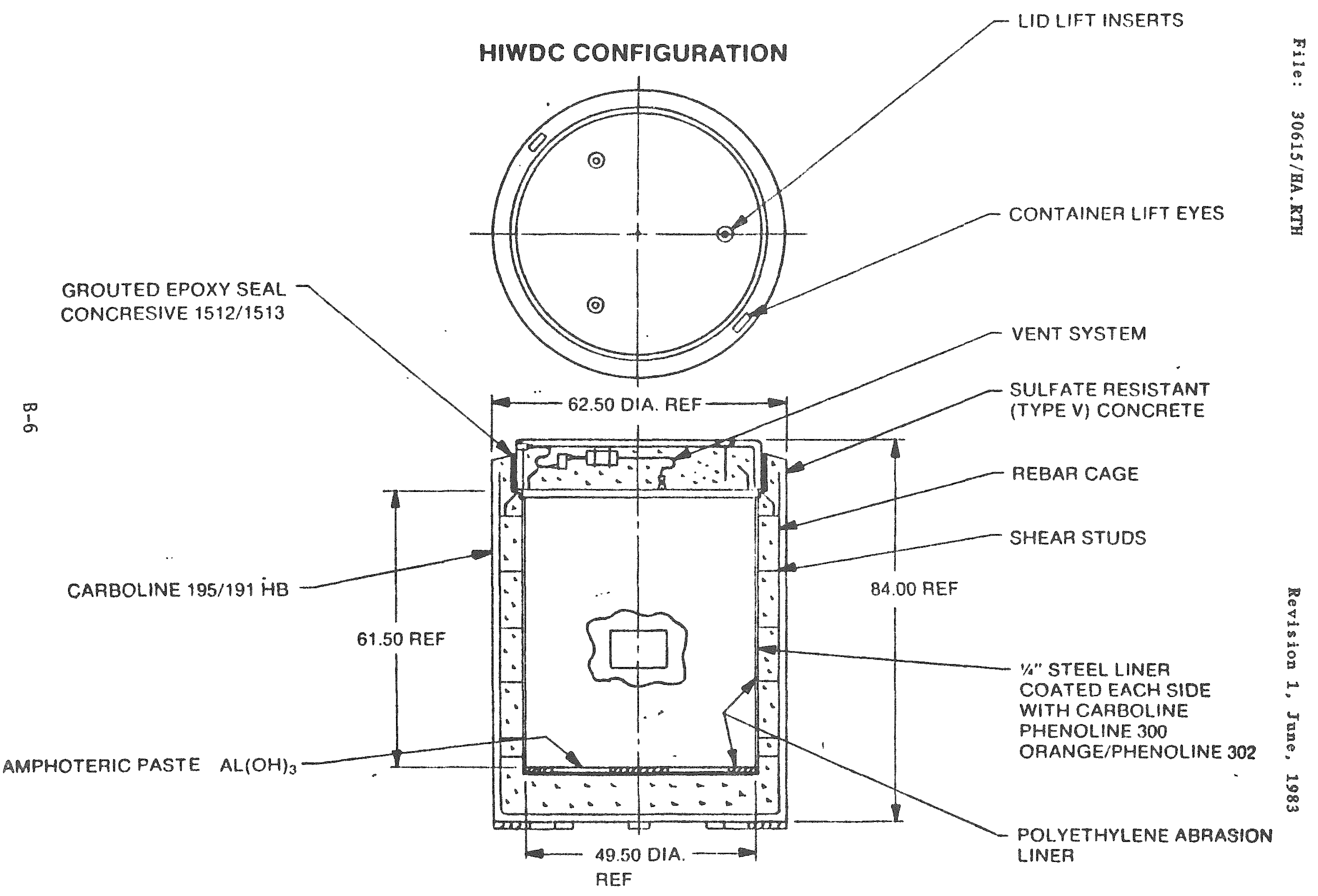


The container is fitted ith two peranent seals installed by different techniques and processes to assare the concepts of diverse redundacy are preserved. The interior, or primary seal, is formed from Concresive AEX1513. product of Adhesive Engineering Company. It is a custom formulated long pot life epory gel compatible with the epory coatings on the steel 1 iner.

The secondry seal is formed from Concresive AEX-1512. It is custom formulated as a flowable grout that bonds to the concrete and provide structural support to the lid. Both primary and secondary seal materials hove tensile strengths in excess of $6,000 \mathrm{psi}$ and will continue to gain strength in the presence of gama radiation. This post-cure strength increase results from further cross-linking of the polymer.

The radioactive waste aterials evolve significant quatities of nonradioactive gases. As a consequence, the container is provided with a venting system cast integrally and protected by the reinforced concrete lid assembly. The venting system is designed to permit plagging during transport. Within the vent itself, redundancy is provided. More importantly, andyses demontrate the contaner possesses suficient burst strength to contain all probable generated gases without venting for the 300 year 1 ife of the container.

The design weights of the HIWDC are en follows:

\begin{tabular}{lr} 
Container Body & 11,096 pounds \\
Lid & 2,531 \\
Payload (EPICOR II) & 3,250 \\
Seal & 110 \\
Rub Strips + Amphoteric & \\
\multicolumn{1}{|c}{ Material } & $\frac{139}{17.126}$ pounds
\end{tabular}

EG/G letter. Apri1 27, 1983. Addendum No. 2 to Request for Proposal No. $\mathbb{E}-$ 9063 - High Integrity Waste Disposal Overpack Container MDL-37-81. 


\subsubsection{Shielding Evaluations}

The HIWDC w1l be used to encapulate EPICOR II liners as loaded at TMI 2. Of the 49 loaded liners. PF-46 exhibits the greatest isotope inventorg. This EPICOR II PF-46 1 iner has been used in ISOSHD-II shielding calcalations to predict dose rates external to the CNS $14-190$ package. Dose rate results have been derived for two bounding assmptions: (1) assuming the HIWDC remains intact and (2) assuming total failure of the HIWDC.

Sumary results from EG/G-Idaho malyses of Janury 25 and May 10, 1983 , are as follows:

(1) Integrity of BIWDC Assumed

\begin{tabular}{|c|c|c|}
\hline & PREDICTED & REGULATORY \\
\hline LOCATION & DOSE & LIMIT \\
\hline \multirow[t]{2}{*}{ On Contact } & $50 \mathrm{mR} / \mathrm{h}$ & $200 \mathrm{mR/h}{ }^{(1)}$ \\
\hline & & [49CFR173.193(i)] \\
\hline \multirow{2}{*}{ At 3 Ft. } & $10 \mathrm{mR} / \mathrm{hr}$ & $1000 \mathrm{mR} / \mathrm{hr} \mathrm{f}^{(2)}$ \\
\hline & & [10CrR71.36(2)] \\
\hline \multirow[t]{2}{*}{ At $6 \mathrm{Ft}$. } & - & $10 \mathrm{mR} / \mathrm{hr}{ }^{(1)}$ \\
\hline & & {$[49 C E R 173.193(j)(3)]$} \\
\hline
\end{tabular}


(2) Failore of HIWDC Assumed

\begin{tabular}{|c|c|c|}
\hline \multirow{2}{*}{ LOCATION } & PREDICTED & REGULATORY \\
\hline & DOSE & LIMIT \\
\hline \multirow[t]{2}{*}{ On Contact } & $630-660 \mathrm{mR} / \mathrm{hr}$ & $200 \mathrm{mR} / \mathrm{hr}{ }^{(1)}$ \\
\hline & & {$[49 \operatorname{CFR} 173.193$ (i)] } \\
\hline \multirow[t]{2}{*}{ At $3 \mathrm{Ft}$. } & $400 \mathrm{mR} / \mathrm{hr}$ & $1000 \mathrm{mR} / \mathrm{hI}{ }^{(2)}$ \\
\hline & & [190CFR71.36(2)] \\
\hline At $6 \mathrm{Ft}$. & $64 \mathrm{R} / \mathrm{hr}$ & $10 \mathrm{mR} / \mathrm{hr}$ \\
\hline
\end{tabular}

[49CFR173.193(j)(3)]

\footnotetext{
Notes: (1) Normal Condition Limits

(2) Hypothetical Accident Condition Limits
}

These results very clearly indicate that all dose rate limits are satisfied provided the HIWC maintains its integrity when subjected to "normal conditions of tranport. HIWDC integrity is not a necesary condition to satisfy hypothetical accident dose rate limits when transported within the CNS 14-190 package.

\subsubsection{Impact Tests of the HIWDC}

The HIVDC has been subjected to an extensive series of drop tests demonstrating structural integrity well in excess of that required of Type $A$ containers, $10 \mathrm{CFR}$ 71.35. Description and evaluation of the following tests follow:

- A corner impact on an unyielding surface from 3 foot height.

- A corner impact on any unyelding surface from 9 foot heigbt. 
- A corner impact on soil from 25 foot height.

- A 40 inch penetration pin arop on the container sidewall.

The first and forrth events demonstrated the ability of the container to vithstand Type 'A' Normal Conditions per 10CFr71. The second sequential test involving a 9 foot drop ws a developmental test to explore the ultimate capacity of the container: this 9 foot drop exceeded design requirements of the container by a factor of three (3), based on energy considerations.

In sumary, the package survived the first and third Type 'A' tests ith little damge and full retention of all functional capabilities. The altimate capacity test at a 9 foot drop showed potential dogradation of sealing features (for gaseous contents) but no loss of containent or ejection of contents for solids or particulate content forms. The drop from 25 feet on soil showed no damage whatsoever.

Botb bottom corner drop tests on an yielding surface employed a lifting bar that rotated the container to $42^{\circ}$ with respect to vertical. This angle was selected to cause the container to topple-over foliowing corner impact. striking the 1id closure region in 'slap-down' impact. Analyses demonstrated this 'slap-dow' impact in conjuction with corner impact was the most severe orientation for the packge.

In both anyielding sarface drop tests, the lifting bar produced modest local distress in the concrete ajacent to the 1 if $10 \mathrm{~g}$ eye due to the introduction of lateral prying forces at the lighty reinforced top edge. In sact, modest cracking, due to these 1 ateral prying forces, developed just as soon as the container wa hoisted at inclined angle.

\section{(1) Three (3) Foot Corner Drop}

Figure 2.10.3-2 illustrates the drop test set-up just prior and at the instant of i ipact. The drop pod, or "ungielding' surface, shown, consists of bout 200,000 pounds of concrete topped with $1-1 / 8$ inch 
grouted steel plate. The package as rigged to a 'quick release' latch sapported by a mobile crane.

Resultant dame from the three (3) foot drop is illustrated in Figure 2.10.3-3. The left hand photo indicates a crash, or crumble, zone at the point of initiol impact, characterized by 24 inch flat. Concrete on the sides and end spalled a wa from the hoop reinforcing for a height of about 12 inches: about as gredicted.

The top right photo shows very modest (insignificant) distress to the seal area. A small hairline crack is seen at the center of the photo on the top edge of the concrete body sidewall. The epory sealant top surface showed a circumerential hairline crack from the Iug eye location to the body sidewal1 crack.

The lower right photo shows distress around the lug eye caused by prying forces externally applied to the container by the lift firture. None of these observed distress locations compromise functional performance of the container in any fashion.

Acceleration forces can be approximated from corner deformation geometry. The package impacted at $42^{\circ}$ with respect to vertical and concrete spalled to the extent that the 'flat' or chord. measured in the base circle, wa 24 inches long. This chord subtends an angle, 20, measured in the base circle, calculated as:

$$
\theta=\sin ^{-1} \frac{24 / 2}{62.5 / 2}=22.58^{\circ}
$$

The crosh deformation, 8 , is calculated as:

$\delta=\mathbb{R}(1-\cos \theta) \sin a=1.60$ inches

Where: $\mathbb{R}=62.5 / 2$, inches

$$
a=42^{\circ}
$$


FIGURE $2.10 .3-2$

TUREE (3) FOOT CORNER DROP
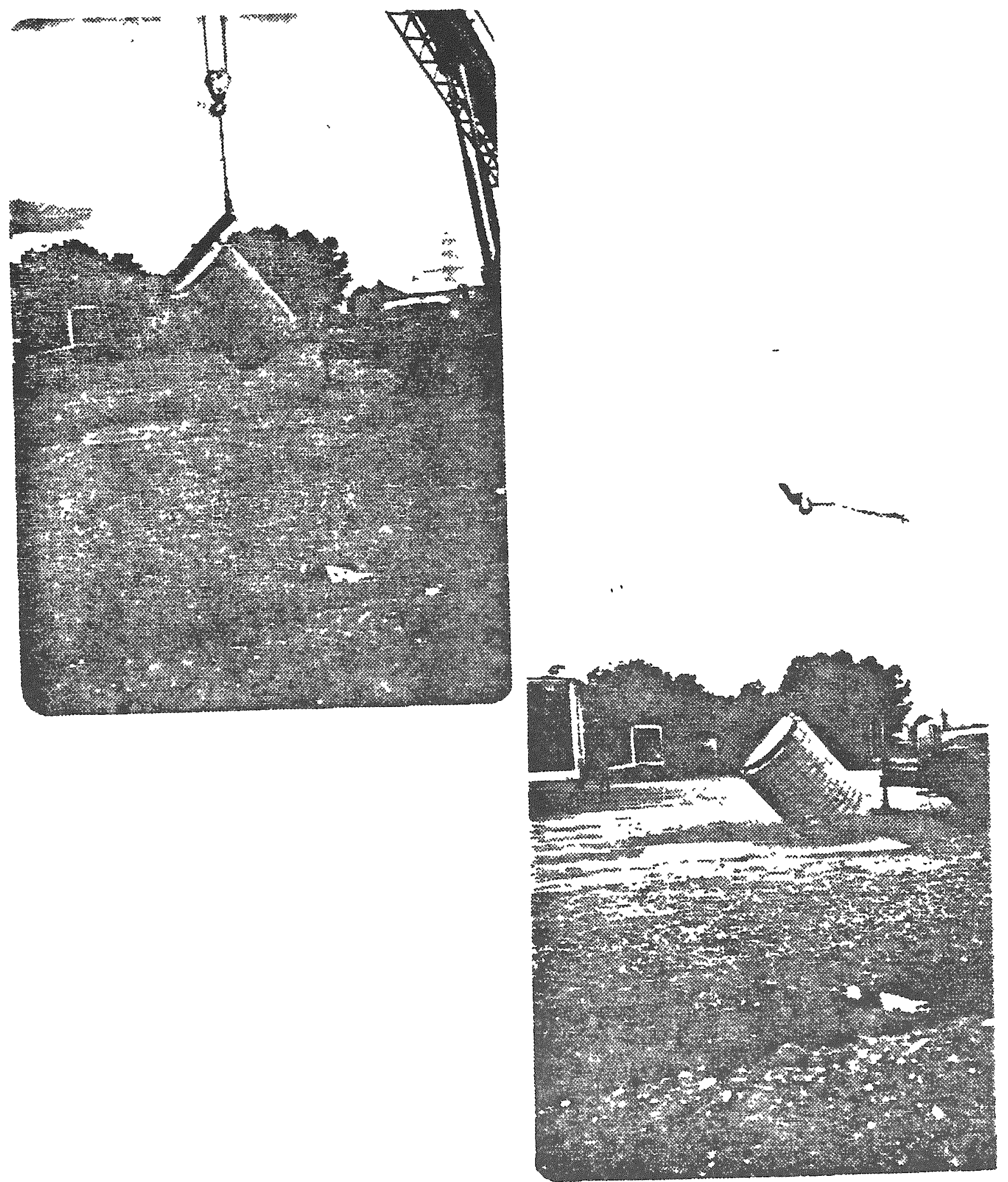
FIGURR 2.10.3-3

DAMAGE - THREE (3) FOOT DROP

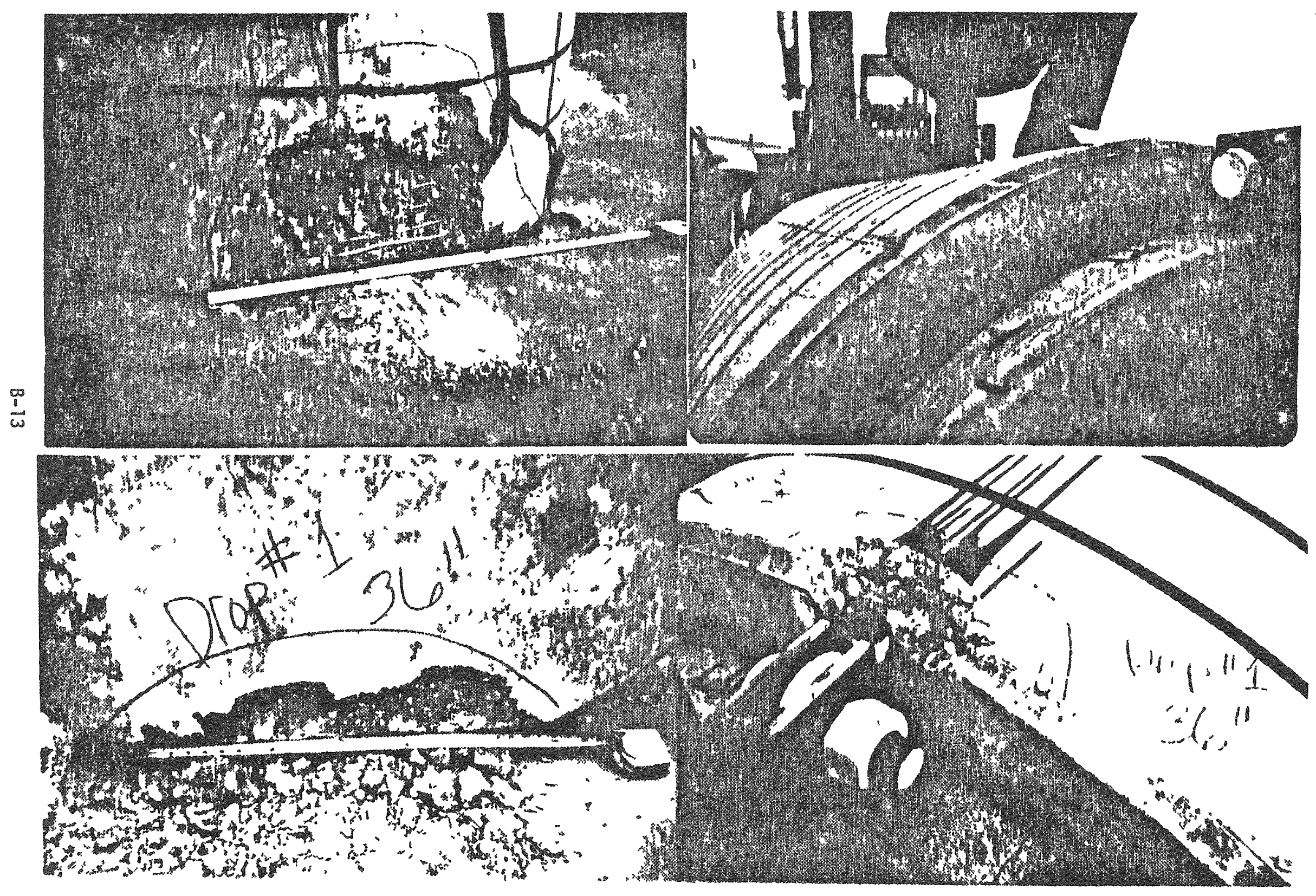


For corner impcts, the crasing area and force increases as the square of the linear dimensions of the crash zone geometry. Thus, the energy absorbed apon impact varies as a cubic function of deformation. From this, the corner impat acceleration can be calculated as:

$$
\eta_{3} \cong 3(36 / 1.60) \cong 67.5 \mathrm{~g}^{\prime} \mathrm{s}
$$

(2) Nine (9) Foot Corner Drop

The container was initially rotated $180^{\circ}$ about a vertical ass, with respect to the 1 ifting bar, in order to impact on the opposite, andamaged side of the container. Prior to hoisting to the nine (9) foot drop beight, the container acidently dropped due to premature release of the 'quich-release' 1atch. Danage was somewht more extensive than for the three (3) foot drop described previously.

Figure 2.10.3-4 shows the package immediately before and after impact. Figure 2.10.3-5 shows resultant typical damage. The left hand photos show that the initial impact zone is little changed in character from that experienced during the three (3) foot drop. The crush or crumble zone increasd up to about 30 inches flat (versus 24 inches for a three foot drop).

The right hand photos show significant damage to the contaner closure region opposite the point of imact. A crack developed aroun the complete circumference of the lid with with approximately $1 / 8$ inch. Failure occurred in the lid concrete ajacent to the stronger epory grout. The bult of radial crack dage wa concentrated in the vicinity of the lit lug eyes. The ajority of dame was due to prying forces induced by the test lift bar.

It appears that the majority of damage was due to the rigid body lid accelerating into the top edge of the body lip. The body lip Iesists these forces by hoop tersion in the reintorcing steel. This reimforcing steel yielded and ruptried with the top 6-8 inches of the 
FIGURE $2.10 .3-4$

NINE (9) FOOT CORNER DROP
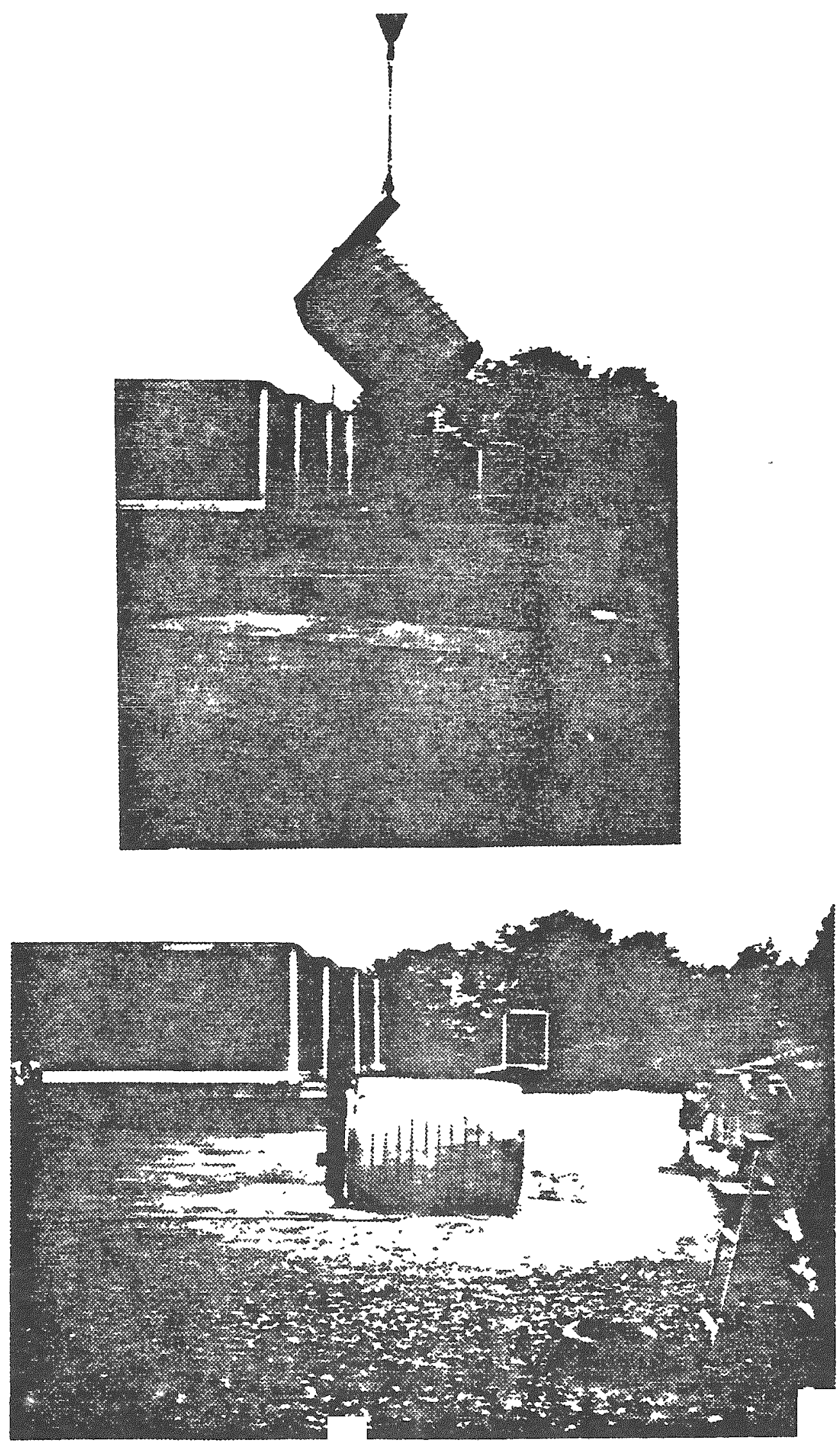

$B-15$ 
FT GURE $2.10 .3-5$

DAMAGE - NINE (9) FOOT DROP

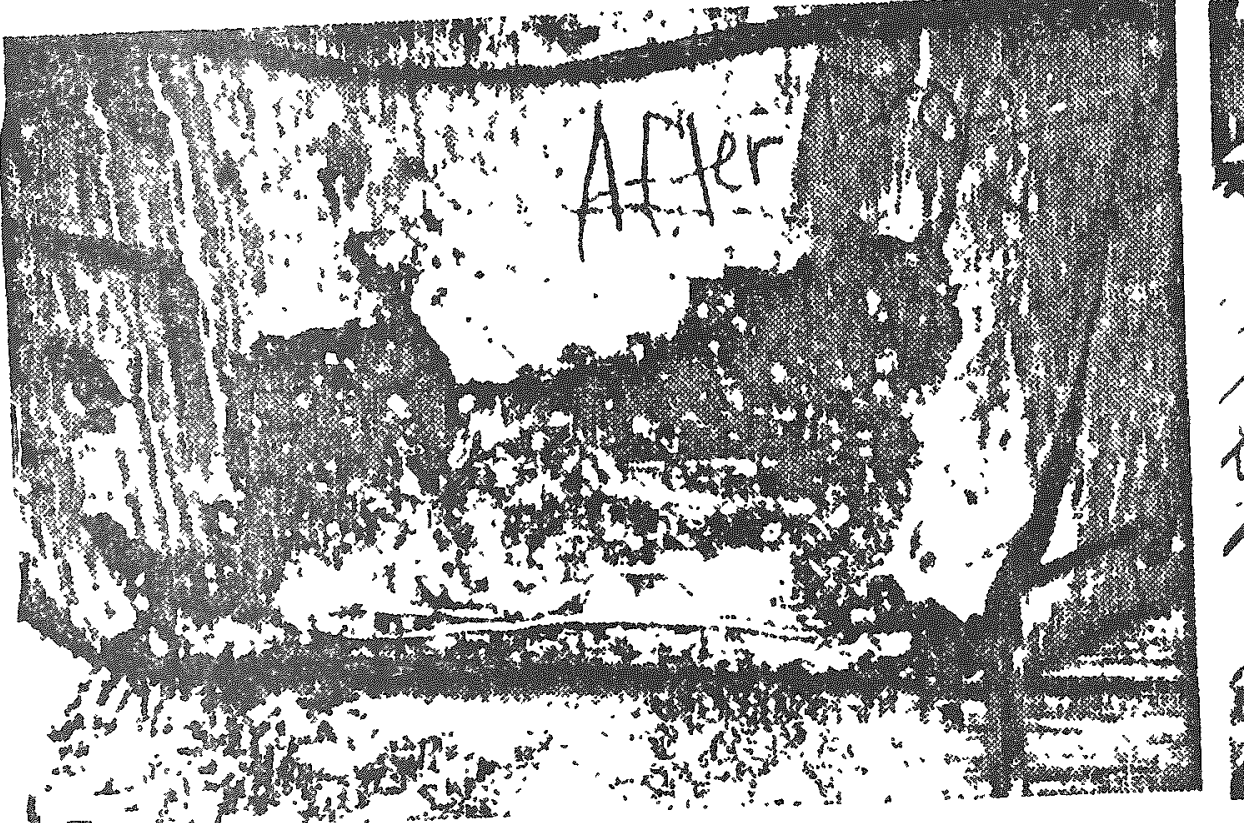

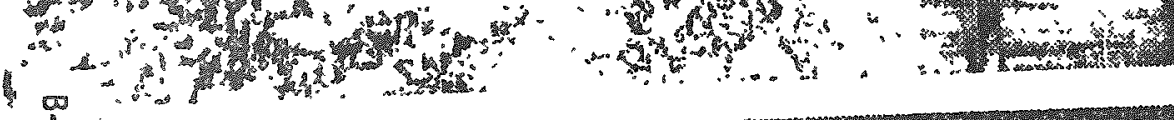
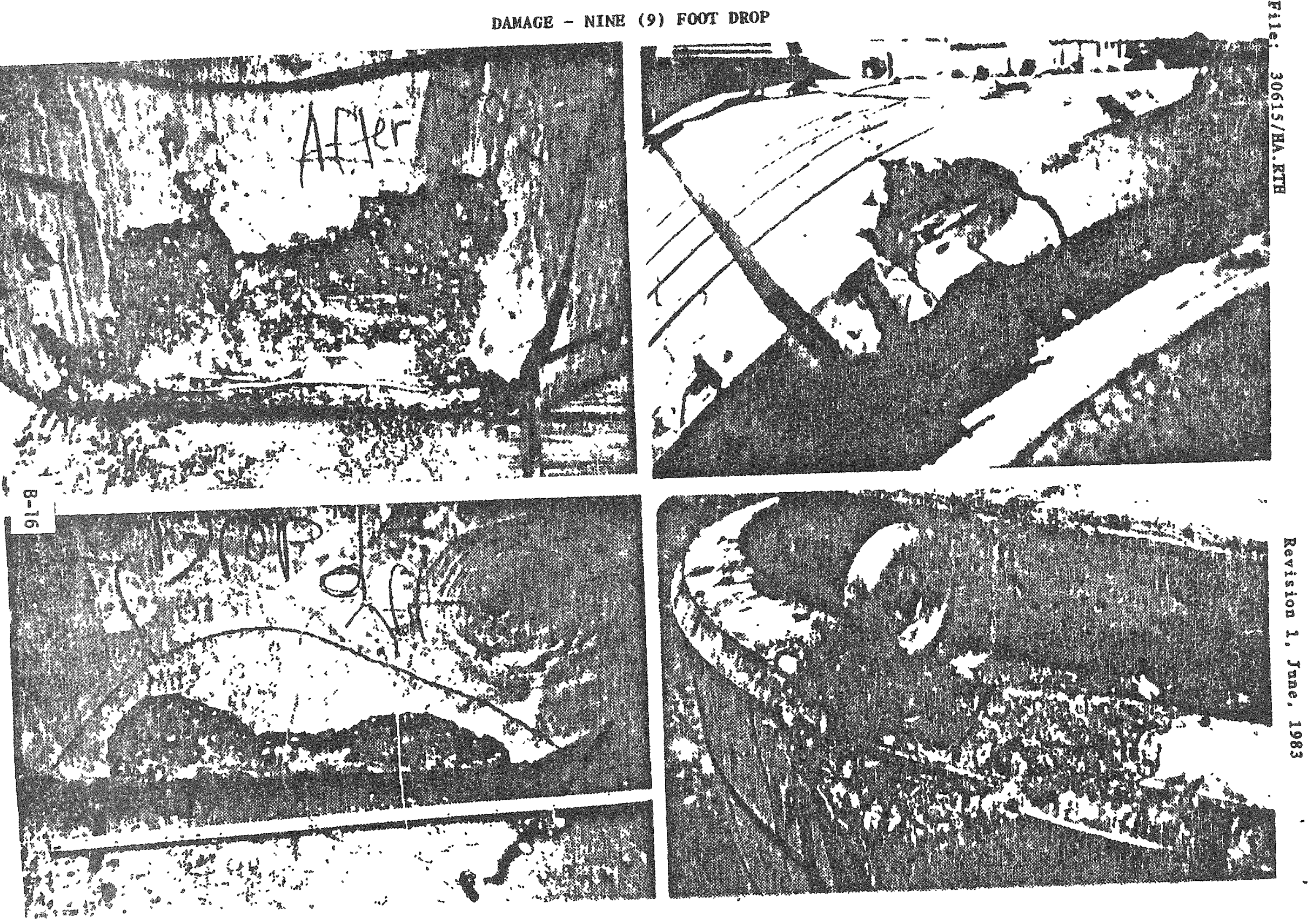

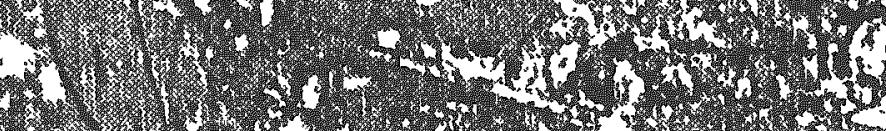

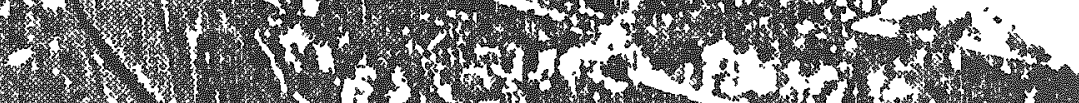
(3) 2.ting 
container lip region: 'gecked'bars can be seen in the lower right phota. Dpon yield of the steel, the lip region of the body imereased in dimeter producing tensile circunferential crack arond the lid.

Despite this complete circumferential crack, the lid remained firmly attached to the body. This is becarse the lower plate of the 1 id is held captive beneath the intact epozy grout attached to the body lip. Lid atachment vas verified by destructive eramination of the joint wich showed the primary gel seal remaining intact. Sabsequenty, a bu11dozer fitted with a ripper bar failed to remove the lid from the body.

The acceleration forces under 9 foot corner drop maye estimated followig the procedures used for the 3 foot drop. The 30 inch flat or chord subtends are angle. 20 , of:

$$
\theta=\sin ^{-1}\left(\frac{30 / 2}{62.5 / 2}\right)=28.69^{\circ}
$$

The corner deformation, $\delta$, is found as:

$$
\delta=\mathbb{R}(1-\cos \theta) \text { sina }=2.57 \text { inches. }
$$

And, the corner impact acceleration is found to be:

$$
\eta_{9} \cong 3(108 / 2.57) \cong 126.3 \mathrm{~g}
$$

(3) Treaty-rive (25) Foot Coraer Drop

The IIIWD was igged for cog. Overstruck corner impact $\left(36.7^{\circ}\right.$ to vertical) on typical sandy desert soil. The container was supported by a 'quick release' latch hang from a mobile crane.

Upon impact, Figure 2.10.3-6, the HIIDC derted the soil to approsimateis the maldameter of the cylinder base. The package experienced no visur 1 drage and did not slap-dom.

Inpact acceleration from the 25 foot drop may be estimated from the 
soil deformation to mid-dianeter of the cylinder base. The deformation of the soil is:

$\delta=\mathbb{R} \sin Q=18.7$ inches

Where: $\mathbb{R}=62.5 / 2$, inches

$a=36.7^{\circ}$

The corresponding acceleration is:

$$
\eta_{25} \cong 3(25)(12) / 18.7 \cong 48.2 \mathrm{~g} \text { s. }
$$

(4) Penetration Tests

The 40 inch penetration pin drop test showed no damage to the container except for fingernal simed whitening of the concrete in the impact zone.

\subsubsection{Structural Evaluation of the MIWDC}

The HIWDC has been extensively tested for cormer ingets well in excess of those experienced when contained within the CNS 14-190. Due to the weight of the CNS 14-190, the normal condition drop height is limited to one foot. HIWDC has been dropped from and heigh of 9 feet, mpon an unyielding surface, vithout loss of containment. Thas, the corner drop Margin of Safety, on an energy basis, is:

$$
\text { H.S. }=\frac{9}{1}-1= \pm 8.00
$$

End and side impacts are less critical and have therefore not been tested. For completeness and conservaris. the rollowing angses demonstrate

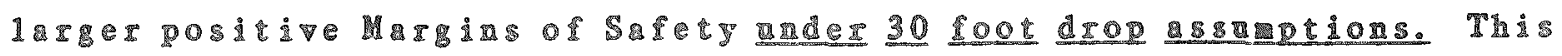
conclusively demonstrates he ablity of

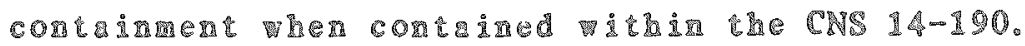




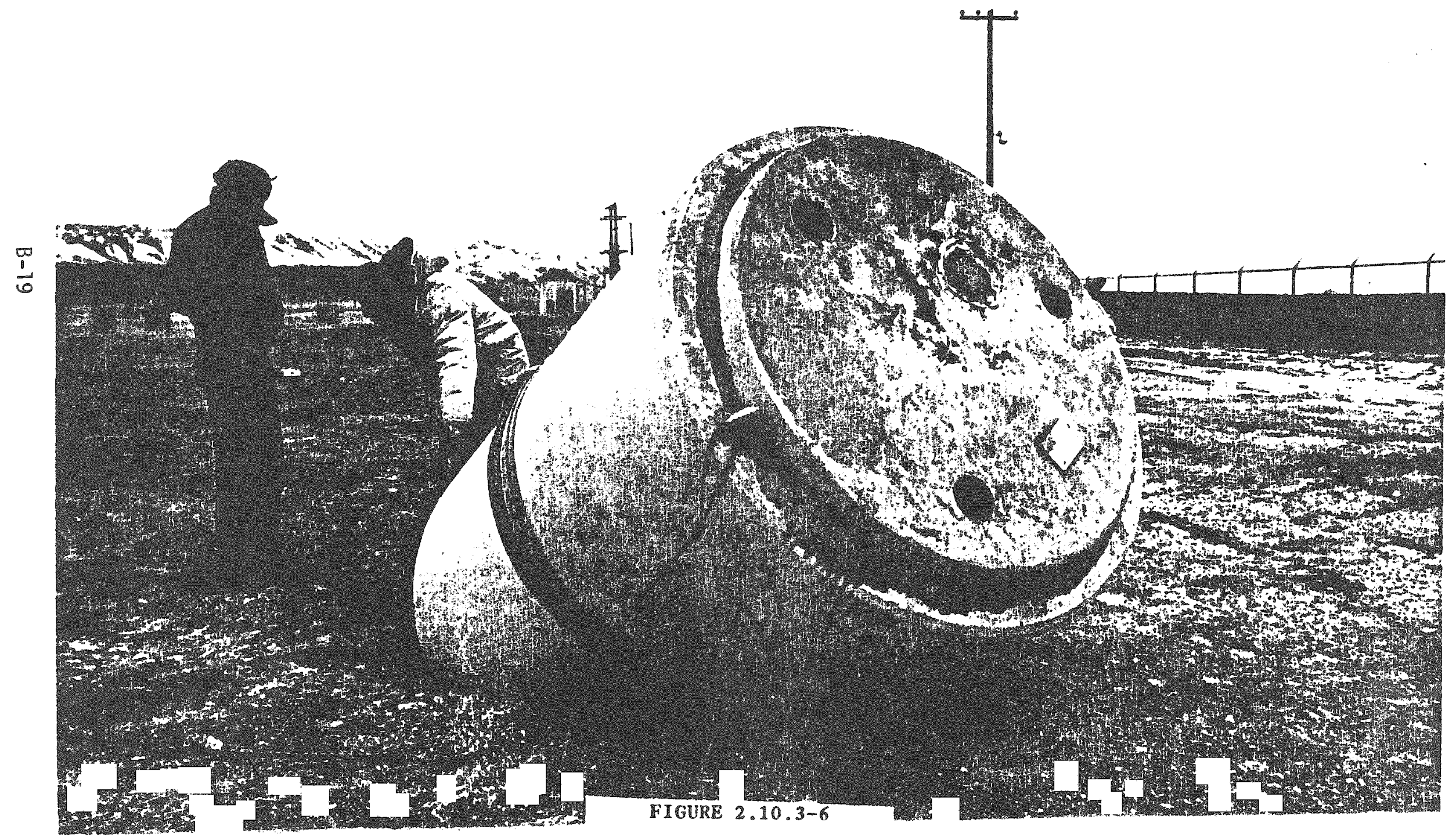


Under end inact the 11 inch thick lid and ends are loaded by self weight. For end impact, this is the nost critical loadig for the HIWDC. The HIWDC has been evaluated for a 150 psi external pressure wich induces an identical tate of stress. For this 150 psi external logd, stresses versus allowables were found to be: (1)

$\begin{array}{llr}\text { Calculated } & \text { Allowble } & \\ \text { Stress } & \text { Stress } & \text { Factor of } \\ & & \text { Safety }\end{array}$

$\begin{array}{llll}\text { Inner Steel Liner } & 4.12 \text { ksi } & 21.6 \text { ksi } & 5.24 \\ \text { Outer Concrete } & 841 \mathrm{psi} & 2700 \mathrm{psi} & 3.21\end{array}$

Noles: 1. Design Analysis Report, High Integrity Waste Disposal Container, Revision 1, Nuclear Packging, Inc., EG/G Contract $\mathbb{K}$-9063, September 1982, Page 8, Appendix A.6.

2. ACI Code $318-77$

Thus, the HIFDC lids and ends can withstand an external pressure of:

$$
(150)(3.21)=482 \mathrm{psi}
$$

without exceding conventional reinforced concrete allowales(2). This is equivaleat to and arop impact acceleration of:

$$
\eta_{e}=\frac{482}{(145 / 1728)(11)}=522 \mathrm{~g}^{\prime} \mathrm{s}
$$

In Section 2.7.1.1, the end impact deformation of the CNS 14-190 due to 30 foot drop is calculated as 1.23 inches. This is equivalent to an acceleration of:

$$
\eta_{300}=\frac{(30)(12)}{1.23}=293 \mathrm{~g}^{\prime} \mathrm{s}
$$


Thus, the HIWDC and impact Margin of Safoty for the 30 foot drop is:

$$
\text { M.S. }=522 / 293-1= \pm \underline{0.78}
$$

Under ide lapac differential bending moments are induced along vertical and horizontal planes. Along vertical planes, concrete is $10 \mathrm{ded}$ in compression whle steel is loaded in torion. Along horizontal planes, both steel and the adjacent portion of concrete are loaded in compression. The stresses induced along vertical plames are the most critical since a tensile failure bere of the steel liner can induce rupture and loss of containent. The moment capacity of the 6 inch thick concrete w 11 and $1 / 4$ inch carbon steel liner is calculated asuming conventional concrete allowables is follows:

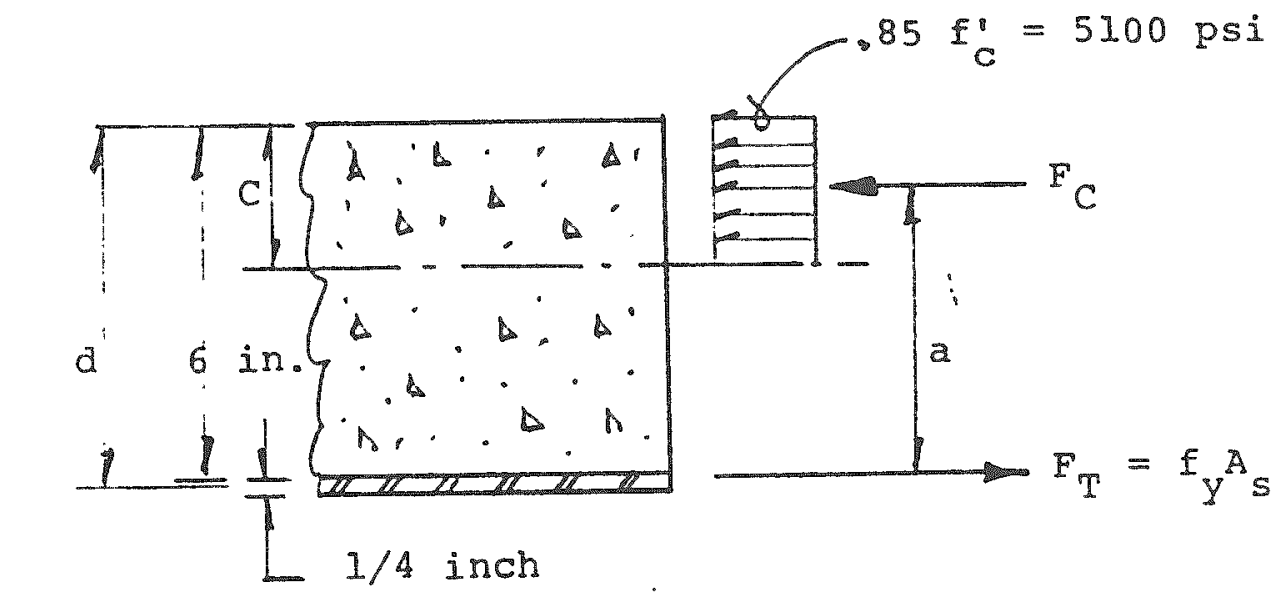


The moment is:

$$
F_{T^{2}}=F_{C^{2}}
$$

There a is determined from:

$$
\begin{aligned}
& \mathbb{F}_{\mathfrak{T}}=\mathbb{E}_{\mathbb{C}} \\
& f_{\mathrm{y}} \mathrm{A}_{\mathbb{S}}=.85 \mathfrak{f}_{\mathrm{c}} \mathrm{c} \\
& c=\frac{\mathbb{f}_{T_{s}}}{.85} \mathbb{f}_{c}^{\prime}=\frac{(60.000)(.25)}{5100}=2.94 \text { inches } \\
& a=d-c / 2=6.125-(2.94 / 2)=4.65 \text { inches }
\end{aligned}
$$

Therefore:

$$
\begin{aligned}
& =F_{T^{2}}=(60.000)(.25)(4.65) \\
& =69.750 \mathrm{in}-1 \mathrm{~b} / \mathrm{in}
\end{aligned}
$$

The moment expression for a ring loaded with self weight, supported at base is given in Case 13. Table 17, Rork sth Edition, as:

$$
\begin{aligned}
& M=w R^{2} / 2 ;=2 M / \mathbb{R}^{2} \\
& M=\frac{2(69,750)}{[(62.5-6) / 2]^{2}}=1751 \mathrm{bs} / \mathrm{in}^{2}
\end{aligned}
$$

This is equivalent to a side drop acceler tion of:

$$
\eta_{S}=\frac{175}{1 / 1728[(145)(6)+(490)(.25)]}=305 \mathrm{~g}^{\prime} \mathrm{s}
$$

In Section 2.7.1.2, the side impact deformation of the CNS 14-190 due to 30 foot drop is calculated as 3.7 inches. This is equivient to an acceleration of:

$$
\eta_{30 s}=\frac{2(30)(12)}{37}=1958^{\circ}
$$


Thas, the HIWDC side impact Margin of Safety for the 30 foot drop is:

$$
\text { M.S. }=305 / 195-1= \pm 0.56
$$


APPENDIX C

SUPPORT EQUIPMENT

$C-1$ 
APPENDIX C

SUPPORT EQUIPMENT

Preparation of the EPICOR-II prefilter and high integrity container (HIC) required using specialized equipment that could be used remotely in a hot shop environment. This appendix provides a description of that equipment and how it was used.

\section{Liner Lifting Device}

Lifting a prefilter requires a special lifting device (T-bar) which connects to the lifting ears on an EPICOR-II prefilter liner remotely (Figure $(-1)$. The T-bar has a reinforced lifting eye which can be attached to a crane hook remotely. Guide plates provide handles for manipulators to guide the fixture when being attached to a prefilter. The spreader bar part of the device has a tip on each end which slides into the liner lifting ears.

\section{Venting Tool}

The venting tool (Figure C-2) originally was designed and built at the INEL for removing the vent plugs from EPICOR-II prefilters as the prefilters were received from TMI. The vent plugs were removed so the prefilters could be vented continuously during interim storage. ${ }^{\mathrm{C}-1}$ For the HIC disposal demonstration, the venting tool also was used to remove the lower distribution port plug of PF-18 so the prefilter could be dewatered before being sealed in the HIC.

The venting tool was designed and fabricated for remote use in the Hot Shop of TAN-607. It consists of the tool, which is located in the Hot Shop and maneuvered by an overhead manipulator, and the control panel, located in the operations gallery of the Hot Shop, for remote operation of the too1. In preparing the prefilter for the dewatering and purging operations, 


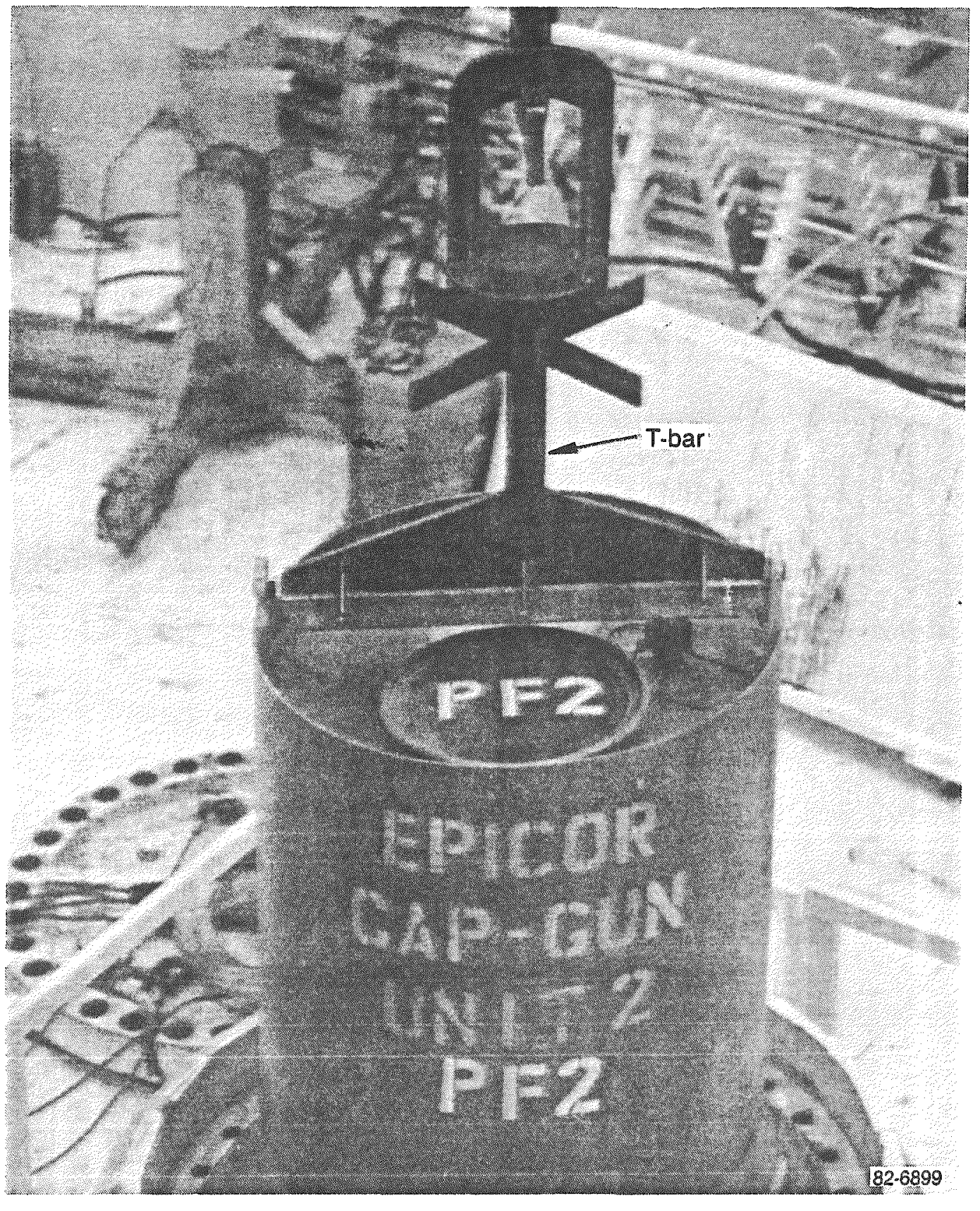

Figure C-1. Photograph of an EPICOR-II prefilter being lifted using the T-bar lifting device. 


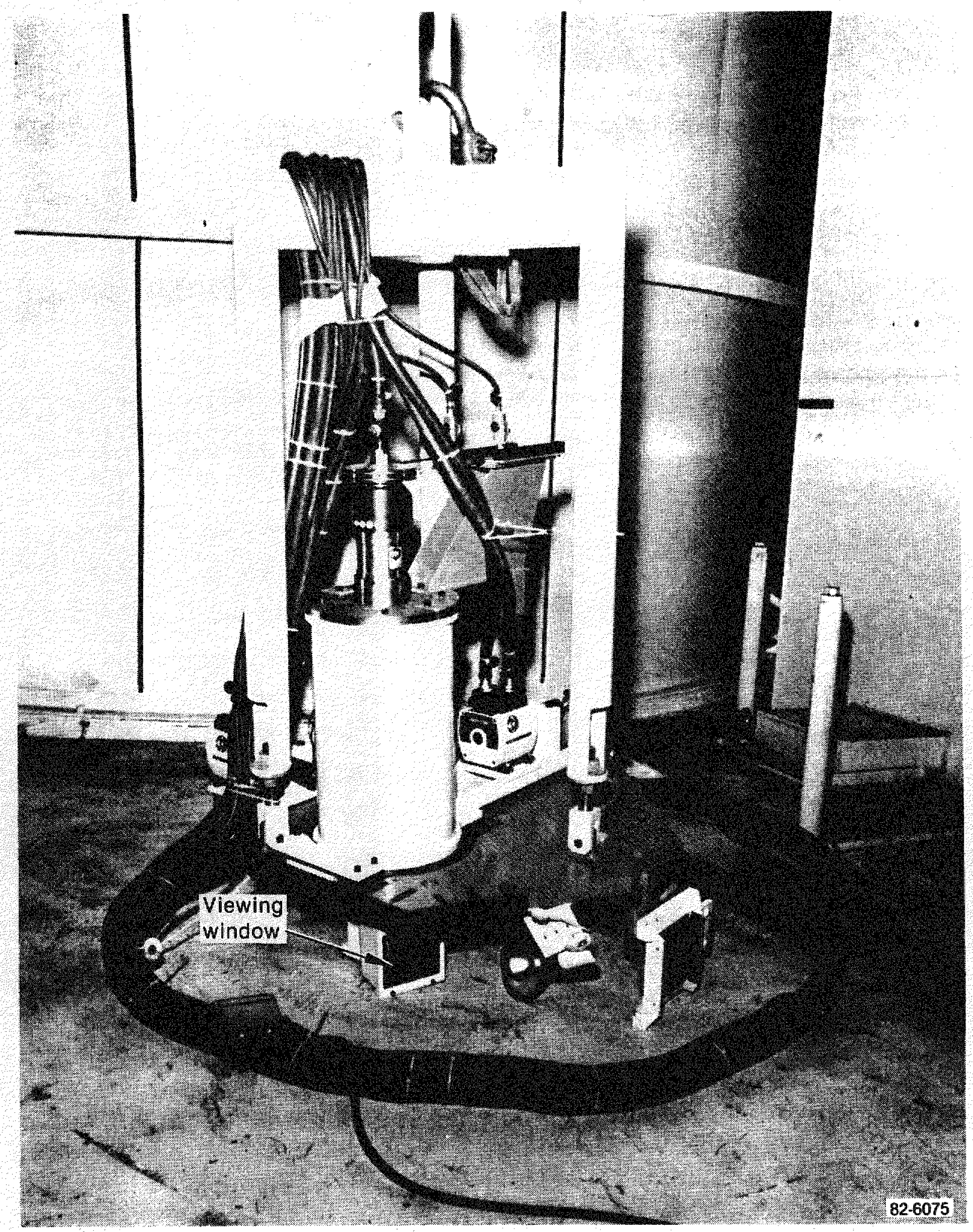

Figure $\mathrm{C}-2$. Photograph of the venting tool fabricated for use on EPICOR-II prefilters. 
the tool is lowered onto the top of the prefilter, the square tool tip is inserted into the plug, and the plug is screwed out by an air-motor-drive tool.

The tool drive system consists of an air powered torque wrench, two air cylinders, and a splined spindle. The wrench is capable of producing up to $345 \mathrm{~kg}-\mathrm{m}$ (2500 $\mathrm{ft}-1 \mathrm{~b})$ of torque with a maximum unloaded speed of 5 rpm. It is driven by $4.8 \times 10^{5} \mathrm{~Pa}(70-\mathrm{psi})$ air at a maximum flow of $1.2 \mathrm{~m}^{3} / \mathrm{min}(40 \mathrm{cfm})$. The torque and speed of the wrench are controlled by varying the air pressure and air flow with a pressure regulator and ball valve. After the plug is loosened, removal is accomplished by air cylinders mounted vertically on the sides of the tool housing. The cylinders move the tool tip, and the loose plug is secured to the tip during vertical movements.

\section{Dewatering Equipment}

The dewatering equipment used to remove excess water from PF-18 is shown in Figure $\mathrm{C}-3$. The dewatering process involves vacuuming water through the lower distribution (effluent) port of the EPICOR-II prefilter into the water extraction drum, using a vacuum pump. Exhaust air from that process is pumped through a high-efficiency particulate air (HEPA) filter assembly to eliminate the possible spread of contamination. A11 of the equipment is placed on a $4.3-$ by $3-\mathrm{m}$ (14- by 10-ft) catch pan.

The water extraction drum assembiy is composed of a 208-L (55-gat) drum used to catch water from the prefilter, a sight glass for monitoring water levels in the drum, a drum drain for obtaining water samples for $\mathrm{pH}$ analysis and draining the drum, a vacuum gauge, and two hoses, one connecting the drum to the lower distribution port of the liner and the other connecting the drum to the vacuum pump assembly.

The vacuum pump assembly is composed of a vacuum pump connected to the water extraction drum assembly and the HEPA filter assembly. The vacuum pump has a capability of $660 \mathrm{~mm}(26-i n$.) $\mathrm{Hg}$ for intermittent use and $381 \mathrm{~mm}$ 


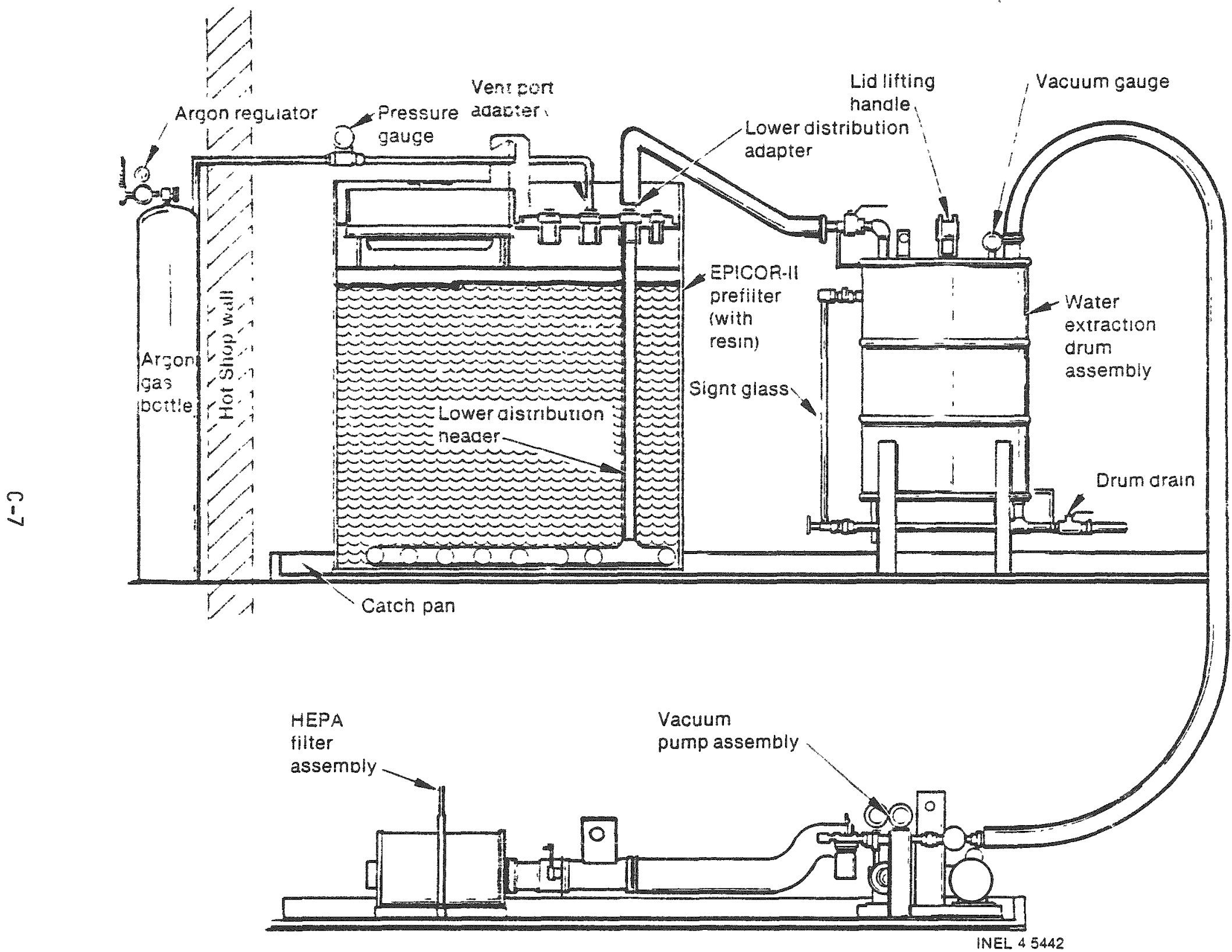

Figure $\mathrm{C}-3$. Schematic of the dewatering and purging equipment used to prepare PF-18 before loading into the HIC. 
(15-in.) Hg for continuous use. The HEPA filter assembly is constructed of four HEPA filters placed side by side. The filters are connected to the effluent side of the vacuum pump by a flex hose.

\section{Purging Equipment}

The purging equipment (see Figure $(-3$ ) is composed of an argon bottle, argon regulator, tygon tubing, and prefilter vent port adapter. Argon gas goes from the bottle, regulated by the regulator (located in the Hot Shop galiery), through the tubing to the adapter, which is inserted into the vent port of the EPICOR-II prefilter. The gas enters the prefilter, displaces whatever gas might be in the liner, and forces the gas out through the lower distribution port.

\section{HIC Spreader Bar}

The HIC spreader bar is designed to lift an HIC vertically without applying an inward or outward stress on the HIC lifting eyes. The spreader bar (Figure $\mathrm{C}-4$ ) is a carbon steel beam which is attached to a crane hook via a shackle connected to a $2.54-\mathrm{cm}\left(1-\mathrm{in}_{0}\right)$ thick steel plate welded in the middle of the beam. The device has two $1.91-\mathrm{cm}\left(3 / 4-i n_{0}\right)$ wire rope legs which are attached to the spreader bar with an open spelter socket at one end and a shackle connected to a spelter socket and hoist hook at the other end. The device has a safe working load of $7,940 \mathrm{~kg}(17,500 \mathrm{lb})$.

\section{MIC Lid Lifting Assembiy}

The HIC lid lifting assembly (Figure $\mathrm{C}-5$ ) is constructed of a master link with three legs. Each leg is a $1.27-\mathrm{cm}\left(1 / 2-i_{0}\right)$ diameter wire rope with a spelter socket on each end. One end of the leg is connected to the master link by a connecting link, and the other end is connected to a quick-disconnect lift fitting by an anchor shackle. The lifting assembly is designed to fit the three recessed, precast inserts in the lid of the HIC, using the quick-disconnect lift fittings which can be disconnected remotely. 


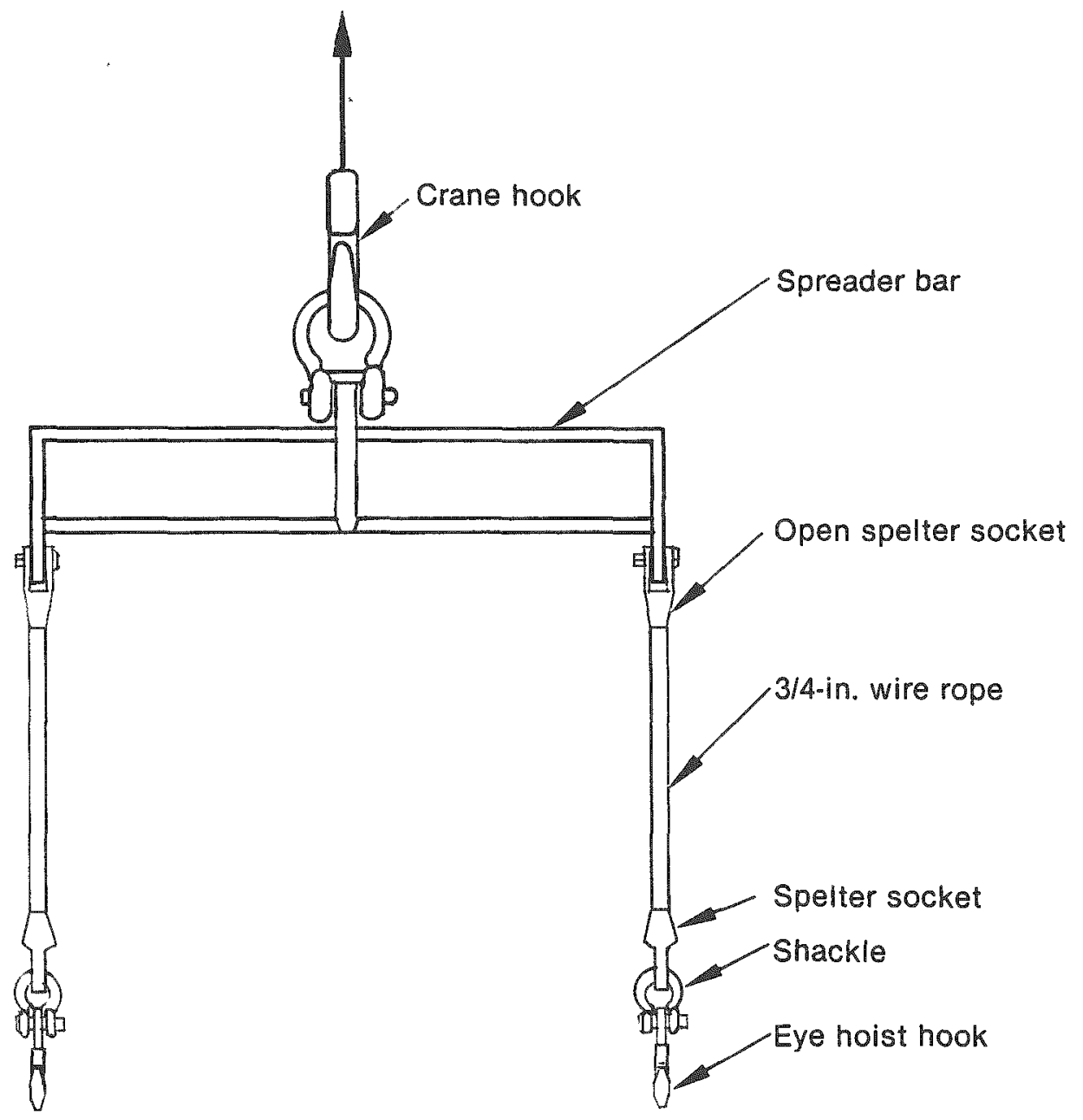

INEL 40667

Figure C-4. Schematic of the HIC spreader bar. 


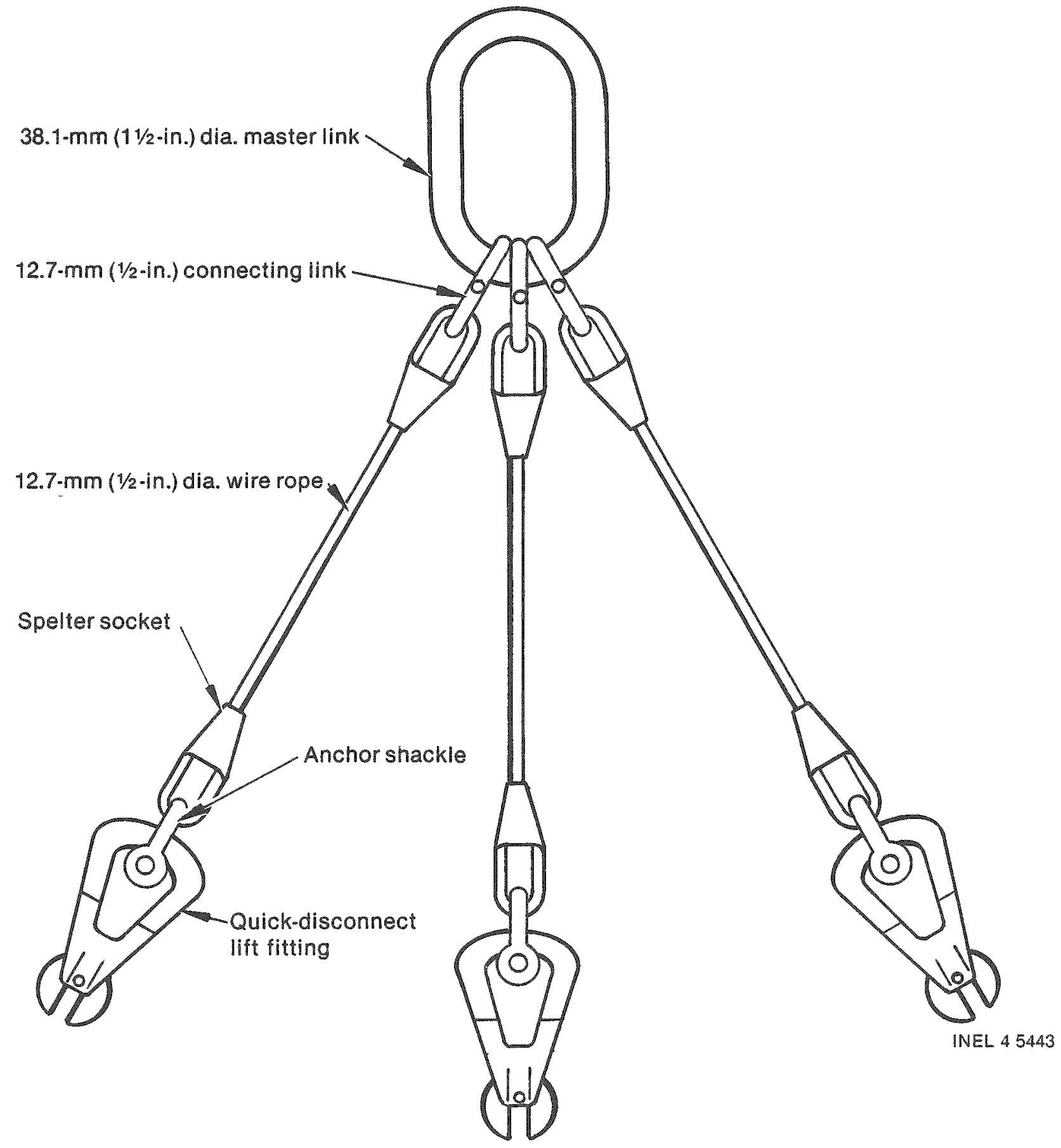

Figure $\mathrm{C}-5$. Schematic of the HIC lid lifting assembly. 


\section{Liner Interface Collar}

The liner interface collar is a tapered polyethylene loading ring used to guide an EPICOR-II prefilter into an HIC (Figure C-6). The collar protects the HIC polyethylene liner from damage. It also protects the lifting eyes, top edge of the HIC, and the lid step inside the HIC. The collar has three lift points, which allow for remote placement and removal.

\section{Grouting Equipment}

Two pieces of equipment were designed and fabricated for remote grouting of the demonstration HIC lid to its body. Those were the HIC funnel bracket assembly and grout pouring cup. The HIC funnel bracket assembly (Figure $(-7)$ is a three-armed device with a rectangular shaped funnel at the end of each leg. The assembly is designed so each arm is used to grout one-third of the HIC lid-body void. The grout is poured through each funnel to fill the void immediately under the funnel. Using the overhead manipulator (0-man), the assembly is rotated and the process repeated until the void space is filled.

The grout pouring cup (Figure $C-8)$ is a 9.5-L (2.5-gal) aluminum container. It is designed for pouring grout into the HIC funnel bracket assembly remotely using the 0 -man. The container has two pouring spouts (on opposite sides of each other) and an aluminum bar handle that is grasped by the 0 -man fingers.

\section{References}

C-1. J. M. Bower, Development of a Prototype Gas Sampler for EPICOR-II Prefilter Liners, GEND-INF-025, September 1982. 


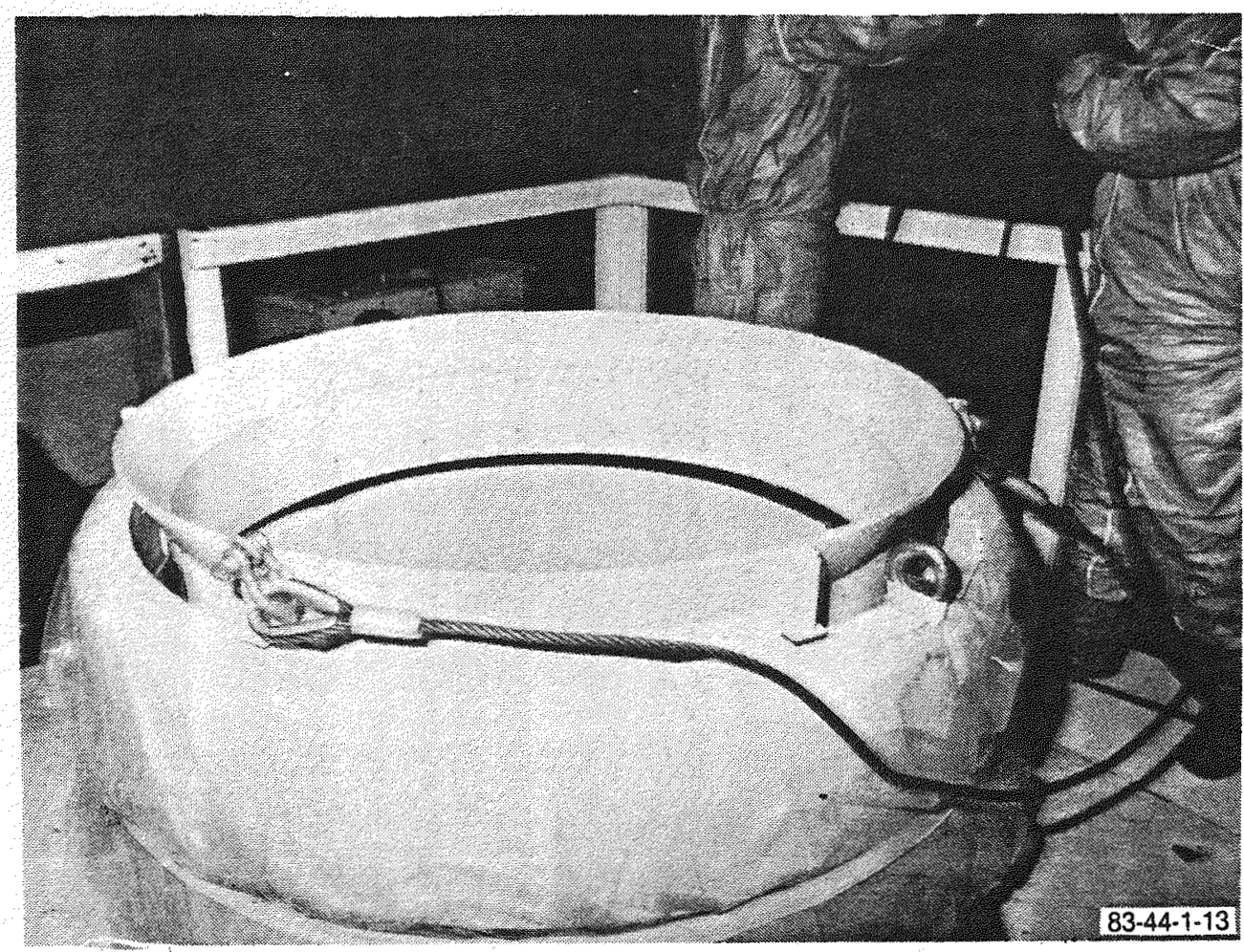

Figure C-6. Photograph of the liner interface collar placed in an HIC. 


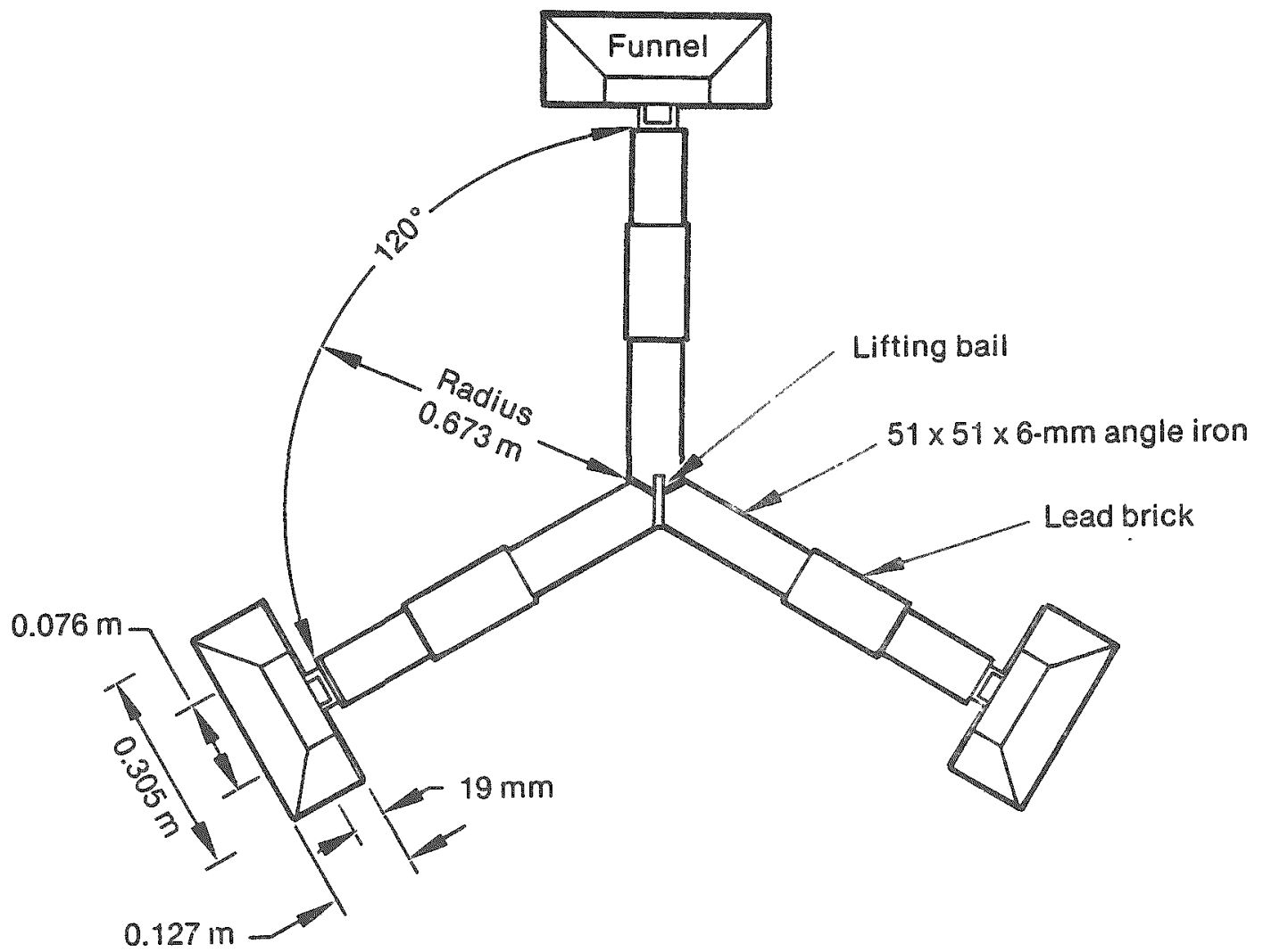

Figure C-7. Schematic of the HIC funnel bracket assembly used to grout the HIC.

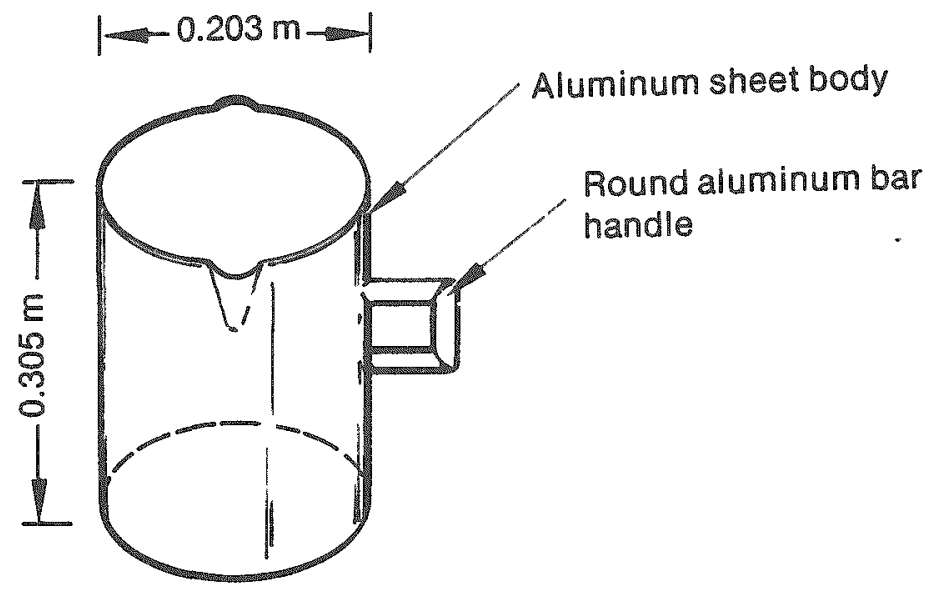

INEL 45444

Figure C-8. Schematic of the HIC grout pouring cup used to pour grout into the HIC funnel bracket assembly. 
APPENDIX D

CERTIFICATION OF COMPLIANCE

FOR THE

HIGH INTEGRITY CONTAINER 


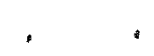




\author{
STATE OF WASHINGTON \\ DEPARTMENT OF SOCIAL AND HEALTH SERVICES \\ RADIATION CONTROL SECTION \\ OLYMP IA, WASHINGTON \\ CERTIFICATION OF COMPLIANCE \\ High Integrity Container
}

Certificate Number WN-HIC-01 Package Identification Number DSHS-HIC-TMI-01

Issued to:

Title and Identification of Application

US Ecology, Incorporated

EGRG Design Analysis Report

9200 Shelbyville Road

Suite 526

P.0. Box 7246

Louisville, Kentucky 40207

High Integrity Container for Disposal of

Epicor II Prefilter Liners. (June 1983)

1. Application:

This certificate is applicable to the High Integrity Containers (HIC) specified below for use at US Ecology. Incorporated low-level radioactive waste burial facility located near Richland, Washington. The HIC will be used for transporting and disposing of TMI Epicor II radioactive waste.

2. General Design:

The high integrity containers shall conform to the design specifications and materials testing data wich received approval by the Department based on the following:

A. "Design Analysis Report: High Integrity Container for Disposal of EPICOR II Prefilter Liners," June, 1983.

B. "U.S. Nuclear Regulatory Commission Technical Position on Waste Form," May, 1983, Rev. 0.

C. "Receipt and Disposal Procedures for High Integrity Containers," RW-T-001, July, 1983.

D. "Design Evaluation Report," March, 1983, Rev. July 1983.

E. Drop Test Conditions and Acceptance Criteria KCS $83-83$ dated April $27,1983$.

F. Additional supportive information dated September 16, 1983, to HIC use application dated July 1, 1983. 


\section{Applicable Approved Container:}

This approval shall apply only to the high integrity containers furnished by Nuclear Packaging. Inc., 1010 South 336 th Street, Federal Way, Washington and built in conformance with EGEG specification ES-50652. A prototype HIC manufactured by Bingham Mechanical and Metal Products, Inc.. Idaho Falls, Idaho, is also approved by this certifio cate. Other manufacturers may be used provided acceptable quality assurance procedures are specifically approved by the department.

4. Quality Assurance:

The high integrity container authorized by this certificate shall be manufactured, stored, and used in accordance with Section 2.

5. User Requirements:

Use of this container shall be in accordance with all applicable requirements specified in documents listed in Section 2 of this cero tificate; U.S. Department of Transportation Regulations: State of Washington Rules and Regulations for Radiation Protection: and conditions of License WN-IO19-2, issued to US Ecology, Incorporated, by the state of Washington.

\section{Specifications:}

The following specific limitations for the DSHS-HIC-TMI-01 container as identified in this certificate shall also apply and be strictly adhered to:

A. Free Standing Liquid: Any free standing liquid must have a $\mathrm{pH}$ 24.0 , be noncorrosive and less than one percent (1\%) by waste volune.

B. Radiation: The specific activity of dewatered resins shall not cause radiation levels to exceed 1 × $10^{10} \mathrm{rads}$ (beta-gamma) as the maximum integrated dose to the inner coating of the container.

C. Chemicals: Only eleven EPICOR II liners with organic resins, and 39 EPICOR II liners with organic resins combined with inorganic Zeolite layers may be placed into the containers.

D. Thermal: The containers must not be exposed to temperatures from the contents or surroundings above $165^{\circ} \mathrm{F}$ or below $-40^{\circ} \mathrm{F}$.

E. Weather: The containers should be stored and transported in such a way as to minimize exposure to unnecessary heat (sunilight) and inclement weather conditions.

F. Weight: The weight of the container and contents must not exceed 18,000 pounds.

G. Drop Test: Container must be capable of withstanding a free fall drop of 25 feet onto the ground, yielding surface simulating the type of soin found at the Richland site. 
H. Mechanical Strength: The HIC shall be designed to have sufficient mechanical strength to withstand horizontal and vertical loads on the container equivalent to 45 feet of material (overburden) having a density of approximately 120 pounds per cubic foot.

1. Name Plate: All containers filled after March 1, 1984, shall bear the Package Identification Number. The marking shall be fabricated of materials that are fireproof and rustproof and capable of maintaining their legibility through all normal shipping and handling conditions.

Any modification or changes of the container design, materials or usage are subject to prior approval by the Department.

This approval is contingent upon successfur use and demonstration of the package. These containers will be subjected to continuing evaluation and assessed for their integrity to meet all specified conditions and criteria. Should the evaluation determine that additional requirements are necessary. appropriate modifications shall be made prior to continued use. This Certificate is subject to revocation by the department.

Is sue Date: 23 MARRCH 1984

For the Washington State Department of Social and Health Services

T. R. Strong, Head

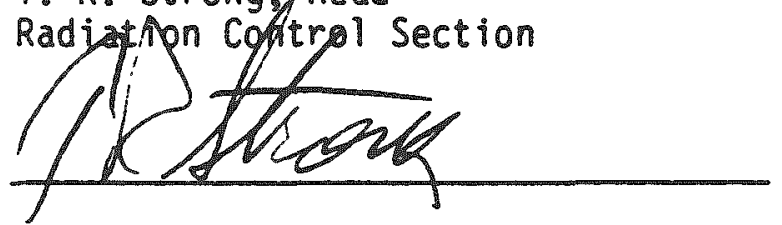


APPENDIX E

CERTIFICATE OF COMPLIANCE

FOR THE

CNS 14-190 SHIPPING CASK

E-1 
, 
UNITED STATES

NUCLEAR REGULATORY COMMISSION

WASHINGTON, D. C. 20555

JAN $2 \unlhd 1984$

Chem-Nuclear Sys tems, Inc.

ATTN: Ms. Robin Deal

240 Stoneridge Drive, Suite 100

Columbia, SC 29210

Gentlemen:

As requested by your letter dated January 18, 1984, enclosed is Certificate of Compliance No. 5026, Revision No. 10, for the Model No. CNS 14-190 shipping package. This certificate supersedes, in its entirety, Certificate of Compliance No. 5026, Revision No. 9, dated September 6, 1983.

Changes made to the enclosed certificate are indicated by vertical lines in the margin.

Those on the attached list have been registered as users of this package under the general license provisions of 10 CFR $\$ 71.12$ or 49 CFR $\$ 173.471$.

This approval constitutes authority to use this package for shipment of radioactive material and for the package to be shipped in accordance with the provisions of 49 CFR $\$ 173.471$.

Sincerely,

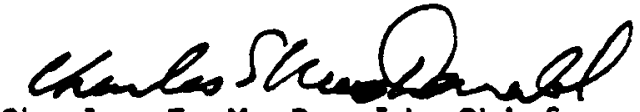

Charles E. MacDonald, Chief

Transportation Certification Branch

Division of Fuel Cycle and

Material Safety, NMSS

Enclosures:

1. Certificate of Compliance

No. 5026, Rev. No. 10

2. Approval Record

cc w/encls:

Mr. Richard R. Rawl

Department of Transportation 


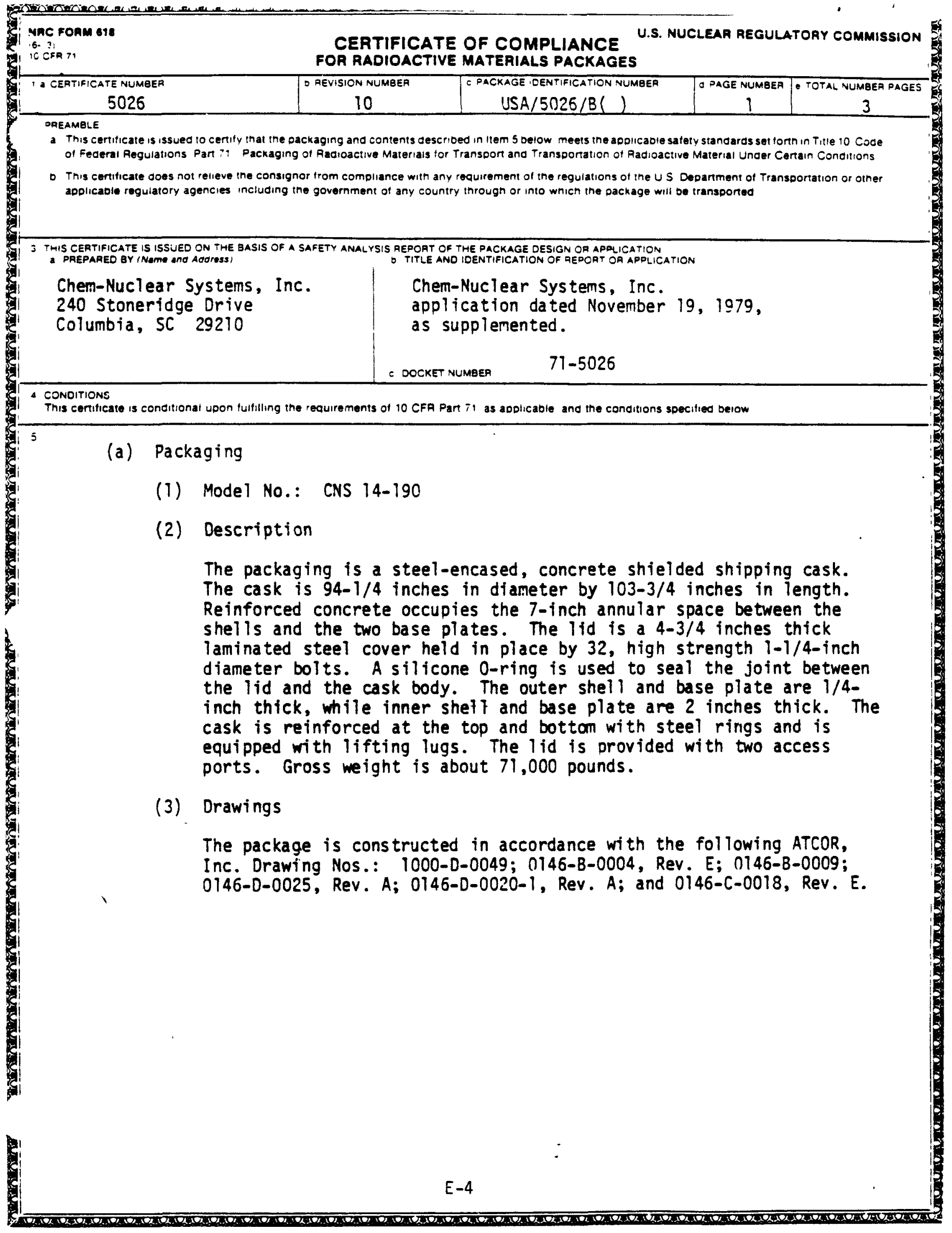




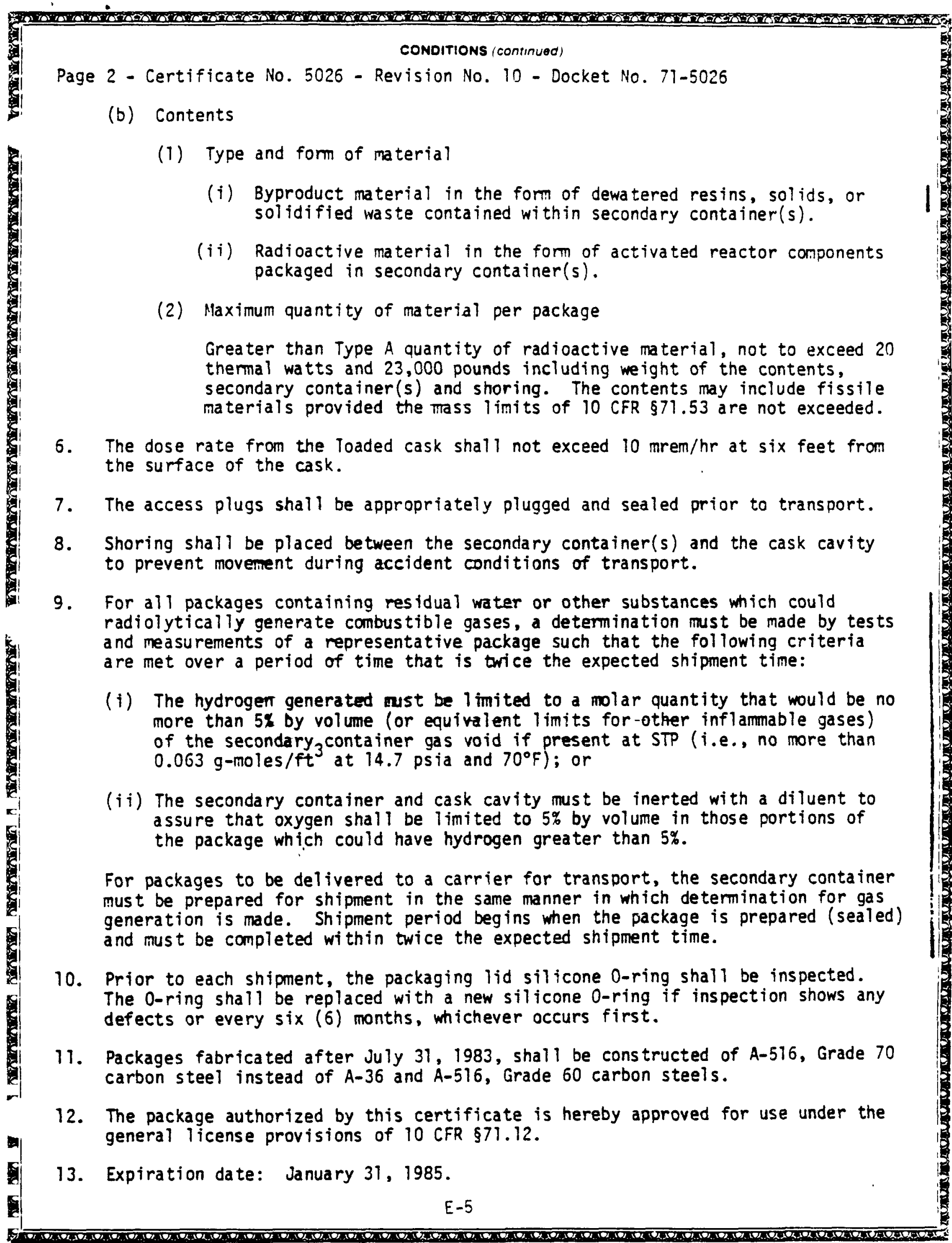




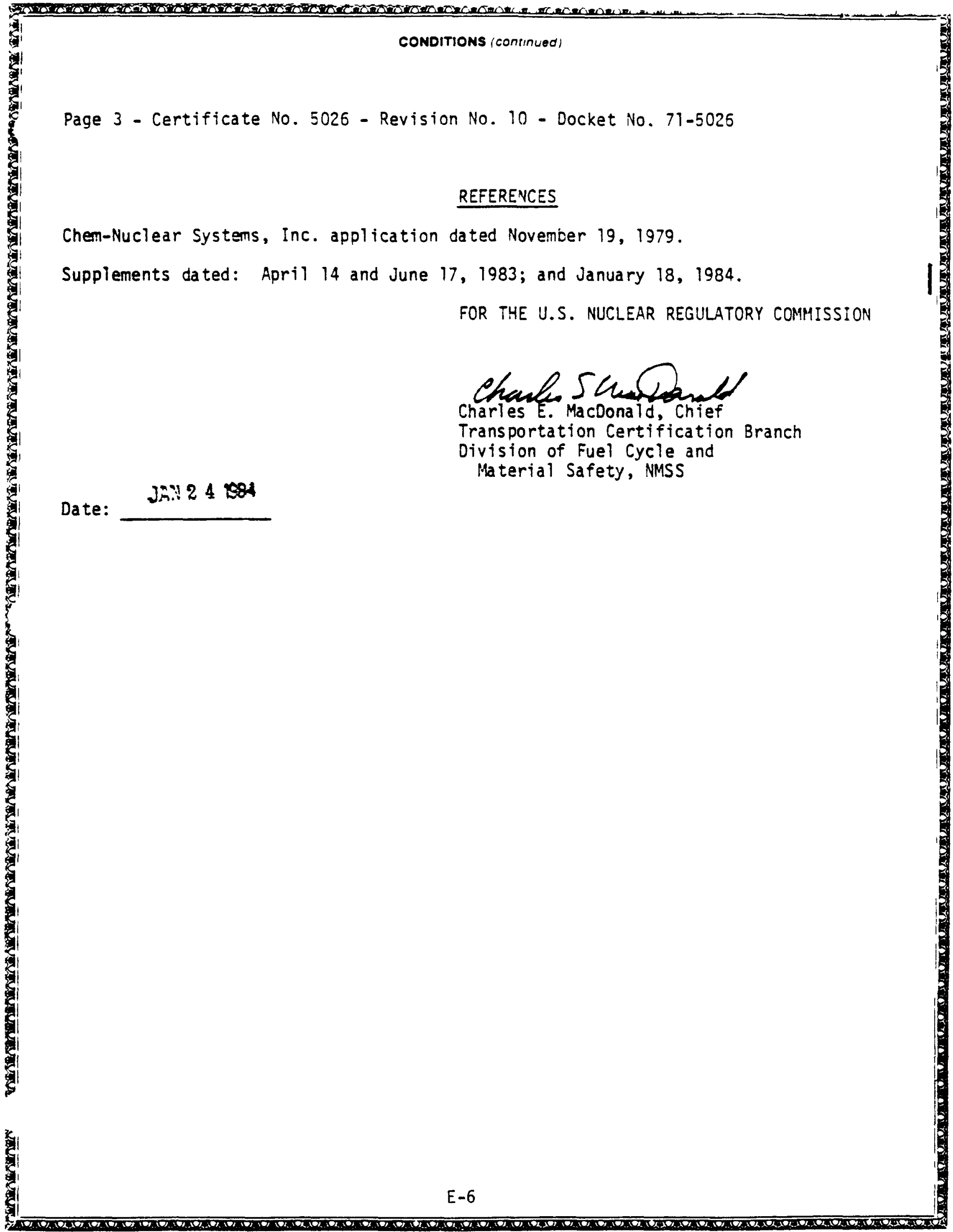


U.S. Nuclear ReguTatory Commission

Transportation Certification Branch

Approval Record

Model NO. CNS 14-190 Package

Docket No. $71-5026$

By application dated January 18, 1984, Chem-Nuclear Systems, Inc. requested that the certificate be amended to include dewatered resins in the contents and permit the shipment of materials with the potential to generate combustible gases.

\section{CONTENTS}

The applicant requested authorization to ship dewatered resins as part of the contents. The NRC staff has no objections because it was addressed in the original Safety Analysis Report for the package.

\section{COMBUSTIBLE GAS MIXTURES}

The applicant has proposed conditions to limit the accumulation of radiolytically generated gases over the shipping period to preclude the possibility of significantly reducing the packaging effectiveness due to explosion. The conditions require a representative package be prepared as for shipment, and a determination by tests and measurements be made to show that the limiting conditions are met over a time period of twice the expected shipping period. The contents are held in a secondary container prior to and during shipment. Tests and measurenents are to be performed on the secondary containers as they will be representative of the packages for this purpose.

The limiting conditions proposed are:

"(i) The hydrogen generated must be limited to a molar quantity that would be no more than $5 \%$ by volume (or equivalent limits for other inflammable gases) of the secondary containgr gas void if present at STP (i.e.s no more than $0.063 \mathrm{~g}-$ moles $/ \mathrm{ft}^{3}$ at $14.7 \mathrm{psia}$ and $70^{\circ} \mathrm{F}$; or

(ii) The secondary container and cask cavity must be inerted with a diluent to assure that oxygen shall be limited to $5 \%$ by volume in those portions of the package which could have hydrogen greater than $5 \%$."

Furthemore, shipments must be completed within a time period equal to the test period (i.e., twice the expected shipping period), and shipment time begins when the package is sealed. 
Condition (i) limits the quantity of hydrogen to $0.063 \mathrm{gmoles} / \mathrm{ft}^{3}$, but does not require any inerting of the container (air environment is assumed). This mixture, if ignited, could result in a combustion reaction, but it has been shown that such a reaction would yield a pressure rise of about 2.3 psig. The limit may be satisfied by shipments exhibiting sufficiently low rates of radiolytic gas generation, or by the use of a recombiner device which could catalytically recombine the hydrogen/oxygen to produce water and maintain a steady state hydrogen concentration below $5 \%$.

Condition (ii) requires inerting the secondary container and cask cavity with a diluent gas (e.g. nitrogen) to limit the maximum oxygen concentration to $5 \%$ in any portion of the package where hydrogen may exceed $5 \%$ by volume. It is shown that a mixture limited to $5 \%$ oxygen in any combination of hydrogen and nitrogen will not support combustion.

The applicant also proposes approaches that may be used in preparing the package to meet the conditions. They are categorized under the general description of: (1) conbustible gas control by inerting, and (2) conbustible gas supression. The approaches described should be use ${ }^{\text {inl }}$ to other potential users in setting up administrative procedures for satisfying the approval condition.

The proposed conditions and the possible approaches to satisfy those conditions have been reviewed by the staff, and found to be adequate to assure that there will be no mixture of gases in the package which could, through an explosion, significantily reduce the effectiveness of the package.

Date:

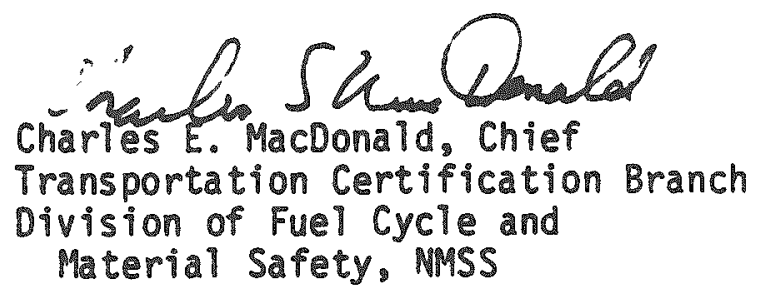


